\author{
Universidade de São Paulo \\ Instituto de Química de São Carlos
}

Larissa Zibordi Besse

\title{
Estudo da adsorção de hidroxila, água e etanol sobre clusters de metais de transição com 13 átomos
}

São Carlos 
Larissa Zibordi Besse

\section{Estudo da adsorção de hidroxila, água e etanol sobre clusters de metais de transição com 13 átomos}

Dissertação apresentada ao Programa de PósGraduação em Química do Instituto de Química de São Carlos da Universidade de São Paulo, como parte dos requisitos para obtenção do título de mestre em ciências.

Área de concentração: Físico-Química

Orientador: Prof. Dr. Juarez Lopes Ferreira da Silva

Exemplar revisado

O exemplar original encontra-se em acervo reservado na Biblioteca do IQSC-USP

São Carlos

2015 
Aos meus pais Luci e Fernando

e à minha irmã Letícia. 


\section{Agradecimentos}

Agradeço a Deus por tudo. Sou também infinitamente grata ao meu orientador, Prof. Dr. Juarez, pela oportunidade de crescimento e aprendizado. Muito obrigada, professor, pelo incentivo, apoio e todo o conhecimento que generosamente tem compartilhado comigo.

Sou grata à minha família pelo amor incondicional, e por acreditarem em mim mesmo nos momentos mais difíceis. Agraceço também aos velhos e novos amigos por tornarem minha vida mais doce, pois como já dizia o poeta "eu poderia suportar, embora não sem dor, que tivessem morrido todos os meus amores, mas enlouqueceria se morressem todos os meus amigos!".

Agradeço à todos os companheiros de trabalho, membros atuais e antigos do grupo de Teoria Quântica de Nanomateriais, pelo auxílio e discussões. Especialmente, o meu muito obrigada ao Anderson S. Chaves e à Polina Tereshchuk pelas discussões, pela ajuda e paciência que têm comigo.

Agradeço à CAPES e Fapesp pelo apoio financeiro; ao CISC por hospedar o cluster de computadores do nosso grupo; e ao IQSC-USP pela infraestrutura disponilizada ao QTNano. 
"Tão correto e tão bonito

$O$ infinito é realmente

Um dos deuses mais lindos"

Renato Russo 


\section{Resumo}

A escolha do catalisador no processo de reforma a vapor de etanol é de suma importância na determinação da eficiência de produção de hidrogênio, utilizado em células combustíveis. Superfícies de metais de transição (MT) são normalmente utilizadas como catalisadores, porém resultados experimentais têm apresentado que clusters MT suportados sobre óxidos são mais eficientes e mais seletivos que seus análogos macroscópicos. Assim, para se compreender o mecanismo de interação de etanol e água, e também do radical hidroxila, com clusters mágicos $\mathrm{MT}_{13}(\mathrm{MT}=\mathrm{Ni}, \mathrm{Cu}, \mathrm{Pd}, \mathrm{Ag}, \mathrm{Pt}$ e Au$)$, foram utilizados cálculos $a b$ initio baseados na teoria do funcional da densidade com o funcional GGA-PBE de troca e correlação, e a aproximação de Tkatchenko-Scheffler para as correções de van der Waals (vdW). Os orbitais de Kohn-Sham foram expandidos através de orbitais numéricos centrados nos átomos (NAOs), que estão implementados no código Fritz Haber Institute ab initio molecular simulations (FHI-aims). Foi encontrado que clusters $3 d$ e $4 d$ apresentam configurações mais compactas, enquanto os sistemas de $\mathrm{Pt}_{13}$ e $\mathrm{Au}_{13}$ adotam geometrias mais abertas. Em particular, $\mathrm{Au}_{13}$ possui uma estrutura planar como configuração mais estável, enquanto o seu primeiro isômero mais energético possui uma estrutura 3D. Para os cálculos de adsorção foram selecionados os clusters de menor energia (LOW), e os clusters icosaédricos (ICO). Observou-se que a hidroxila $(\mathrm{OH})$ adsorve preferencialmente sobre sítios de alta coordenação, dada à distribuição espacial da densidade de carga ao redor do átomo de oxigênio, já água e etanol se ligam preferencialmente através do oxigênio no sítio top. Para o caso do etanol também é possível encontrar isômeros com energias mais altas, na ordem de $k T$, que se ligam via $\mathrm{H}$ do grupo $\mathrm{CH}$ e que são prováveis a temperatura ambiente. OH possui um elétron desemparelhado, o que favorece a formação de ligações químicas entre a molécula e $\mathrm{MT}_{13}$, de forma que a energia de adsorção varia entre -4.11 e $-2.94 \mathrm{eV}$, condizente com a transferência de carga do cluster para a molécula. Quando se compara a adsorção de água (etanol) sobre superfícies MT(111) e $\mathrm{MT}_{13}$, nota-se que a energia de adsorção, que segue a ordem $3 d>4 d>5 d$ para $\mathrm{MT}(111)$, é maior em relação aos clusters e varia entre $-255 \mathrm{meV}(-317 \mathrm{meV})<-E_{a d}<-670 \mathrm{meV}(-837 \mathrm{meV})$; porém a magnitude da interação ocorre na ordem $3 d>4 d$, mas $4 d<5 d$. A quebra da tendência pode ser explicada através dos efeitos de tamanho, que potencializam a atividade catalítica dos clusters de platina e ouro. É possível se observar ainda que as moléculas interagem mais fortemente com os $\mathrm{MT}_{13}$ dos metais com orbitais $d$ semi-preenchidos, uma vez que esses proporcionam um maior rearranjo da densidade eletrônica. Há uma pequena transferência de carga das moléculas de água e etanol para os clusters, apontando para a fraca interação. Cálculos vibracionais suportam as modificações estruturais e energéticas que ocorrem no sistema, onde $\nu_{\mathrm{O}-\mathrm{H}}$ aumenta para a hidroxila e diminui para água e etanol.

Palavras-chave: Química Quântica, Teoria do Funcional da Densidade, Simulação. 


\begin{abstract}
The choice of the catalyst in steam reforming of ethanol process has a central hole in determining the hydrogen production efficiency, used in fuel cells. Transition-metal (TM) surfaces are commonly used as catalysts, but experimental results have shown that TM clusters supported on oxides are more efficient and more selective than their macroscopic analogues. Therefore, to understand the mechanism of interaction between ethanol and water, and also the hydroxyl radical with $\mathrm{TM}_{13}$ magic clusters $(\mathrm{TM}=\mathrm{Ni}, \mathrm{Cu}, \mathrm{Pd}, \mathrm{Ag}, \mathrm{Pt}$ and $\mathrm{Au}$ ), we performed ab initio calculations based on density functional theory within the GGA-PBE exchange-correlation functional, and Tkatchenko-Scheffler approach for van der Waals corrections (vdW). The Kohn-Sham orbitals were expanded by numerical atomcentered orbitals (NAOs), which are implemented at the Fritz Haber Institute - ab initio molecular simulations code (FHI-aims). We found that clusters $3 d$ and $4 d$ prefer more compact configurations, while $\mathrm{Pt}_{13}$ and $\mathrm{Au}_{13}$ systems adopt more open geometries. In particular case of $\mathrm{Au}_{13}$, our lowest energy configuration is a planar structure, while the first high energy isomer is a $3 \mathrm{D}$ configuration. For adsorption calculations, we selected the lowest energy configurations (LOW), and the icosahedral clusters (ICO). We observed that the hydroxyl $(\mathrm{OH})$ adsobs preferentially on sites with high coordination, due to spatial distribution of charge density around the oxygen atom, while water and ethanol preferentially bind via oxygen at the top site. In the case of ethanol, it is also possible to find isomers with higher energies, which bind via $\mathrm{H}$ from $\mathrm{CH}$ group, and they are probable at room temperature. $\mathrm{OH}$ has an electron unpaired, which favors the formation of chemical bonds between the molecule and $\mathrm{TM}_{13}$, so that the adsorption energy varies from -4.11 to $-2.94 \mathrm{eV}$, consistent with charge transfer from cluster to the molecule. When we compare the water and ethanol adsorption on $\mathrm{TM}(111)$ surfaces and on $\mathrm{TM}_{13}$, we note that the adsorption energy, that follows the order $3 d>4 d>5 d$ for $\operatorname{TM}(111)$, is higher compared to the clusters energy. For water (ethanol), this property varies between $-255 \mathrm{meV}(-317 \mathrm{meV})<-E_{A d}<-670 \mathrm{meV}(-837 \mathrm{meV})$; however, the magnitude of the interaction occurs in the order $3 d>4 d$, but also $4 d<5 d$. The breaking of the trend can be explained by size effects, that enhances the catalytic activity of platinum and gold clusters. It is also observed that the stronger interaction between molecules and $\mathrm{TM}_{13}$ with $d$-orbitais partly occupied, since these metals provide a higher rearrangement of the electron density. There is a small charge transference from water and ethanol molecules to the clusters, pointing to the weak interaction. Vibrational calculations support the structural and energetic changes that occur in the system, where $\nu_{\mathrm{O}-\mathrm{H}}$ increases for the hydroxyl and decreases to water and ethanol.
\end{abstract}

Keywords: Quantum Chemistry, Density Functional Theory, Simulation. 


\section{Lista de Figuras}

Figura 1.1 - Caminhos de reação que podem ocorrer durante a reforma a vapor do etanol utilizando catalisadores metálicos. . . . . . . . . . . . . . 9

Figura 3.1 - Geometria molecular da hidroxila, água e as conformações trans- e gauche-etanol. . . . . . . . . . . . . . . . .

Figura 3.2 - Estados eletrônicos para as moléculas de água e etanol. Na parte inferior são encontrados os orbitais atômicos de oxigênio e carbono e, na parte superior se encontram os orbitais moleculares. . . . . . . . .

Figura 3.3 - Espectro das frequências vibracionais do trans-etanol obtido através de cálculos DFT-PBE. . . . . . . . . . . . . . . . . .

Figura 3.4 - Energia relativa (meV/átomo) para $\mathrm{Ni}_{13}, \mathrm{Pd}_{13}$ e $\mathrm{Pt}_{13}$ em que as estruturas com alta simetria e as de mais baixa energia são mostradas. . .

Figura 3.5 - Energia relativa (meV/átomo) para $\mathrm{Cu}_{13}, \mathrm{Ag}_{13}$ e $\mathrm{Au}_{13}$ em que as estruturas com alta simetria e as de mais baixa energia são mostradas.

Figura 3.6 - Estruturas icosaédricas e de mais baixa energia para $\mathrm{Ni}_{13}, \mathrm{Cu}_{13}, \mathrm{Pd}_{13}$, $\mathrm{Ag}_{13}, \mathrm{Pt}_{13}$, e $\mathrm{Au}_{13}$. As cargas relativas de Mulliken $\left(\Delta Q=\sum_{i} Z_{A}^{i}-\right.$ $\left.\sum_{i} q_{m}^{i}\right)$ são mostradas para os átomos não-equivalentes. . . . . . . . .

Figura 3.7 - Frequências de vibração $\left(\mathrm{em} \mathrm{cm}^{-1}\right)$ para as configurações ICO e LOW dos $\mathrm{MT}_{13}$ clusters. . . . . . . . . . . . . . . .

Figura 4.1 - Sítios de adsorção para estruturas de 13 átomos (a) icosaédrica e (b) com baixa simetria. Para o icosaedro, destacam-se (a1) top; (a2) bridge e (a3) hollow. Na estrutura de baixa simetria são mostrados somente os sítios top. . . . . . . . . . . . . . . . . .

Figura 4.2 - Curva de energia potencial hipotética que ilustra a aplicação do critério de similaridade. . . . . . . . . . . . . . . . . . .

Figura 4.3 - Estruturas de mais baixa energia para $\mathrm{OH} / \mathrm{MT}_{13}$. Para os casos particulares $\mathrm{OH} / \mathrm{Pt}_{13}{ }^{\mathrm{ICO}}, \mathrm{OH} / \mathrm{Au}_{13}{ }^{\mathrm{ICO}}, \mathrm{OH} / \mathrm{Au}_{13}{ }^{3 \mathrm{D}}$, e $\mathrm{OH} / \mathrm{Au}_{13}{ }^{2 \mathrm{D}}$, ocorreram distorções das configurações iniciais ao longo da otimização.

Figura 4.4 - Projeção da densidade de estados para os orbitais $s$ e $p$ do hidrogênio e do oxigênio puros e após adsorção. A energia do HOMO foi definida como origem. . . . . . . . . . . . . . . . . 
Figura 4.5 - Configurações de mais baixa energia para água/ $\mathrm{MT}_{13}^{\mathrm{ICO}}$ e etanol $/ \mathrm{MT}_{13}^{\mathrm{ICO}}$. Os comprimentos de ligação O-MT e H-MT estão em A, e os números subscritos às estruturas ligadas através do hidrogênio mostram a diferença de energia em relação às estruturas ligadas através do oxigênio

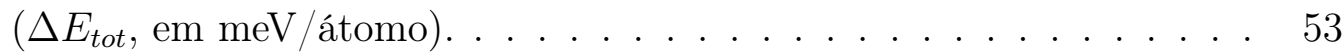

Figura 4.6 - Configurações de mais baixa energia para água/ $\mathrm{MT}_{13}^{L O W}$ e etanol $/ \mathrm{MT}_{13}^{L O W}$. Os comprimentos de ligação O-MT e H-MT estão em $\AA$, e os números subscritos às estruturas ligadas através do hidrogênio mostram a diferença de energia em relação às estruturas ligadas através do oxigênio $\left(\Delta E_{t o t}, \mathrm{em} \mathrm{meV/átomo).} \mathrm{.} \mathrm{.} \mathrm{.} \mathrm{.} \mathrm{.} \mathrm{.} \mathrm{.} \mathrm{.} \mathrm{.} \mathrm{.} \mathrm{.} \mathrm{.} 54\right.$

Figura 4.7 - Densidade de estados para os orbitais moleculares. Moléculas em fase gasosa e após adsorção molécula/MT $\mathrm{MT}_{13}^{\mathrm{ICO}} \ldots$. . . . . . . . . . . 56

Figura 4.8 - Densidade de estados para os orbitais moleculares. Moléculas em fase gasosa e após adsorção molécula/MT $\mathrm{MT}_{13}^{\mathrm{LOW}} \ldots$. . . . . . . . . . 57

Figura 4.9 - Diferença de densidade eletrônica para água e etanol sobre $\mathrm{MT}_{13}^{\mathrm{ICO}}$. $\quad 58$ Figura 4.10 - Diferença de densidade eletrônica para água e etanol sobre $\mathrm{MT}_{13}^{\mathrm{LOW}}$. 59 


\section{Lista de Tabelas}

Tabela 3.1 - Propriedades geométricas para $\mathrm{OH}, \mathrm{H}_{2} \mathrm{O}$, trans- e gauche-etanol obtidas através dos cálculos DFT-PBE e de dados experimentais. . . . . .

Tabela 3.2 - Propriedades dos clusters com 13 átomos. Comprimento de ligação ponderado $\left(d_{a v}\right.$, em $\AA$ ), número de coordenação efetiva (NCE, em número de vizinhos próximos), energia de ligação ( $E_{b}$, em eV/átomo) e momento magnético total $\left(m_{T}\right.$, em $\left.\mu_{B}\right) \ldots \ldots \ldots$

Tabela 4.1 - Parâmetros de adsorção para $\mathrm{OH} / \mathrm{MT}_{13}$. Energia de adsorção $\left(E_{a d}\right.$, em eV), comprimento de ligação O-MT ( $d_{\mathrm{O}-\mathrm{MT}}$, em $\AA$ ), variações de número de coordenação efetiva e comprimento de ligação ponderado $\left(\Delta \mathrm{NCE}\right.$ e $\Delta d_{a v}$, ambos em \%), frequência de vibração $\mathrm{O}-\mathrm{H}\left(\nu_{\mathrm{O}-\mathrm{H}}\right.$, em $\left.\mathrm{cm}^{-1}\right)$, e as cargas relativas de Mulliken para oxigênio e hidrogênio $(\Delta Q$, em $e) \ldots \ldots \ldots \ldots \ldots \ldots$

Tabela 4.2 - Energia de adsorção $\left(E_{a d}\right.$, em meV) e comprimentos de ligação O-MT ( $d_{\mathrm{O}-\mathrm{MT}}$, em $\left.\AA\right)$ de água e etanol sobre as configurações icosaédricas* e de mais baixa energia dos clusters de metais de transição, calculados através de PBE-DFT e DFT com correções de van der Waals. Os resultados para superfícies de alto empacotamento foram retirados da literatura**

Tabela 4.3 - Cargas relativas de Mulliken $(\Delta Q$, em $e$ ), para os átomos $\mathrm{O}$ e $\mathrm{H}$ da água, e C, H, O do etanol. . . . . . . . . . . . . . . . 60

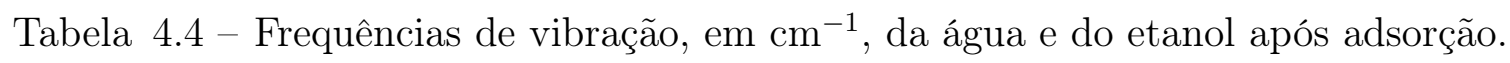

Tabela B.1 - Comprimentos de ligação $\left(d_{a v}\right.$, em $\AA$ ) para hidroxila, água e etanoltrans utilizando os conjuntos light-tier 1 (LT1), light-tier 2 (LT2), lighttier 2 (LT3), tight-tier 1 (LT1) e tight-tier 2 (TT2). . . . . . . . . . .

Tabela B.2 - Ângulos $\left(\widehat{A B C}\right.$, $\left.\mathrm{em}^{\circ}\right)$ para hidroxila, água e etanol-trans utilizando os conjuntos light-tier 1 (LT1), light-tier 2 (LT2), light-tier 2 (LT3), tight-tier 1 (LT1) e tight-tier $2(\mathrm{TT} 2)$. . . . . . . . . . . . . .

Tabela B.3 - Energia de ligação $\left(E_{b}\right.$, em eV) para hidroxila, água e etanol-trans utilizando os conjuntos light-tier 1 (LT1), light-tier 2 (LT2), light-tier 3 (LT3), tight-tier 1 (TT1) e tight-tier 2 (TT2) . . . . . . . . . . . 
Tabela B.4 - Momentos de dipolo elétrico ( $\mu$, em D) para hidroxila, água e etanoltrans utilizando os conjuntos light-tier 1 (LT1), light-tier 2 (LT2), lighttier 3 (LT3), tight-tier 1 (TT1) e tight-tier 2 (TT2). . . . . . . . . . .

Tabela B.5 - Comprimentos de ligação ponderados $\left(d_{a v}\right.$, em $\left.\AA\right)$ e número de coordenação efetiva (NCE, em átomos vizinhos próximos) para $\mathrm{MT}_{13} \mathrm{ICO}$ e LOW, utilizando conjuntos light-tier 1 (LT1), light-tier 2 (LT2), tighttier 1 (LT1) e tight-tier 2 (TT2) . . . . . . . . . . . . . .

Tabela B.6 - Energia de ligação $\left(E_{b}\right.$, em eV/átomo) para $\mathrm{MT}_{13}$ ICO e LOW, utilizando conjuntos light-tier 1 (LT1), light-tier 2 (LT2), tight-tier 1 (LT1) e tight-tier $2(\mathrm{TT} 2) \ldots \ldots \ldots \ldots \ldots$ 


\section{Sumário}

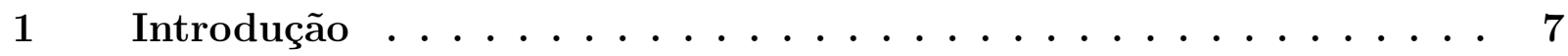

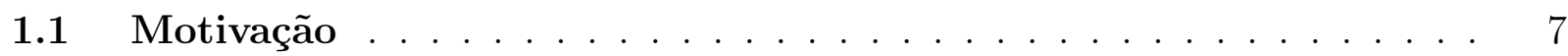

1.2 Revisão da literatura . . . . . . . . . . . . . . . . . . . . . 10

1.3 Objetivos . . . . . . . . . . . . . . . . . . . . 11

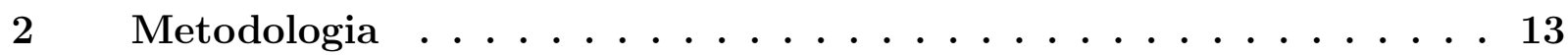

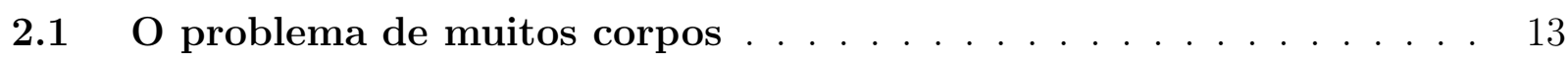

2.2 Aproximação de Born-Oppenheimer . . . . . . . . . . . . . . . . . . . 14

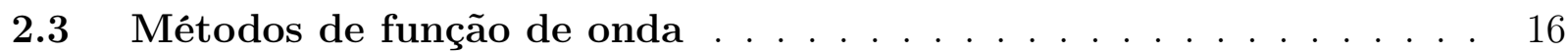

2.3.1 O método de Hartree . . . . . . . . . . . . . . . . . . . . 16

2.3.2 O método de Hartree-Fock . . . . . . . . . . . . . . . . . 17

2.4 Teoria do funcional da densidade . . . . . . . . . . . . . . . 18

2.4.1 Teoremas de Hohenberg e Kohn . . . . . . . . . . . . . . . . . . . 19

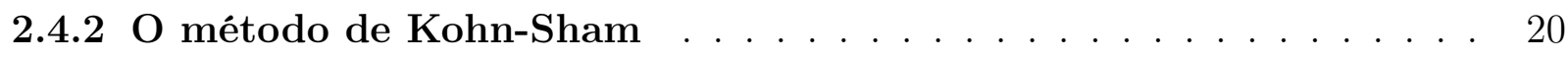

2.4.3 Funcionais de troca e correlação . . . . . . . . . . . . . . . . . 21

2.4 .4 Correção de van der Waals . . . . . . . . . . . . . . . . . . . . 24

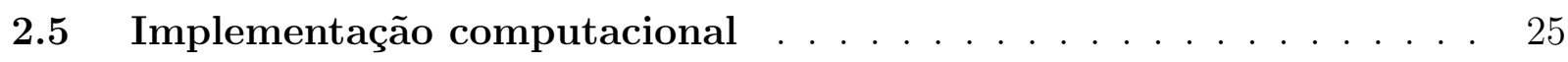

3 Resultados: Sistemas isolados . . . . . . . . . . . . . 28

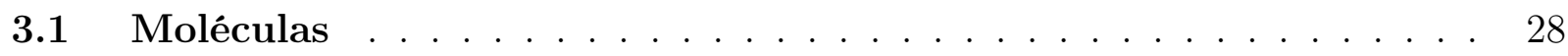

3.2 Clusters: $\mathrm{Ni}_{13}, \mathrm{Cu}_{13}, \mathrm{Pd}_{13}, \mathrm{Ag}_{13}, \mathrm{Pt}_{13}$ e $\mathrm{Au}_{13} \ldots \ldots \ldots \ldots$

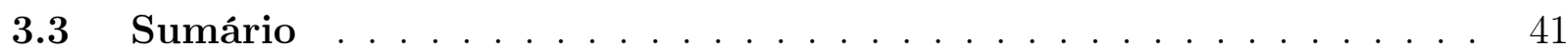

4 Resultados: Sistemas adsorvidos . . . . . . . . . . . 43

4.1 Geração de estruturas de adsorçãao . . . . . . . . . . . . . . . . 43

4.2 Adsorção de hidroxila sobre $\mathbf{M T}_{13} \ldots \ldots \ldots \ldots$

4.3 Adsorção de água sobre $\mathrm{MT}_{13} \ldots \ldots \ldots \ldots \ldots \ldots \ldots$

4.4 Adsorção de etanol sobre $\mathbf{M T}_{13} \ldots \ldots \ldots \ldots$

4.5 Discussão e sumário . . . . . . . . . . . . . . . . . . . . . . 63

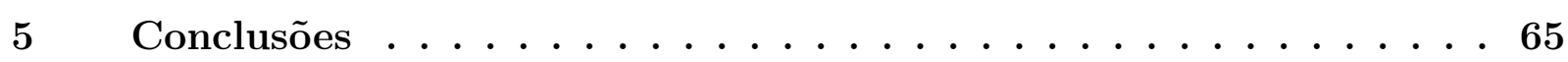

Referências .....................66 


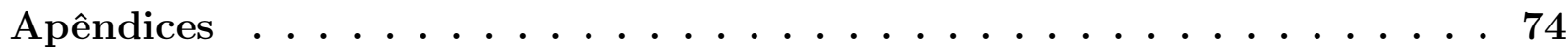

A Teoria do funcional da densidade: Teoremas . . . . . . . . 74

A.1 Primeiro teorema de Hohenberg-Kohn . . . . . . . . . . . . . . . . . 74

A.2 Segundo teorema de Hohenberg-Kohn . . . . . . . . . . . . . . 75

B Testes de convergência em função do número de funções base . . . . 77 


\section{Capítulo 1}

\section{Introdução}

O presente capítulo está dividido em três partes: $(i)$ Motivação - serão apresentadas a motivação e a justificativa para realizar o presente estudo; (ii) Nesta seção serão apresentados os principais resultados existentes na literatura, e na última seção do presente capítulo, (iii) os principais objetivos da presente dissertação de mestrado serão apresentados.

\subsection{Motivação}

Grande parte da energia consumida no mundo é proveniente da queima de petróleo, o qual em seu estado natural é uma mistura de diversos hidrocarbonetos contendo proporções menores de impurezas (nitrogênio, enxofre, oxigênio, e metais). Apesar dos avanços realizados na tecnologia de refinamento de petróleo nas últimas décadas, o processo de combustão de hidrocarbonetos libera várias sustâncias nocivas à saúde e ao meio ambiente, exemplo, monóxido e dióxido de carbono $\left(\mathrm{CO}, \mathrm{CO}_{2}\right)$, óxidos de enxofre $\left(\mathrm{SO}_{\mathrm{x}}\right)$, óxidos de nitrogênio $\left(\mathrm{NO}_{\mathrm{x}}\right)$, e hidrocarbonetos $(\mathrm{HC})$ não totalmente queimados ao longo da combustão. (1) Portanto, existe um grande interesse na utilização de fontes renováveis de energia (hidrelétrica, geotérmica, marés, ventos, solar, hidrogênio, etanol, e biodiesel), (2, 3) dentre as quais o gás hidrogênio $\left(\mathrm{H}_{2}\right)$ é uma fonte atraente que pode ser utilizado em células de combustível, $(4,5)$ que combinam $\mathrm{H}_{2}$ e $\mathrm{O}_{2}$ em uma reação química $\left(2 \mathrm{H}_{2}+\mathrm{O}_{2} \longrightarrow 2 \mathrm{H}_{2} \mathrm{O}\right)$ para gerar eletricidade e tendo como resíduo somente vapor de água. (2) Portanto, as emissões são muito menores que em um processo de combustão de hidrocarbonetos.

Aproximadamente $50 \%$ da produção mundial de $\mathrm{H}_{2}$ é proveniente da reforma de gás natural $\left(\mathrm{CH}_{4}+2 \mathrm{H}_{2} \mathrm{O} \longrightarrow \mathrm{CO}_{2}+4 \mathrm{H}_{2}\right)$, entretanto, gás natural não é uma fonte renovável e libera $\mathrm{CO}_{2}$ ao longo do processo de formação de hidrogênio. Além deste fato, a maior parte da produção mundial de $\mathrm{H}_{2}$ é utilizada em indústrias químicas para a fabricação de vários produtos, como a amônia, que é utilizada na indústria de fertilizantes. Outro grande problema para o uso de $\mathrm{H}_{2}$ está relacionado ao seu armazenamento, o que requer grandes recepientes ou altas pessões. Normalmente são utilizadas altas pressões, o que pode comprometer a segurança, principalmente, em veículos automotores. 
Muitos estudos têm sugerido que os problemas mencionados anteriormente, produção e armazenamento de $\mathrm{H}_{2}$, para aplicações em meio de transporte, podem ser solucionados através da geração $\mathrm{H}_{2}$ a partir de metanol $\left(\mathrm{CH}_{3} \mathrm{OH}\right)$ ou etanol $\left(\mathrm{CH}_{3} \mathrm{CH}_{2} \mathrm{OH}\right)$, (6-8) os quais podem ser facilmente armazenados na fase líquida. No caso particular do etanol, o mesmo pode ser produzido a partir de cana-de-açúcar. Pode-se mencionar, ainda, que o etanol é significativamente menos tóxico que o metanol e que a gasolina, e posui um baixo custo de produção, em particular no Brasil.

Ao longo dos anos foram propostas duas abordagens para o uso de etanol em células de combustível, em que ambas envolvem basicamente a quebra de molécula de etanol para a retirada do hidrogênio (9) através da seguinte reação:

$$
\mathrm{CH}_{3} \mathrm{CH}_{2} \mathrm{OH}+3 \mathrm{H}_{2} \mathrm{O} \longrightarrow 2 \mathrm{CO}_{2}+6 \mathrm{H}_{2} \text {. }
$$

No entanto, um problema comum nas duas propostas é o de se encontrar um catalisador estável e com baixo custo de produção, ou seja, o problema envolve o desenvolvimento de novos materiais que possam facilitar esta reação. (4, 5) Na figura (1.1) se observam vários caminhos de reação, de forma que a reforma a vapor do etanol possui um grande número de reações intermediárias, onde as diferenças são dadas de acordo com o catalisador. A escolha do catalisador no processo de reforma a vapor do etanol possui um papel central, uma vez que este determina a eficiência da produção de hidrogênio para aplicações em células combustíveis. $(5,10)$

Um catalisador ideal é um composto que ajuda a acelerar a velocidade de uma reação química sem ser consumido ou danificado durante a reação. Uma superfície metálica pode atuar como catalisador para um grande número de moléculas devido à alta densidade de estados eletrônicos na energia Fermi que funciona como um reservatório de elétrons, o qual pode fornecer ou receber elétrons de moléculas adsorvidas. Neste processo, a energia de ligação intramolecular é reduzida e, assim, contribuindo para a redução das barreiras de energia de ativação das reações. (12-14) Portanto, o sucesso ou fracasso de um catalisador depende diretamente da magnitude das interações entre sistemas moleculares e supefícies, bem como das condições experimentais (temperatura e pressão). Um catalisador típico é composto por partículas de metais de transição (Pt, Pd, Rh, Fe, Co, Ni, etc) depositadas sobre superfícies de óxidos $\left(\mathrm{Al}_{2} \mathrm{O}_{3}, \mathrm{CeO}_{2}, \mathrm{SiO}_{2}\right.$, etc), os quais funcionam como suporte.

Ao longo das últimas décadas o tamanho das partículas (diâmetro - número de átomos) suportadas sobre óxidos têm sido reduzidas gradativamente, partindo de partículas com milhões de átomos (macroscópicas) a, até mesmo, partículas contendo somente poucos átomos (clusters) devido ao aumento da reatividade com a redução do tamanho das partículas. (15) Um dos exemplos clássicos para ilustar este contexto é o caso particular de partículas de ouro, as quais em tamanho macroscópico não apresentam nenhuma característica de catalisador, o que pode ser entendido pela densidade de estados na fase bulk deste material. Entretanto, foi descoberto que partículas de ouro com diâmetro entre 1 e 3 nanometros 
Figura 1.1 - Caminhos de reação que podem ocorrer durante a reforma a vapor do etanol utilizando catalisadores metálicos.

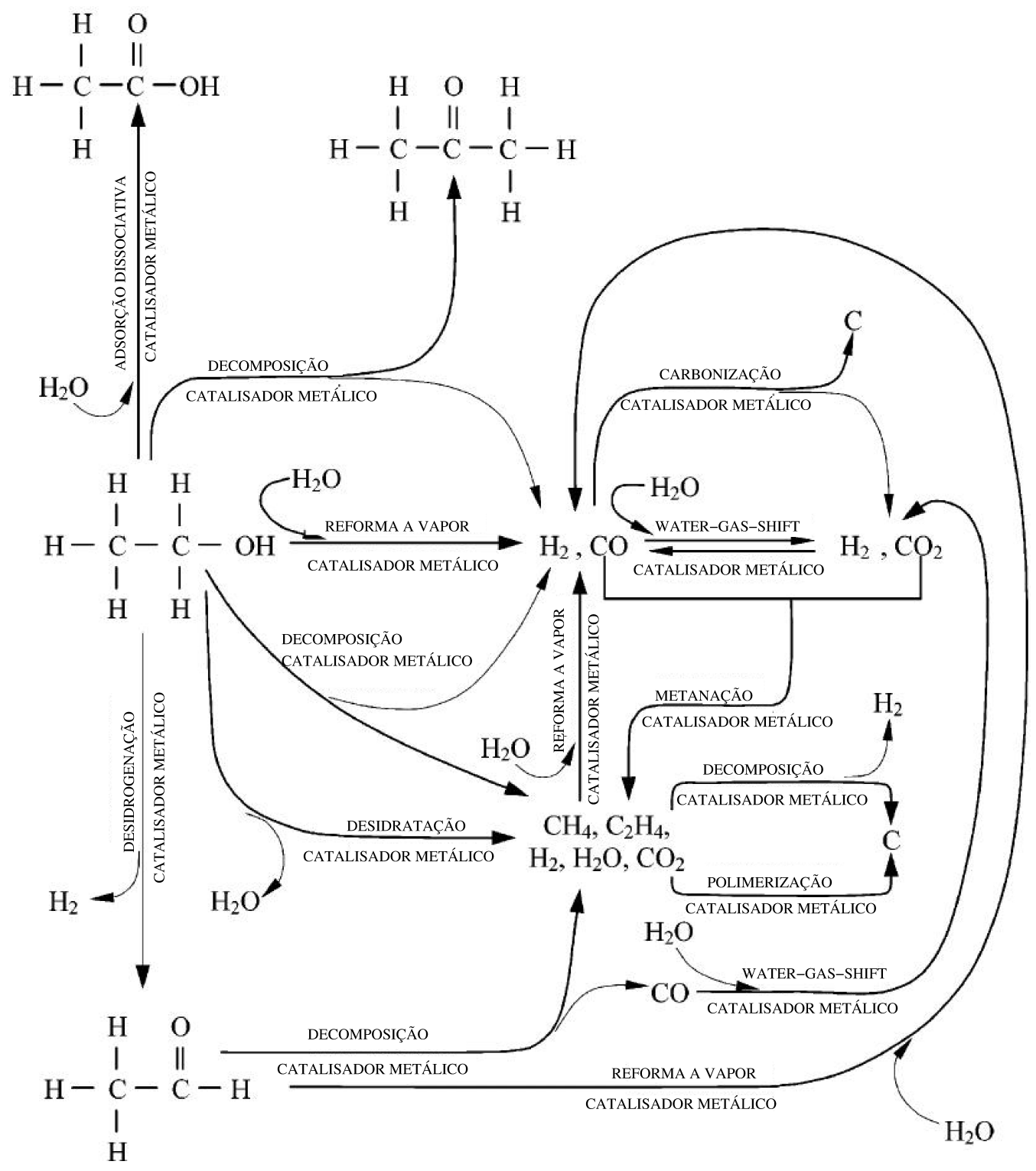

Fonte: Adaptação própria a partir de (11).

suportadas sobre $\mathrm{TiO}_{2}$ apresentam alta reatividade para um grande número de reações. (16-18) Recentemente, Vajda e colaboradores demostraram experimentalmente que é possível aumentar a eficiência da seletividade para a desidrogenação oxidativa do propano de 40 - 100 vezes utilizando clusters de platina contendo somente oito átomos $\left(\mathrm{Pt}_{8}\right)$ suportados sobre $\mathrm{Al}_{2} \mathrm{O}_{3}$ em comparação com partículas macroscópicas de platina suportadas sobre vanádio. (19)

Estes resultados indicam claramente que partículas contendo somente poucos átomos podem desempenhar um papel fundamental em catálise. Neste contexto, existe uma grande expectativa de que partículas nanométricas ou sub-nano possam fornecer uma contribuição fundamental para a produção de $\mathrm{H}_{2}$ utilizando uma mistura de etanol-água. Portanto, a presente dissertação de mestrado têm o objetivo de fornecer uma contribuição 
para melhorar o entendimento atomístico deste problema.

\subsection{Revisão da literatura}

Um grande número de trabalhos na literatura mostram que a reação de produção de $\mathrm{H}_{2}$ através da reforma a vapor de etanol, em diferentes condições de pressão e temperatura, pode gerar uma grande quantidade de produtos intermediários, o que está ilustrado na figura (1.1). Por exemplo, os seguintes intermediários, metano, eteno, etanal, podem ser formados, os quais podem originar outras reações e envolver uma posterior formação de hidrogênio; mas também há reações as quais desviam da ideal que impedem a formação de hidrogênio, resultando, por exemplo, em ácido etanóico ou propanona, ou ainda podem envenenar o catalisador como o coque. (11) Naturalmente, pode-se notar a complexidade do problema e os desafios envolvidos. Portanto, a presente revisão ficará restrita ao estudo da primeira etapa, ou seja, a interação de moléculas de etanol e água com os catalisadores compostos por sistemas metálicos.

A interação de moléculas de água com superfícies metálicas é relativamente antigo em comparação com moléculas de etanol, principalmente, devido à importância da mesma. É consenso através de vários estudos experimentais e teóricos (simulações de química quântica) que moléculas de água adsorvidas sobre superfícies compactas de metais de transição* estão orientadas paralelamente à superfície com o átomo de oxigênio localizado próximo de um sítio top de baixa coordenação. (20-22) A energia de adsorção é somente uma fração de $1.0 \mathrm{eV}$ e, por isso, pode ser caracterizada como um processo de adsorção física, a qual pode originar alterações na função trabalho da superfície. $(23,24)$ O átomo de oxigênio está localizado aproximadamente entre 2.20 e $2.80 \AA$ da supefície dos principais metais de transição, exemplo, Fe(111), Co(0001), Ni(111), Cu(111), Ru(0001) Rh(111), Pd(111), $\mathrm{Ag}(111), \operatorname{Os}(0001), \operatorname{Ir}(111), \mathrm{Pt}(111)$, e $\mathrm{Au}(111)$. O processo de adsorção praticamente não altera o comprimento de ligação O-H, ou seja, alterações da ordem de $0.01 \AA$.

O aumento do número de moléulas sobre a superfície pode originar fenômenos muito interessantes devido à interação entre as moléculas de água e a competição entre as interações, água-superfície e água-água. As interações entre as moléculas levam à formação de ligações de hidrogênio, o que ocorre também na fase sólida (gelo) e líquida da água. Estudo teóricos com base em química quântica mostraram que existe um aumento na energia de interação através das ligações de hidrogênio sobre superfícies metálicas devido à interação água-superfície, a qual afeta a estrutura eletrônica (densidade de carga) das moléculas. $(25,26)$ Portanto, devido à forte interação água-água, essas moléculas podem se orientar formando estruturas hexagonais sobre superfícies metálicas com algumas características que lembram as estruturas de camadas observadas nas estruturas do gelo. Este tópico é amplo e outras informações podem ser encontrados em artigos de revisão. (27-29)

\footnotetext{
* Podemos denominar de superfícies compactas a superfície (111) da estrutura cúbica de face-centrada ou a superfície (0001) na estrutura hexagonal close-packed.
} 
Devido à sua complexidade, o estudo da adsorção de etanol sobre superfícies metálicas é relativamente reduzido em comparação com o grande número de estudos da água. Recentemente, Tereshchuk e colaboradores realizaram um estudo sistemático da interação de etanol com superfícies metálicas, em particular, 12 superfícies compactas com baixos índices de Miller utilizando cálculos de química quântica com base na teoria do funcional da densidade. (30) Os autores reportam que o etanol se liga preferencialmente em sítios top via oxigênio, com uma distância que varia entre 2.14 e $2.77 \AA$ da superfície. Os autores ainda mostram que o etanol varia seu ângulo de posicionamento em relação à superfície quando são consideradas as interações de van der Waals, de forma que a molécula deixa a posição perpendicular para ficar aproximadamente paralela à superfície. Essa variação proporciona uma maior sobreposição entre os orbitais da molécula e dos metais de transição, fazendo com a energia de adsorção aumente significativamente, chegando a uma intensificação de até $366 \%$.

Dos trabalhos que utilizam mais de uma molécula de etanol no processo de adsorção sobre superfícies, obtêm-se que existe uma preferência das moléculas em se aglomerarem, formando dímeros, em que as ligações de hidrogênio estabilizam o sistema. Yang e colaboradores mostram que a adsorção de moléculas de etanol sobre $\mathrm{Rh}(111)$ induzem uma diminuição da frequência de vibração do grupo hidroxila, dada a formação da ligação de hidrogênio. (31) Tereshchuk e Da Silva também ressaltam a importância da formação de ligações de hidrogênio entre as moléculas de etanol, que induzem a adsorção sobre Pt(111); os autores ainda destacam a relevância do uso de correções para descrição das forças de London, dada a baixa magnitude da energia de adsorção. (24)

\subsection{Objetivos}

Apesar do grande número de trabalhos sobre a interação de etanol e água sobre metais de transição, grande parte dos estudos foi realizado sobre supefícies compactas, entretanto, existem uma grande variedade de sítios de adsorção sobre substratos reais. Geralmente estes efeitos são estudados através de superfícies com desníveis que apresentam sítios com baixa coordenação. Por outro lado, grande parte dos resultados publicados nos últimos anos ficou restrita ao estudo da adsorção sobre superfícies, ou seja, é quase inexistente o estudo da interação de moléculas de água com clusters, e não existe nenhum trabalho envolvendo etanol e clusters metálicos até o presente momento. O estudo da interação de moléculas de água e etanol com clusters metálicos permite estudar os efeitos de estruturas totalmente irregulares e efeitos de tamanho. Para atingir estes objetivos, nesta dissertação de mestrado, são utilizados métodos de química quântica com base na teoria do funcional da densidade.

Existe uma infinidade de clusters com diferentes números de átomos, entretanto, vários estudos experimentais e teóricos ao longo de várias décadas demonstraram a existência de 
clusters mágicos, $(15,32)$ os quais são clusters com uma alta taxa de ocorrência devido à sua alta estabilidade relativa. Este trabalho se restringe a clusters contendo 13 átomos, os quais são bastante estáveis, e foram largamente estudados no grupo de teoria quântica de nanomateriais nos últimos anos. Para entender os efeitos das diferenças entre os estados $3 d, 4 d$, e $5 d$, foram selecionados os seguintes metais de transição, $3 d(\mathrm{Ni}, \mathrm{Cu}), 4 d(\mathrm{Pd}, \mathrm{Ag})$, e $5 d(\mathrm{Pt}, \mathrm{Au})$, os quais possuem grande importância para o processo de reforma a vapor de etanol. Como mencionado acima, a energia de interação das moléculas de água e etanol com superfícies de metais de transição é relativamente pequena e, portanto, para efeito comparativo, foi realizado também o estudo da interação do radical $\mathrm{OH}$ com os mesmos sistemas não-periódicos.

Em suma, a presente dissertação de mestrado tem o seguinte objetivo:

- Estudar a interação de sistemas moleculares $\left(\mathrm{OH}, \mathrm{H}_{2} \mathrm{O}, \mathrm{CH}_{3} \mathrm{CH}_{2} \mathrm{OH}\right)$ com clusters de metais de transição contendo 13 átomos $\left(\mathrm{Ni}_{13}, \mathrm{Cu}_{13}, \mathrm{Pd}_{13}, \mathrm{Ag}_{13}, \mathrm{Pt}_{13}, \mathrm{Au}_{13}\right)$ através de métodos de química quântica com base na teoria do funcional da densidade. 


\section{Capítulo 2}

\section{Metodologia}

Este capítulo está divido em cinco partes: (2.1) o problema de muitos corpos; (2.2) a aproximação de Born-Oppenheimer; (2.3) métodos de função de onda; (2.4) teoria do funcional da densidade; (2.5) implementação computacional.

\subsection{O problema de muitos corpos}

A abordagem teórica que envolve este trabalho está diretamente relacionada com o nível de entendimento que se pretende obter acerca dos sistemas em estudo. Como visto no capítulo anterior, sabe-se que o comportamento de clusters metálicos diverge daquele encontrado em seus análogos macroscópicos, de forma que se faz necessário um estudo em nível atomístico para se compreender as modificações estruturais e eletrônicas que ocorrem nessa escala. Assim sendo, ao se considerar um sistema constituído por $N$ elétrons e $M$ núcleos, obtêm-se seus observáveis físicos a partir da solução da equação de Schrödinger independente do tempo, uma vez que o potencial externo atuante não possui variação temporal, que é dada por

$$
\hat{H} \Psi(\{\mathbf{r}\},\{\mathbf{R}\})=E \Psi(\{\mathbf{r}\},\{\mathbf{R}\}),
$$

onde a função de onda, $\Psi$, que descreve o sistema é função tanto das $N$ coordenadas eletrônicas, denotadas por $\{\mathbf{r}\}=\left\{\mathbf{r}_{1}, \mathbf{r}_{2}, \mathbf{r}_{3}, \ldots, \mathbf{r}_{N}\right\}$, quanto das $M$ coordenadas nucleares, representadas por $\{\mathbf{R}\}=\left\{\mathbf{R}_{1}, \mathbf{R}_{2}, \mathbf{R}_{3}, \ldots, \mathbf{R}_{M}\right\}$. O Hamiltoniano não relativístico, $\hat{H}$, que descreve o problema de muitos corpos, é composto pelas energias cinéticas e pelas interações de Coulomb, e é definido como

$$
\hat{H}=\hat{T}_{n}+\hat{T}_{e}+\hat{V}_{n n}(\{\mathbf{R}\})+\hat{V}_{n e}(\{\mathbf{r}\},\{\mathbf{R}\})+\hat{V}_{e e}(\{\mathbf{r}\})
$$

Fazendo uso de unidades atômicas*, ao se explicitar cada operador à direita de (2.2),

* Comprimentos são dados em bohr (1 bohr = $0.529177 \AA$ ); energias, em Hartree (1 Hartree = 2 Rydberg, e a energia do estado fundamental para o átomo de hidrogênio equivale a -1 Rydberg); $m_{e}=1, \hbar=1$, 
obtém-se os operadores de energia cinética escritos através dos laplacianos ${ }^{*}\left(\nabla_{\mathbf{R}_{\alpha}}^{2}\right.$ e $\left.\nabla_{\mathbf{r}_{\mathbf{i}}}^{2}\right)$,

$$
\hat{T}_{n}=\sum_{\alpha=1}^{M}-\frac{\nabla_{\mathbf{R}_{\alpha}}^{2}}{2 M_{\alpha}} \quad \text { e } \quad \hat{T}_{e}=\sum_{i=1}^{N}-\frac{\nabla_{\mathbf{r}_{\mathbf{i}}}^{2}}{2}
$$

onde $M_{\alpha}$ é a massa nuclear do $\alpha$-ésimo núcleo. Os operadores de repulsão eletrostática entre núcleos e entre elétrons e, ainda, o de atração núcleo-elétron, são dados respectivamente por

$$
\begin{aligned}
\hat{V}_{n n}(\{\mathbf{R}\}) & =\sum_{\alpha=1}^{M-1} \sum_{\beta>\alpha}^{M} \frac{Z_{\alpha} Z_{\beta}}{\left|\mathbf{R}_{\alpha}-\mathbf{R}_{\beta}\right|}, \\
\hat{V}_{e e}(\{\mathbf{r}\}) & =\sum_{i=1}^{N-1} \sum_{j>i}^{N} \frac{1}{\left|\mathbf{r}_{i}-\mathbf{r}_{j}\right|}, \\
\text { e } \hat{V}_{n e}(\{\mathbf{r}\},\{\mathbf{R}\}) & =\sum_{\alpha=1}^{M} \sum_{i=1}^{N}-\frac{Z_{\alpha}}{\left|\mathbf{R}_{\alpha}-\mathbf{r}_{i}\right|},
\end{aligned}
$$

em que $Z_{\alpha}$ é o número atômico do $\alpha$-ésimo núcleo.

A não trivialidade da solução para o problema de muitos corpos é devida, notoriamente, às interações Coulombianas entre os elétrons, que possuem descrição analítica. Contudo, não se conhece a função de onda dos elétrons sob esse tipo de interação. Além disso, o acomplamento dos movimentos eletrônico e nuclear, que ocorre através do potencial de atração eletrostático, $\hat{V}_{n e}$, mostra a necessidade de se propor uma solução aproximada para esse tipo de problema.

\subsection{Aproximação de Born-Oppenheimer}

A fim de simplificar a equação de Schrödienger que descreve o problema de muitos corpos, pode-se observar que os operadores de energia cinética em (2.3) são inversamente proporcionais às respectivas massas das partículas que descrevem. Dito isso, e sabendo que a razão massiva de um próton em relação a um elétron envolve três ordens de grandeza $\left(m_{p}=1836 m_{e}\right)$, Born e Oppenheimer (33) propuseram que o movimento de resposta dos eletróns em relação ao movimento nuclear pode ser considerado como que instantâneo. Ou seja, ao se tratar os núcleos como partículas estacionárias, o problema se restringe a encontrar os autovalores referentes ao comportamento eletrônico, os quais serão usados como valores médios na solução do problema nuclear.

A primeira aproximação ocorre na definição da função de onda total, onde há o desacoplamento dos movimentos eletrônico e nuclear. A função de onda que descreve o problema total é escrita através da multiplicação de uma função de onda nuclear $(\chi(\{\mathbf{R}\}))$ e outra

$e=1$. Interações eletrostáticas, $4 \pi \varepsilon_{0}=1$.

${ }^{*} \nabla^{2}=\frac{\partial^{2}}{\partial x^{2}}+\frac{\partial^{2}}{\partial y^{2}}+\frac{\partial^{2}}{\partial z^{2}}$ 
eletrônica $(\psi(\{\mathbf{r}\}, \mathbf{R}))$, que utiliza as posições nucleares como parâmetros pré-estabelicidos, dada por

$$
\Psi(\{\mathbf{r}\},\{\mathbf{R}\})=\chi(\{\mathbf{R}\}) \psi(\{\mathbf{r}\}, \mathbf{R}) .
$$

Na separação de variáveis, o Hamiltoniano que descreve o sistema pode ser escrito como a soma do Hamiltoniano nuclear e do Hamiltoniano eletrônico, $\hat{H}=\hat{H}_{n}+\hat{H}_{e}$ e ao ser aplicado, juntamente à função de onda, na equação de Schrödinger, são obtidas as seguintes equações:

$$
\hat{H}_{e} \psi(\{\mathbf{r}\}, \mathbf{R})=\varepsilon_{e} \psi(\{\mathbf{r}\}, \mathbf{R})
$$

$\mathrm{e}$

$$
\hat{H}_{n} \chi(\{\mathbf{R}\})=E_{n} \chi(\{\mathbf{R}\}) .
$$

Como os núcleos são dados como entes estacionários, a energia cinética nuclear será, então, nula e o potencial de interação eletrostático entre os núcleos será constante para o Hamiltoniano eletrônico, ou seja, $\hat{T}_{n}=0$ e $\hat{V}_{n n}(\{\mathbf{R}\})=$ constante. Desse modo, a energia eletrônica depende explicitamente das posições eletrônicas, mas também depende parametricamente das posições nucleares, ou seja, $\varepsilon_{e}=\varepsilon_{e}(\mathbf{R})$. Assim, a equação (2.8) é escrita como

$$
\left(\hat{T}_{e}+\hat{V}_{e e}(\{\mathbf{r}\})+\hat{V}_{n e}(\{\mathbf{r}\},\{\mathbf{R}\})\right) \psi(\{\mathbf{r}\}, \mathbf{R})=\varepsilon_{e}(\mathbf{R}) \psi(\{\mathbf{r}\}, \mathbf{R}) .
$$

Logo, para uma dada configuração nuclear, a energia total do sistema será dada por

$$
\varepsilon_{t o t}(\mathbf{R})=\varepsilon_{e}(\mathbf{R})+\sum_{\alpha=1}^{M-1} \sum_{\beta>\alpha}^{M} \frac{Z_{\alpha} Z_{\beta}}{\left|\mathbf{R}_{\alpha}-\mathbf{R}_{\beta}\right|}
$$

que consitui o problema eletrônico. Ao seguir essa linha de raciocínio, observa-se que a equação (2.9) pode ser resolvida, ao passo que o Hamiltoniano para o termo nuclear é dado por

$$
\hat{H}_{n}(\{\mathbf{R}\})=\hat{T}_{n}+\varepsilon_{t o t}(\mathbf{R}) .
$$

A função de onda obtida para o comportamento nuclear é, por sua vez, responsável pela descrição dos movimentos de vibração, translação e rotação do sistema. O desenvolvimento quantitativo para a aproximação de Born-Oppenheimer pode ser consultada na referência (34). Para sistemas particulares em que a energia cinética nuclear não pode ser desconsiderada, a aproximação de BO falha, como é o caso colisões de alta energia, ou quando ocorre um acoplamento significativo entre os estados vibracionais nucleares e os estados eletrônicos, como em uma dinâmica reacional. (35) Porém, os sistemas que compõem essa dissertação podem ser entendidos sob a luz da aproximação de Born-Oppenheimer.

Em síntese, essa aproximação promove um ponto de partida na solução do problema de muitos corpos, de modo a simplificá-lo significativamente. Entretanto, as interações 
intereletrônicas, que não possuem um tratamento analítico, tem sido fonte de pesquisas e do refinamento de aproximações a fim de se descrever um sistema com muitas partículas de forma satisfatória. Para isso, empregam-se diferentes métodos, classificados em métodos de função de onda e métodos que utilizam a densidade eletrônica.

\subsection{Métodos de função de onda}

Dentro das abordagens que se utilizam das funções de onda como meio direto de acesso aos autovalores da equação de Schödinger destacam-se o método de Hartree e o método de Hartree-Fock.

\subsubsection{O método de Hartree}

A partir da aproximação de Born-Oppenheimer, Hartree propôs, em 1928, (36) uma função multieletrônica (contendo $N$ elétrons) aproximada, que poderia ser escrita como o produto de $N$ funções monoeletrônicas, dada por

$$
\psi_{H}\left(\mathbf{r}_{1}, \mathbf{r}_{2}, \ldots, \mathbf{r}_{N}\right)=\phi_{1}\left(\mathbf{r}_{1}\right) \phi_{2}\left(\mathbf{r}_{2}\right) \ldots \phi_{N}\left(\mathbf{r}_{N}\right)
$$

onde $\phi_{i}\left(\mathbf{r}_{i}\right)$ está relacionado ao estado em que o $i$-ésimo elétron se encontra.

Observa-se que através da função de onda proposta por Hartree há o desacoplamento do movimento eletrônico, de modo que o problema inicial de $N$ elétrons se simplifica a $N$ problemas de um elétron. Porém, o modo como a função de onda foi proposta não promove a descrição plena dos elétrons, que são férmions e, portanto, necessitam de uma função de onda antissimétrica para descrevê-los. Dessa forma, o princípio de exclusão de Pauli é obedecido de forma fraca, quando a inclusão a descrição do spin é adicionado posteriormente.

A partir da função de onda dada por (2.13) e do cálculo variacional, obtém-se a energia através do método de Hartree, no qual o Hamiltoniano contém os operadores de energia cinética, de potencial eletrostático de interação núcleo-elétron (potencial externo, $\hat{V}_{\text {ext }}(\mathbf{r})$ ) e um potencial de campo médio denominado potencial de Hartree $\left(\hat{V}_{H}(\mathbf{r})\right)$, que faz uma aproximação em que os elétrons interagem com um campo médio. Assim, ao se minimizar o valor esperado do Hamiltoniano para cada $\phi_{i}\left(\mathbf{r}_{i}\right)$, obtêm-se as equações de partícula única de Hartree, dadas por

$$
\left(-\frac{\nabla^{2}}{2}-\sum_{\alpha=1}^{M} \frac{Z_{\alpha}}{\left|\mathbf{R}_{\alpha}-\mathbf{r}_{i}\right|}+\sum_{j=1, j \neq i}^{N} \int d \mathbf{r}_{j} \frac{\left|\phi_{j}\left(\mathbf{r}_{j}\right)\right|^{2}}{\left|\mathbf{r}_{i}-\mathbf{r}_{j}\right|}\right) \phi_{i}\left(\mathbf{r}_{i}\right)=\varepsilon_{i} \phi_{i}\left(\mathbf{r}_{i}\right),
$$

*Uma função antissimétrica apresenta inversão de sinal na troca de quaisquer duas coordenadas, ou seja, $\phi\left(\mathbf{r}_{1}, \mathbf{r}_{2}, \ldots, \mathbf{r}_{i}, \mathbf{r}_{i+1}, \ldots, \mathbf{r}_{N}\right)=-\phi\left(\mathbf{r}_{1}, \mathbf{r}_{2}, \ldots, \mathbf{r}_{i+1}, \mathbf{r}_{i}, \ldots, \mathbf{r}_{N}\right)$ 
onde os dois últimos operadores que atuam sobre $\phi_{i}\left(\mathbf{r}_{i}\right)$ compõem o chamado potencial efetivo, $\hat{V}_{\text {eff }}$.

Como é necessário um conjunto completo de funções para descrever o sistema de $N$ elétrons, Hartree propôs uma solução auto-consistente para a equação (2.14), de modo que através de uma expansão com um número finito de funções seja possível se obter os parâmetros a serem analisados com uma margem de erro aceitável. Esse processo é explicado detalhadamente na seção (2.4.2).

\subsubsection{O método de Hartree-Fock}

Apesar de ser o primeiro momento na história da ciência em que se assume uma função de onda multieletrônica escrita como orbitais monoeletrônicos, a proposta de Hartree desconsidera a natureza fermiônica dos elétrons. Deve-se ressaltar, também, que o potencial de Hartree se baseia apenas na repulsão Coulombiana entre os elétrons, fazendo com que a energia do sistema seja superestimada, uma vez que não reflete as interações de troca e correlação que existem entre os entes.

Assim, em 1930, Fock mostra que ao se utilizar uma função de onda antissimétrica, através de um determinante de Slater*, ocorre o chamado fenômeno de troca, que obedece ao princípio de Pauli na forma forte. (37) Assim sendo, cada elétron descrito através do método de Hartree-Fock (HF) interage com um campo médio gerado pelos outros elétrons do sistema que leva em consideração o movimento intrínseco de spin dos elétrons. Nota-se que os orbitais monoeletrônicos $\phi_{i}$ são dados através do produto da função de onda espacial e de spin, ou seja, $\phi_{i}\left(\mathbf{x}_{i}\right)=\phi_{i}\left(\mathbf{r}_{i}\right) \chi(\sigma)$, onde $\sigma$ equivale ao spin "up" $\left(+\frac{1}{2}\right)$ ou "down" $\left(-\frac{1}{2}\right)$, de modo a formar um conjunto de funções ortogonais, $\int \chi^{*}\left(\sigma_{i}\right) \chi\left(\sigma_{j}\right) d \sigma=\delta_{i j}$. A energia total para o sistema contendo $N$ elétrons e $M$ núcleos obtida através do método HF é dada por

$$
E_{H F}=\sum_{i=1}^{N} H_{i}+\frac{1}{2} \sum_{i=1}^{N} \sum_{j=1}^{N}\left(J_{i j}-K_{i j}\right),
$$

onde os termos dos somatórios são dados por

$$
H_{i}=\int \psi_{i}^{*}(\mathbf{x})\left[\frac{1}{2} \nabla^{2}+\hat{V}_{e x t}(\mathbf{x})\right] \psi_{i}(\mathbf{x}) d \mathbf{x}
$$

* A função de onda multieletrônica escrita por um determinante de Slater é dada por:

$$
\psi_{H F}\left(\mathbf{x}_{1}, \mathbf{x}_{2}, \ldots, \mathbf{x}_{N},\{R\}\right)=\frac{1}{\sqrt{N !}}\left|\begin{array}{cccc}
\phi_{1}\left(\mathbf{x}_{1}\right) & \phi_{2}\left(\mathbf{x}_{1}\right) & \ldots & \phi_{N}\left(\mathbf{x}_{1}\right) \\
\phi_{1}\left(\mathbf{x}_{2}\right) & \phi_{2}\left(\mathbf{x}_{2}\right) & \ldots & \phi_{N}\left(\mathbf{x}_{2}\right) \\
\vdots & \vdots & \ddots & \vdots \\
\phi_{1}\left(\mathbf{x}_{N}\right) & \phi_{2}\left(\mathbf{x}_{N}\right) & \ldots & \phi_{N}\left(\mathbf{x}_{N}\right)
\end{array}\right|
$$




$$
J_{i j}=\iint \psi_{i}^{*}\left(\mathbf{x}_{i}\right) \psi_{i}\left(\mathbf{x}_{i}\right) \frac{1}{\left|\mathbf{r}_{i}-\mathbf{r}_{j}\right|} \psi_{j}^{*}\left(\mathbf{x}_{j}\right) \psi_{j}\left(\mathbf{x}_{j}\right) d \mathbf{x}_{i} d \mathbf{x}_{j}
$$

e, por fim,

$$
K_{i j}=\iint \psi_{i}^{*}\left(\mathbf{x}_{i}\right) \psi_{j}\left(\mathbf{x}_{i}\right) \frac{1}{\left|\mathbf{r}_{i}-\mathbf{r}_{j}\right|} \psi_{j}^{*}\left(\mathbf{x}_{j}\right) \psi_{i}\left(\mathbf{x}_{j}\right) d \mathbf{x}_{i} d \mathbf{x}_{j}
$$

A equação (2.16) envolve a energia cinética e a energia de interação entre núcleos e elétrons; a equação (2.17) mostra a energia de repulsão clássica entre os elétrons, e a equação (2.18) é proveniente do caráter antissimétrico da função de onda, que define a estabilização do sistema na troca de spin de um elétron, ao se considerar o par, a fim de diminuir a repulsão entre eles.

É interessante notar que o termo de energia proveniente de auto-interação é nulo, uma vez que o termo de Coulomb é cancelado pelo termo de troca. No entanto, a energia de interação proveniente ao movimento correlacionado dos elétrons não é descrito pelo método Hartree-Fock e, desse modo, são necessárias aproximações que incluam esses efeitos, por exemplo, métodos perturbativos. Porém, a maioria dos métodos pós Hartree-Fock, como são chamados, possuem um alto custo computacional e, por isso, são aplicáveis a sistemas com um número reduzido de partículas. (38)

\subsection{Teoria do funcional da densidade}

Diferentemente dos métodos que utilizam a função de onda como variável, a Teoria do Funcional da Densidade (do inglês Density Functional Theory - DFT) faz uso, como o próprio nome diz, da densidade eletrônica do sistema, o qual possui seu significado físico atrelado diretamente à grandeza mensurável. A ideia de se utilizar a densidade surgiu na década de 1920, baseada no sistema de gás de elétrons desenvolvido por Fermi-Dirac, quando Thomas e Fermi, independentemente, propuseram que a energia desse sistema poderia ser calculada utilizando-se funcionais da densidade. (39) Para esse modelo, eles escreveram a energia cinética e os potenciais de interação externo e de Hartree em termos da densidade eletrônica, respectivamente,

$$
E_{T F}[\rho]=\frac{3}{10}\left(3 \pi^{2}\right)^{\frac{2}{3}} \int \rho(\mathbf{r})^{\frac{5}{3}} d \mathbf{r}-Z_{\alpha} \int \frac{\rho(\mathbf{r})}{\left|\mathbf{r}_{1}-\mathbf{R}_{\alpha}\right|} d \mathbf{r}+\frac{1}{2} \iint \frac{\rho\left(\mathbf{r}_{1}\right) \rho\left(\mathbf{r}_{2}\right)}{\left|\mathbf{r}_{1}-\mathbf{r}_{2}\right|} d \mathbf{r}_{1} d \mathbf{r}_{2} .
$$

Observa-se na equação (2.19) que as interações não-clássicas entre os elétrons (troca e correlação) são desconsideradas, de forma que a descrição da energia cinética, dada somente pelos graus de liberdade, possui uma aproximação grotesca, fonte de maior erro do cálculo energético. (39) Assim, a proposta de Thomas-Fermi é vista, atualmente, como um modelo simplificado de importância histórica por ser a primeira vez que 3 variáveis são utilizadas (necessárias para se obter a densidade) ao invés de $3 N$, como é escrita a função 
de onda multieletrônica. Assim, a DFT como é conhecida hoje teve ínicio em 1964, através dos teoremas de Hohenberg-Kohn, (40) mas alcançou uma aplicação prática a partir do método proposto por Kohn e Sham, em 1965. (41) A seguir, serão detalhadas ambas as propostas.

\subsubsection{Teoremas de Hohenberg e Kohn}

Hohenberg e Kohn propuseram em seu artigo, Inhomogeneous Electron Gas, um ponto de vista na obtenção das propriedades para um sistema de gás de elétrons interagentes ilustrado através de dois teoremas. O primeiro afirma que:

Teorema 2.4.1. O potencial externo $V_{\text {ext }}$ é determinado, com a adição de uma constante trivial, através da densidade eletrônica $\rho(\mathbf{r})$ de forma única. O mesmo ocorre para a energia do estado fundamental, que também é funcional único de $\rho(\mathbf{r})$.

Esse teorema é demonstrado no apêndice (A.1), onde se pode observar que dois funcionais que difiram em mais de uma constante não podem levar à mesma densidade eletrônica, de forma que a diferença entre os sistemas é dada pelo potencial externo, funcional unívoco de $\rho(\mathbf{r})$, a que cada um está submetido. E, uma vez que se obtém uma dada densidade, com uma respectiva energia, o ponto de impasse fica sendo o de se encontrar a energia do estado fundamental. Para isso, então, Hohenberg e Kohn mostraram, no segundo teorema, que:

Teorema 2.4.2. Através do cálculo variacional pode-se obter a energia do estado fundamental do sistema, partindo de uma densidade qualquer $\tilde{\rho}(\mathbf{r})$, que ao ser minimizada pode chegar à densidade correta, $\rho(\mathbf{r})$.

O apêndice (A.2) contém a demonstração desse segundo teorema, que mostra, além da formação do funcional universal $F_{H K}[\rho(\mathbf{r})]$, que a energia do estado fundamental pode ser obtida através do princípio variacional. A energia total do sistema é, então, dada por

$$
E[\rho(\mathbf{r})]=T[\rho(\mathbf{r})]+U[\rho(\mathbf{r})]+V_{e x t}(\mathbf{r})=F_{H K}[\rho(\mathbf{r})]+V_{e x t}(\mathbf{r}),
$$

onde são escritas, respectivamente, a energia cinética e o potencial de interação eletrônica, que independem do sistema analisado e, por isso, compõem o funcional universal, e o potencial externo.

No entanto, a proposta de Hohenberg-Kohn não especifica qual a relação que será utilizada para se obter a densidade eletrônica a partir da função de onda que descreve o sistema, tanto menos a forma que o funcional universal possui. Assim, apesar de incluir todos os termos necessários para a descrição plena de um sistema contendo mais de um elétron, o método não consegue ser posto em prática. 


\subsubsection{O método de Kohn-Sham}

Com o objetivo de escrever a energia de um sistema real, como ocorre em átomos, molécula e, especificamente, em clusters, através de um paralelo de ideias utilizadas para descrever um sistema de gás de elétrons homogêneo, Kohn e Sham propuseram, então, uma nova forma de se escrever a energia total, dada por

$$
E_{t o t}[\rho(\mathbf{r})]=T_{0}[\rho(\mathbf{r})]+V_{H}(\mathbf{r})+\int \hat{V}_{e x t}(\mathbf{r}) \rho(\mathbf{r}) d \mathbf{r}+E_{x c}[\rho(\mathbf{r})]
$$

onde $T_{0}[\rho]$ é a energia cinética para o sistema de gás de elétrons, em que as partículas são consideradas não-interagentes, mas estão sujeitas à densidade $\rho(\mathbf{r})$ idêntica a de um sistema interagente; $V_{H}$ é o potencial de Hartree, que descreve apenas as interações clássicas entre os elétrons; a integral se relaciona ao potencial externo, dado através da atração elétronnúcleo e, por fim, a energia de troca-correlação (exchange-correlation - xc).

Ao se comparar a equações (2.20) e (2.21), observa-se que o funcional universal proposto por HK equivale a

$$
F_{H K}[\rho(\mathbf{r})]=T_{0}[\rho(\mathbf{r})]+V_{H}(\mathbf{r})+E_{x c}[\rho(\mathbf{r})],
$$

onde se nota uma definição formal para a o funcional de troca e correlação, que exibe os termos de troca e correlação eletrônica, além de corrigir a energia cinética do sistema de gás de elétrons não-interagentes para o sistema de elétrons interagentes e é, também, responsável pelo cancelamento da auto-interação proveniente do potencial de Hartree.

Assim, ao se utilizar a função de onda para um sistema de $N$ elétrons através de um determinante de Slater, são obtidas as funções monoeletrônicas $\phi_{i}^{K S}$, conhecidas como orbitais de Kohn-Sham, que também obedecem ao quesito de ortonormalidade, ou seja, $\int \phi_{i}^{K S^{*}} \phi_{j}^{K S} d \mathbf{r}=\delta_{i j}$. Através dos orbitais de KS, e considerando que o estado fundamental do sistema é não-degenerado, a densidade eletrônica é, então, dada por

$$
\rho(\mathbf{r})=\sum_{i=1}^{N}\left|\phi_{i}^{K S}(\mathbf{r})\right|^{2},
$$

de forma que a energia total em termos da densidade será

$$
\begin{aligned}
E_{t o t}[\rho(\mathbf{r})]=\sum_{i=1}^{N} \int \phi_{i}^{* K S}\left(\frac{1}{2} \nabla_{\mathbf{r}_{\mathbf{i}}}^{2}\right) \phi_{i}^{K S} d \mathbf{r} & -\frac{1}{2} \iint \frac{\rho\left(\mathbf{r}^{\prime}\right) \rho(\mathbf{r})}{\left|\mathbf{r}^{\prime}-\mathbf{r}\right|} d \mathbf{r}^{\prime} d \mathbf{r} \\
& -\sum_{\alpha=1}^{M} Z_{\alpha} \int \frac{\rho(\mathbf{r})}{\left|\mathbf{r}-\mathbf{R}_{\alpha}\right|} d \mathbf{r}+E_{x c}[\rho] .
\end{aligned}
$$

É interessante notar que a equação (2.24) mostra claramente a auto-interação no termo de Hartree, e que a energia cinética depende apenas de forma indireta da densidade eletrônica, uma vez que é calculada a partir dos orbitais de KS, os quais compõem a densidade. 
Assim, ao se considerar o segundo teorema de HK, minimiza-se a energia total do sistema através do princípio variacional, tomando como vínculo a ortonormalidade, correspondente à conservação do número de elétrons do sistema. Portanto, obtém-se (através do mesmo procedimento utilizado no apêndice (A.2)) que

$$
\mu=\frac{\delta E_{t o t}[\rho(\mathbf{r})]}{\delta \rho(\mathbf{r})}=\frac{\delta T_{0}[\rho(\mathbf{r})]}{\delta \rho(\mathbf{r})}+\hat{V}_{H}(\mathbf{r})+\hat{V}_{e x t}(\mathbf{r})+\frac{\delta E_{x c}[\rho(\mathbf{r})]}{\delta \rho(\mathbf{r})}
$$

em que o último termo é chamado de potencial de troca e correlação, $V_{x c}$. Assim, pode-se interpretar através da equação anterior que o movimento um elétron $i$ é dado sobre um potencial efetivo formado por suas interações com $N-1$ elétrons e $M$ núcleos, em que o potencial efetivo é definido como $\hat{V}_{\text {eff }}(\mathbf{r})=\hat{V}_{H}(\mathbf{r})+\hat{V}_{e x t}(\mathbf{r})+\hat{V}_{x c}(\mathbf{r})$. Logo, ao se analisar a forma das equações que proporcionam a solução do problema descrito por Hartree, é notada a similaridade para o caso de KS, que para um sistema de gás de elétrons interagentes, a solução da equação de Schrödinger será

$$
\left[-\frac{1}{2} \nabla^{2}+\hat{V}_{e f f}\right] \phi_{i}^{K S}=\varepsilon_{i} \phi_{i}^{K S}
$$

A equação anterior é a chamada equação de Kohn-Sham, que pode ser escrita em termos matriciais, vistas posteriormente.

Sendo o potencial efetivo determinado a partir da densidade eletrônica, que por sua vez é calculado a partir de $\phi_{i}^{K S}$ ao se resolver a equação (2.26), nota-se que uma solução autoconsistente é necessária. Assim, a partir de uma densidade eletrônica qualquer, calcula-se seu referente potencial efetivo, o qual é, por sua vez, utilizado na solução da equação de KS. Através dos orbitais de KS, calcula-se a nova densidade eletrônica, que é comparada à inicial. Caso as densidades inicial e final sejam similares de acordo com os parâmetros que se pretende obter, diz-se que o cálculo convergiu e são obtidos os observáveis físicos; caso contrário, essa nova densidade será utilizada para iniciar novamente o cálculo.

Dreizler e Gross, (42) no entanto, mostram que, na prática, a energia total será dada em função dos autovalores obtidos nas soluções da equação de KS, escrita como

$$
E_{t o t}[\rho(\mathbf{r})]=\sum_{i=1}^{N} \varepsilon_{i}-\frac{1}{2} \iint \frac{\rho\left(\mathbf{r}^{\prime}\right) \rho(\mathbf{r})}{\left|\mathbf{r}^{\prime}-\mathbf{r}\right|} d \mathbf{r}^{\prime} d \mathbf{r}-\int \hat{V}_{x c}(\mathbf{r}) \rho(\mathbf{r}) d \mathbf{r}+E_{x c}
$$

\subsubsection{Funcionais de troca e correlação}

No método de Kohn-Sham os termos escritos como funcionais da densidade são exatos, com exceção do funcional de troca e correlação. Assim, como não há uma definição analítica que possa ser utilizada para expressar tal funcional, é necessário que sejam feitas aproximações para adequá-lo à descrição dos sistemas atômicos e moleculares.

Dentre as propostas que podem ser encontradas para esses funcionais, é possível separá- 
las entre semi-empíricas, que parametrizam dados experimentais, e não-empíricas. Os funcionais semi-empíricos se utilizam de resultados obtidos experimentalmente interpolados à cálculos de primeiros princípios. Por outro lado, cálculos ab initio, do latim "desde o começo", são feitos a partir de princípios físicos fundamentais, onde os potenciais nãoempíricos são utilizados, fazendo com que o problema de troca e correlação seja resolvido a partir do entendimento da física que o descreve. $(42,43)$

Como neste projeto são utilizados cálculos ab initio, foi necessário desenvolver uma compreensão sobre os funcionais não-empíricos existentes e suas formas de aplicação. Especificamente, serão tratados os funcionais com aproximação de densidade local (LDA) e com aproximação do gradiente generalizado (GGA), comumente utilizados. Além desses, ainda existem os funcionais hídridos, que misturam fórmulas exatas para o termo de troca e fórmulas aproximadas para o termo de correlação, com diferentes parametrizações para ambos os funcionais, no entanto, uma descrição mais apurada desse tipo de funcional foge do escopo desse trabalho.

\section{Aproximação da densidade local}

A primeira aproximação foi proposta por KS em 1965, a partir das ideias de Thomas e Fermi, em que um funcional de troca e correlação foi escrito em termos da densidade. A proposta para um funcional que descrevesse a energia de um gás de elétrons uniforme foi inicialmente escrita como

$$
E_{x c}^{L D A}[\rho(\mathbf{r})]=\int \rho(\mathbf{r}) \varepsilon_{x c}[\rho(\mathbf{r})] d \mathbf{r}
$$

em que $\varepsilon_{x c}[\rho(\mathbf{r})]$ é a energia de troca e correlação por partícula, que ao ser multiplicada por $\rho(\mathbf{r})$ garante que haja uma partícula na posição r. Assim, pode-se aproximar um sistema de elétrons com densidade não uniforme como sendo constituído por espaços infinitesimais onde a densidade é localmente uniforme, ou seja, a energia proveniente dos termos de troca e correlação é obtida através da integral sobre o sistema. Como o termo de troca é proveniente da antissimetria da função de onda que descreve os elétrons, pôde-se separar de forma conveniente $E_{x c}$ entre os termos de troca e de correlação:

$$
E_{x c}[\rho(\mathbf{r})]=E_{x}[\rho(\mathbf{r})]+E_{c}[\rho(\mathbf{r})] .
$$

Assim, o termo de troca para o gás de elétrons é dado pelo método HF, ou seja,

$$
E_{x}[\rho(\mathbf{r})]=-\frac{3}{4}\left(\frac{3 \rho(\mathbf{r})}{\pi}\right)^{\frac{1}{3}} .
$$

Já o termo de correlação, por não possuir uma fórmula analítica, foi foco de investigação de pesquisadores que propuseram diversas aproximações, por exemplo, através de 
cálculos refinados de Monte Carlo quântico e esquemas de interpolação. (44, 45) Em geral, a aproximação da densidade local apresenta valores médios consideravelmente bons, uma vez que a energia de troca é subestimada ao passo que a energia de correlação é superestimada, cancelando os erros. No entanto, para descrição de elétrons deslocalizados a LDA falha, uma vez que apresenta energias atômicas subestimadas, resultando em energias de coesão superestimadas. (46)

\section{Aproximação do gradiente generalizado}

A fim de melhorar a descrição de sistemas com densidade eletrônica não homogênea, considera-se, também, o gradiente da densidade. (47) Entretanto, é necessário ressaltar que se a energia de troca e correlação fosse vista como uma expansão em série, em que a LDA se relaciona ao primeiro termo, os erros cometidos na descrição dos sistemas seriam demasiadamente grandes, uma vez que a regra de soma não seria respeitada.

Assim, a aproximação do gradiente generalizado, GGA, (48) é estabelecida através da densidade eletrônica e seu gradiente, em que a regra de soma é satisfeita. A energia de troca e correlação é dada, então, por

$$
E_{x c}^{G G A}[\rho(\mathbf{r})]=\int f(\rho(\mathbf{r}),|\nabla \rho(\mathbf{r})|) d \mathbf{r}=\int \rho(\mathbf{r}) \varepsilon_{x c}[\rho(\mathbf{r}),|\nabla \rho(\mathbf{r})|] d \mathbf{r}
$$

Dentre as diversas propostas GGA, este trabalho faz uso do funcional elaborado por Perdew, Burke e Ernzerhof, denominado GGA-PBE, (49) que seria uma simplificação do funcional PW91, uma vez que se utiliza somente de parâmetros energeticamente representativos. Esse funcional pode ser escrito como a soma dada em (2.29), onde o termo de troca é dado por

$$
E_{x}[\rho(\mathbf{r})]=\int \rho(\mathbf{r}) \varepsilon_{x}^{L D A}(\rho(\mathbf{r})) F_{x}^{P B E}(s) d \mathbf{r},
$$

em que $\varepsilon_{x}^{L D A}(\rho(\mathbf{r}))$ equivale à energia de troca por partícula, apresentada no funcional LDA, que multiplicada pelo fator de intensificação $\left(F_{x}(s)\right)$ mostra a contribuição da energia de troca de acordo com a posição em um sistema não uniforme. O fator de intensificação é dado por

$$
F_{x}(s)=1+k-\frac{k}{1+\frac{\mu s^{2}}{k}} \quad \operatorname{com} \quad s(\mathbf{r})=\frac{|\nabla \rho(\mathbf{r})|}{2 k_{F} \rho(\mathbf{r})},
$$

em que a parametrização é dada por $\mu=\frac{\beta \pi^{2}}{3}, \beta=0,066725$ e $k=0,804$, sendo $s$ o gradiente de densidade reduzida, que mensura a variação de densidade através do vetor de onda de Fermi, $k_{F}(\mathbf{r})=\left(3 \pi^{2} \rho(\mathbf{r})\right)^{\frac{1}{3}}$. Pode-se notar que no limite em que o gradiente tende a zero, para um sistema de gás de elétrons uniforme, $F_{x}=1$. Por outro lado, o funcional de correlação na proposta PBE é dado por

$$
E_{c}^{P B E}[\rho(\mathbf{r})]=\int \rho(\mathbf{r})\left[\varepsilon_{c}\left(r_{s}, \zeta\right)+H_{c}^{P B E}\left(r_{s}, \zeta, t\right)\right] d \mathbf{r}
$$


em que $\varepsilon_{c}\left(r_{s}, \zeta\right)$ é a energia de correlação por partícula e $H_{c}^{P B E}\left(r_{s}, \zeta, t\right)$ descreve a contribuição que o gradiente da densidade possui no termo de correlação, em que os parâmetros utilizados são o raio de Seitz, $r_{s}$; a polarização de spin relativa, $\zeta=\frac{\rho_{\uparrow} \rho_{\downarrow}}{\rho_{\uparrow}+\rho_{\downarrow}}$; e o gradiente da densidade (adimensional), $t=\frac{\nabla \rho}{2 \phi k_{s} \rho}$, onde $\phi(\zeta)=\left[(1+\zeta)^{2 / 3}+(1-\zeta)^{2 / 3}\right] / 2$ é o fator de escala de spin. A fim de representar o gradiente da densidade também nos limites de alta e baixa variação, definiu-se que

$$
H_{c}^{P B E}\left(r_{s}, \zeta, t\right)=\frac{e^{2} \gamma \phi^{3}}{a_{0}} \ln \left\{1+\frac{\beta}{\gamma} t^{2}\left[\frac{1+A t^{2}}{1+A t^{2}+A^{2} t^{4}}\right]\right\}
$$

com

$$
A=\frac{\beta}{\gamma} \frac{1}{\exp \left\{\frac{-\varepsilon_{c}^{L D} D}{\left(\gamma \phi^{3} e^{2} / a_{0}\right)}\right\}-1},
$$

sendo $\gamma=\frac{1-\ln 2}{\pi^{2}}$.

Os autores mostram que o cálculo da energia de ligação para uma série envolvendo 20 moléculas, orgânicas e inorgânicas, possui uma descrição melhor através do funcional GGA se comparado ao LDA. Ademais, o funcional GGA-PBE possui resultados semelhantes ao seu antecessor PW91, porém com um custo computacional menor, uma vez que se utiliza apenas de parâmetros energéticos representativos para realização do cálculo. (49)

\subsubsection{Correção de van der Waals}

É sabido que as interações fracas provenientes das forças de London possuem um papel crucial na descrição do processo de adsorção de água e etanol sobre superfícies de metais de transição. $(22,30,50)$ Por isso, a fim de descrever precisamente os sistemas moleculares sobre clusters de metais de transição, $\mathrm{MT}_{13}$, foi utilizada a aproximação de TkatchenkoScheffler (TS) para correção de van der Waals (vdW) da energia total do sistema que foi previamente calculado através do funcional GGA-PBE. Dessa forma, a energia total do sistema $\left(E_{t o t}\right)$ é dada por

$$
E_{D F T+v d W}=E_{t o t}^{D F T}+E_{t o t}^{v d W}
$$

em que $E_{t o t}^{D F T}$ e $E_{t o t}^{v d W}$ se referem, respectivamente, à energia obtida pelos cálculos PBE e à correção da energia total ao se considerar as interações de van der Waals. A correção é proveniente da aproximação de TS, a qual inclui, basicamente, as interações induzidas dipolo-dipolo que ocorrem devido às flutuações quânticas na densidade eletrônica. A energia de vdW é, então

$$
E_{v d W}=-\frac{1}{2} \sum_{A, B} f_{d a m p}\left(R_{A B}, R_{A}^{0}, R_{B}^{0}\right) \frac{C_{6 A B}}{R_{A B}^{6}}
$$

onde $R_{A B}$ é a distância entre os átomos $A$ e $B, C_{6 A B}$ corresponde ao coeficiente de dispersão, e $R_{A}^{0}$ e $R_{B}^{0}$ são os raios de vdW. Sabe-se que as interações de dipolo variam de 
acordo com a distância entre os átomos, por isso, utiliza-se uma função de amortecimento, que varia entre $0-1$. A função de amortecimento elimina a singularidade da distância interatômica e corrige as propriedades dos funcionais de troca e correlação a curtas distâncias.

A precisão dos cálculos de vdW depende da determinação dos coeficientes de dispersão $\left(C_{6 A B}\right)$ que, na aproximação em questão, são calculados utilizando os coeficientes de dispersão para os átomos $A$ e $B$ livres $\left(C_{6 A A}\right.$ e $\left.C_{6 B B}\right)$ e, também, suas polarizabilidades $\left(\alpha_{0}^{A}\right.$ e $\left.\alpha_{0}^{B}\right)$

$$
C_{6 A B}=\frac{2 C_{6 A A} C_{6 B B}}{\left(\frac{\alpha_{0}^{B}}{\alpha_{0}^{A}} C_{6 A A}+\frac{\alpha_{0}^{A}}{\alpha_{0}^{B}} C_{6 B B}\right)} .
$$

Os coeficientes para os átomos livres são dados por

$$
C_{6 A A}=\left(\frac{V_{\text {eff }}^{A}}{V_{\text {free }}^{A}}\right)^{2}\left(C_{6 A A}\right)^{\text {free }},
$$

em que, na equação anterior, a razão entre o volume efetivo $\left(V_{\text {eff }}^{A}\right)$ e o volume do átomo $A$ livre $\left(V_{\text {free }}^{A}\right)$ são obtidos do particionamento de Hirshfeld das densidades eletrônicas calculadas para os átomos em interação e livres. Para considerar as interações com o campo elétrico dinâmico, TS empregaram uma aproximação de blindagem auto-consistente $(\mathrm{TS}+\mathrm{SCS})$, em que a polarizabilidade blindada $\left(\alpha_{\mathrm{A}}^{\mathrm{SCS}}(i \omega)\right)$ depende da frequência e é obtida via solução da equação de blindagem auto-consistente. Para maiores detalhes pode-se consultar a referência original. (51) A aproximação de Tkatchenko-Scheffler é um método semi-empírico implementado no código FHI-aims, visto a seguir.

\subsection{Implementação computacional}

A teoria do funcional da densidade é, ao mesmo tempo, muito robusta, pois apresenta resultados condizentes com dados experimentais e cálculos mais precisos dos que utilizam funções de onda para um grande número de propriedades, como energia total e comprimento de ligação. E, de certo modo, a DFT é simples, porque pode resolver problemas contendo centenas de elétrons a partir da sua densidade, que depende de apenas três variáveis. Em todo caso, o foco principal é tornar possível a solução da equação de KS que, como visto anteriormente, necessita ser resolvida auto-consistentemente. Desse modo, é necessário que um conjunto de funções sejam usadas como base para expansão dos orbitais de KS, ou seja,

$$
\phi_{i}^{K S}=\sum_{j} c_{i j} \varphi_{j}
$$

A partir dessa expansão, a energia do estado fundamental será dada através da mini- 
mização dos coeficientes, de modo que

$$
\frac{\delta E_{t o t}[\rho(\mathbf{r})]}{\delta c_{i j}}=0
$$

onde é possível observar que ao se reescrever a equação de KS através da expansão, se obtém um conjunto de funções matriciais que são, de fato, implementadas.

Dessa forma, a questão se resume ao tipo de função base utilizada para encontrar um equilíbrio entre a descrição do sistema e o custo computacional, sendo que quanto maior o número de funções utilizadas, melhor será a descrição, porém, maior também será o custo computacional. Como os sistemas desse trabalho contêm dezenas de átomos (centenas de elétrons), foi possível o uso de um conjunto de funções base que envolvesse todos os elétrons, no caso, os orbitais numéricos centrados nos átomos (NAOs), implementados no código Fritz Haber Institute "ab initio molecular simulations" (FHI-aims).

Os orbitais numéricos centrados nos átomos, do inglês numeric atom-centered orbitals, NAOs, constituem um conjunto de funções base definidos como: (52)

$$
\varphi_{j}(\mathbf{r})=\frac{u_{j}(r)}{r} Y_{l m}(\Omega)
$$

onde $Y_{l m}(\Omega)$ descreve os harmônicos esféricos, e a função radial $u_{j}(\mathbf{r})$ é numericamente tabulada, em que os valores podem ser obtidos a partir da solução da equação de Schrödinger para a parte radial, ou seja,

$$
\left[-\frac{1}{2} \frac{d^{2}}{d r^{2}}+\frac{l(l+1)}{r^{2}}+v_{j}(r)+v_{c u t}(r)\right] u_{j}(r)=\epsilon_{j} u_{j}(r) .
$$

Nota-se que na equação (2.44) a função radial é definida através de um potencial $v_{j}(r)$, que descreve o formato de $u_{j}(r)$, e por um potencial de corte (ou de confinamento) $v_{c u t}(r)$, o qual garante que a função radial decaia a zero de modo suave para fora do raio de corte $r_{c u t}$. As NAOs são construídas hierarquicamente a partir de um conjunto mínimo de funções para cada átomo, sendo que essa base mínima pode ser expandida através de funções auxiliares que melhoram a precisão do cálculo, na ordem de meV. A forma do potencial de corte é dada por

$$
v_{c u t}(r)=\left\{\begin{array}{lr}
0, & r \leq r_{\text {onset }}, \\
s \times \exp \left(\frac{w}{r-r_{\text {onset }}}\right) \times \frac{1}{\left(r-r_{c u t}\right)^{2}}, & r_{\text {onset }}<r<r_{\text {cut }}, \\
\infty, & r \geq r_{\text {cut }} .
\end{array}\right.
$$

onde o potencial de corte começa em $r_{\text {onset }}$ de forma suave, e cresce gradualmente para infinito em $r_{c u t}$, sendo que a região de atuação do potencial de corte é definida por $w=$ $r_{\text {cut }}-r_{\text {onset }}$; e, $s$ é um parâmetro energético de escala global. Ambos os parâmetros são 
pré-definidos como $s=200$ Ha e $w=2.0 \AA$. (52)

O conjunto de funções NAOs é, então, implementado no código FHI-aims, (52) utilizado nessa dissertação. O FHI-aims possui dois arquivos de entrada: o control.in, que contém todas as diretrizes a serem seguidas durante o cálculo, como o funcional de troca e correlação (neste caso, GGA-PBE), parâmetros de convergência e as funções base que serão utilizadas no cálculo; e, o geometry.in que contém as coordenadas cartesianas para todos os átomos do sistema ao se lidar com moléculas e clusters.

Dentre os conjuntos de base disponíveis, foram testados os light tier1 - LT1, light tier2 - LT2, light tier3 (somente para as moléculas), tight tier1 - TT1 e tight tier2 - TT2, a fim de se selecionar aquele para realizar os cálculos de adsorção (apêndice B). As bases LT1 e TT1 são os primeiros conjuntos construídos após o conjunto mínimo; logo em seguida estão LT2 e TT2, respectivamente. A diferença entre as bases ocorre no raio de corte, que para a base light é de $5.0 \AA$, equanto para a base tight é de $6.0 \AA$.

Os cálculos foram realizados da seguinte forma: $(i)$ dadas as estruturas iniciais, a otimização foi realizada com a base LT1; (ii) as configurações finais obtidas através de LT1 foram utilizas como estruturas iniciais para a otimização com LT2; (iii) em seguida, utilizou-se o conjunto TT1 e, por fim, TT2. Dessa forma, com todas as configurações de clusters e moléculas calculados através dos diferentes conjuntos de base, foi possível determinar, além da estrutura mais estável (lowest energy, LOW) de cada cluster, o conjunto de base mais adequado para os cálculos de adsorção, que são LT2 para os metais e LT3 para C, H, e O. Para todas as otimizações de geometria, o parâmetro de força sobre cada átomo foi menor que $0.010 \mathrm{eV} / \AA$ e, a convergência da energia total utilizou $10^{-6} \mathrm{eV}$ para a auto-consistência eletrônica. 


\section{Capítulo 3}

\section{Resultados: Sistemas isolados}

Neste capítulo são apresentados os principais resultados obtidos para as moléculas $\left(\mathrm{OH}, \mathrm{H}_{2} \mathrm{O}, \mathrm{CH}_{3} \mathrm{CH}_{2} \mathrm{OH}\right)$ e clusters $\left(\mathrm{Ni}_{13}, \mathrm{Cu}_{13}, \mathrm{Pd}_{13}, \mathrm{Ag}_{13}, \mathrm{Pt}_{13}, \mathrm{Au}_{13}\right)$ em fase gasosa. Apesar de serem sistemas largamente estudos, este trabalho é necessário para permitir a compreensão das alterações induzidas nas moléculas e clusters após o processo de adsorção, tema que é abordado no próximo capítulo. Foram realizados um grande número de testes de convergência em função do número de funções base para os sistemas isolados, que estão sumarizados no apêndice (B).

O capítulo está dividido em três partes: (3.1) moléculas; (3.2) clusters; e (3.3) sumário.

\subsection{Moléculas}

Existem diferenças fundamentais entre as moléculas em estudo, $\mathrm{OH}, \mathrm{H}_{2} \mathrm{O}, \mathrm{CH}_{3} \mathrm{CH}_{2} \mathrm{OH}$. Por exemplo, a hidroxila é uma molécula linear e possui um elétron desemparelhado, o que pode ser mostrado utilizando o simples modelo de Lewis, ou seja, é um radical. Em contraste à hidroxila, a molécula de água, a qual pode ser considerada uma das moléculas mais estudadas por métodos de química quântica, possui uma estrutura triangular (somente um isômero mais estável) com um ângulo $104.5^{\circ}$ entre as ligações $\mathrm{HOH}$, o que pode ser atribuído à existência dos lone-pairs localizados no átomo de oxigênio. A molécula de etanol é mais complexa devido ao número maior de átomos e pela existência de dois isômeros estáveis quase degenerados, conhecidos como sendo trans e gauche, os quais diferem pela rotação interna do grupo hidroxila em relação ao eixo carbono-oxigênio. (53) Ambos os isômeros são considerados neste capítulo. A seguir, há uma discussão sobre os principais resultados obtidos para os sistemas moleculares: comprimentos de ligação, ângulos entre ligações, energia de ligação, estados eletrônicos, densidades de carga, e frequências vibracionais. 
Figura 3.1 - Geometria molecular da hidroxila, água e as conformações trans- e gauche-etanol.
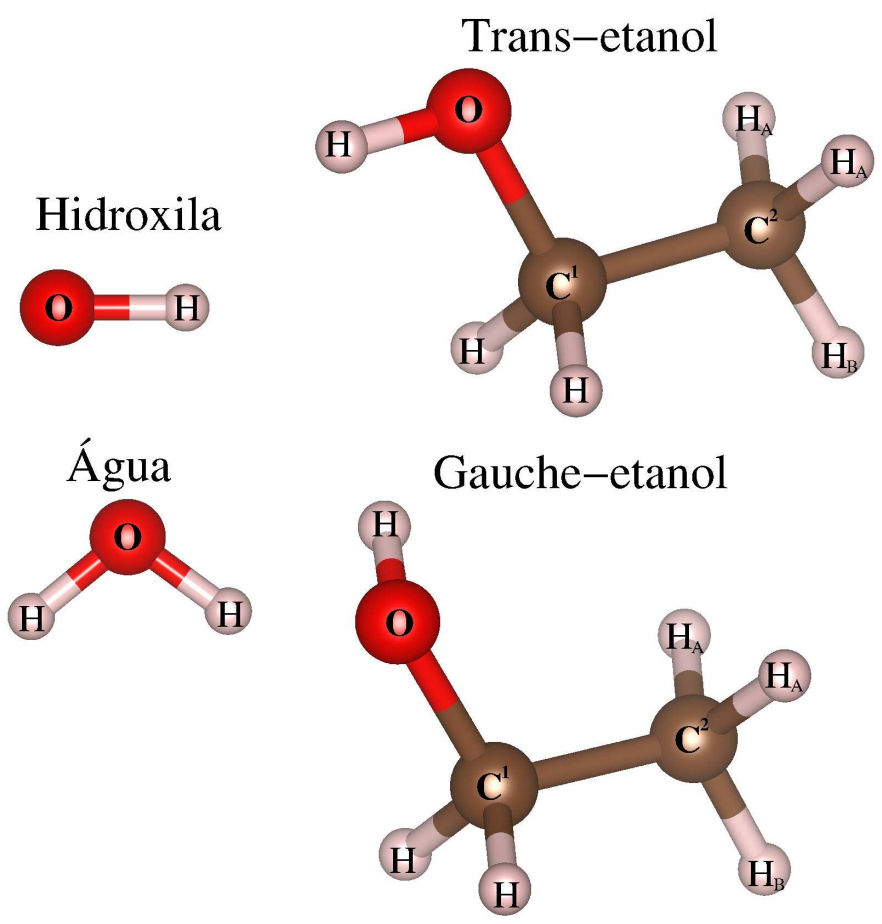

Fonte: Autoria própria.

\section{Parâmetros geométricos}

As estruturas moleculares nas configurações de mais baixa energia estão mostradas na figura (3.1), enquanto os comprimentos de ligação e ângulos entre as ligações estão sumarizados na tabela (3.1). Podemos notar que o comprimento de ligação O-H é $0.98 \AA$ na hidroxila, enquanto é reduzido para $0.97 \AA$ para as moléculas de água e etanol. Como esperado, foi obtido que a água é uma molécula triangular com um erro no ângulo de aproximadamente $-0.3 \%$ em comparação com valores experimentais. $(54,55)$ Como mencionado acima, a principal diferença entre o etanol trans e gauche é a geometria, especificamente o ângulo de torção, o qual sofre um dos maiores desvios em comparação com resultados experimentais. (54) Por exemplo, os erros para os ângulos CCO e HOCC são, respectivamente, $4.82 \%$ e $-4.76 \%$ para a configuração gauche, já os demais desvios nos comprimentos de ligação e ângulos estão entre $-0.74 \%$ e $2.75 \%$ em comparação com os valores experimentais. Assim, observa-se que os maiores desvios ocorrem para a estrutura básica do etanol gauche, ou seja, DFT-PBE possui dificiências para descrever a orientação relativa entre os grupos na mesma molécula.

\section{Energia de ligação}

Uma das quantidades mais importantes em sistemas moleculares é a energia de ligação entre os átomos, a qual pode ser utilizada para medir a estabilidade relativa das moléculas. 
A energia de ligação, $E_{b}$, é calculada através da seguinte equação,

$$
E_{b}=\sum_{i} E_{\text {tot }}^{i}-E_{\text {tot }}^{\text {Molécula }}
$$

onde $\sum_{i} E_{\text {tot }}^{i}$ é a soma da energia total de todos os átomos livres com suas respectivas

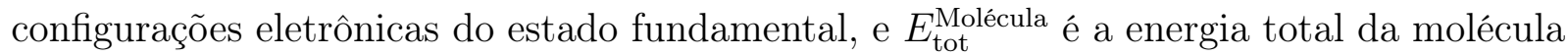
em fase gasosa.

Tabela 3.1 - Propriedades geométricas para $\mathrm{OH}, \mathrm{H}_{2} \mathrm{O}$, trans- e gauche-etanol obtidas através dos cálculos DFT-PBE e de dados experimentais.

\begin{tabular}{|c|c|c|c|c|c|c|}
\hline Molécula & Ligação & $d_{a v}(\AA)$ & $d_{a v}^{\exp }(\AA)$ & Ângulo & $\widehat{A B C}\left(^{\circ}\right)$ & $\widehat{A B C}^{\exp }\left({ }^{\circ}\right)$ \\
\hline Hidroxila & $\mathrm{O}-\mathrm{H}$ & 0.98 & 0.980 & - & - & - \\
\hline Água & $\mathrm{O}-\mathrm{H}$ & 0.97 & 0.972 & $\mathrm{HOH}$ & 104.2 & 104.5 \\
\hline \multirow[t]{8}{*}{ Trans-etanol } & $\mathrm{O}-\mathrm{H}$ & 0.97 & 0.971 & $\mathrm{CCO}$ & 108.0 & 107.8 \\
\hline & $\mathrm{C}^{1}-\mathrm{O}$ & 1.44 & 1.431 & $\mathrm{COH}$ & 108.3 & 105.4 \\
\hline & $\mathrm{C}^{1}-\mathrm{H}$ & 1.11 & 1.098 & $\mathrm{C}^{2} \mathrm{C}^{1} \mathrm{H}$ & 110.2 & 110.7 \\
\hline & $\mathrm{C}^{2}-\mathrm{H}_{\mathrm{A}}$ & 1.10 & 1.091 & $\mathrm{HC}^{1} \mathrm{H}$ & 107.7 & 108.0 \\
\hline & $\mathrm{C}^{2}-\mathrm{H}_{\mathrm{B}}$ & 1.10 & 1.088 & $\mathrm{C}^{1} \mathrm{C}^{2} \mathrm{H}_{\mathrm{A}}$ & 110.6 & 110.1 \\
\hline & $\mathrm{C}-\mathrm{C}$ & 1.52 & 1.512 & $\mathrm{C}^{1} \mathrm{C}^{2} \mathrm{H}_{\mathrm{B}}$ & 110.3 & 110.5 \\
\hline & & & & $\mathrm{H}_{\mathrm{A}} \mathrm{C}^{2} \mathrm{H}_{\mathrm{A}}$ & 108.3 & 108.4 \\
\hline & & & & $\mathrm{HOC}^{1} \mathrm{C}^{2}$ & 180.0 & 180.0 \\
\hline \multirow[t]{8}{*}{ Gauche-etanol } & $\mathrm{O}-\mathrm{H}$ & 0.97 & 0.971 & $\mathrm{CCO}$ & 113.0 & 107.8 \\
\hline & $\mathrm{C}^{1}-\mathrm{O}$ & 1.43 & 1.431 & $\mathrm{COH}$ & 107.8 & 105.4 \\
\hline & $\mathrm{C}^{1-\mathrm{H}}$ & 1.11 & 1.098 & $\mathrm{C}^{2} \mathrm{C}^{1} \mathrm{H}$ & 110.3 & 110.7 \\
\hline & $\mathrm{C}^{2}-\mathrm{H}_{\mathrm{A}}$ & 1.10 & 1.091 & $\mathrm{HC}^{1} \mathrm{H}$ & 107.2 & 108.0 \\
\hline & $\mathrm{C}^{2}-\mathrm{H}_{\mathrm{B}}$ & 1.10 & 1.088 & $\mathrm{C}^{1} \mathrm{C}^{2} \mathrm{H}_{\mathrm{A}}$ & 110.8 & 110.1 \\
\hline & $\mathrm{C}-\mathrm{C}$ & 1.52 & 1.512 & $\mathrm{C}^{1} \mathrm{C}^{2} \mathrm{H}_{\mathrm{B}}$ & 110.7 & 110.5 \\
\hline & & & & $\mathrm{H}_{\mathrm{A}} \mathrm{C}^{2} \mathrm{H}_{\mathrm{A}}$ & 108.2 & 108.4 \\
\hline & & & & $\mathrm{HOC}^{1} \mathrm{C}^{2}$ & 120 & 126 \\
\hline
\end{tabular}

A energia de ligação obtida para $\mathrm{OH}$ e $\mathrm{H}_{2} \mathrm{O}$ valem, respectivamente, $-4.77 \mathrm{eV}$ e $-10.16 \mathrm{eV}$, com desvios de $2.8 \%$ e $0.99 \%$, em comparação com valores experimentais. (56) Os resultados deste trabalho são idênticos aos dados publicados por Perdew, Burke e Ernzerhof. (49) Já para a molécula de etanol, pode-se considerar que as conformações são degeneradas, uma vez que a diferença de energia entre elas é de $0.13 \mathrm{meV} /$ átomo, em que a conformação gauche aparece como sendo a mais estável. Porém, experimentalmente a conformação trans-etanol possui menor energia (57) e, por isso, essa conformação foi utilizada nos cálculos de adsorção, dado que o desvio nas energias está dentro das margens de erro do cálculo DFT. 


\section{Propriedades eletrônicas}

Das propriedades eletrônicas, serão discutidos o momento de dipolo, o momento magnético e a formação dos orbitais moleculares. O momento de dipolo $(\mu)$ é uma grandeza vetorial que descreve a separação de cargas elétricas e nucleares, sendo sua magnitude dada em debye $\left(\mathrm{D}=1 \times 10^{-18}\right.$ e.cm). A simetria da molécula determina se há ou não momento de dipolo. De modo geral, para uma distribuição contínua de carga confinada em um determinado volume (V), o momento de dipolo é dado por

$$
\mu=\int_{V} \rho\left(\mathbf{r}_{0}\right)\left(\mathbf{r}_{0}-\mathbf{r}\right) d^{3} \mathbf{r}_{0}
$$

em que $\mathbf{r}$ localiza o ponto de observação. Para cargas pontuais, como é o caso das moléculas, a densidade de carga pode ser escrita através da soma de funções delta de Dirac, ou seja,

$$
\rho(\mathbf{r})=\sum_{i=1}^{N} q_{i} \delta\left(\mathbf{r}-\mathbf{r}_{i}\right)
$$

onde cada vetor $\mathbf{r}_{i}$ está relacionado com uma carga $q_{i}$. Assim, substituindo (3.3) em (3.2), se obtém que

$$
\mu=\sum_{i=1}^{N} q_{i} \int_{V} \delta\left(\mathbf{r}_{0}-\mathbf{r}_{i}\right)\left(\mathbf{r}_{0}-\mathbf{r}\right) d^{3} \mathbf{r}_{0}=\sum_{i=1}^{N} q_{i}\left(\mathbf{r}_{i}-\mathbf{r}\right) .
$$

Neste trabalho, ao se analisar o módulo do momento de dipolo elétrico de cada molécula, obtêm-se que o radical hidroxila, a água e os isômeros trans e gauche apresentam, respectivamente, $\mu=1.60,1.80,1.51$ e $1.64 \mathrm{D}$. Os dados calculados estão em pleno acordo com os dados da literatura, onde se observa um desvio máximo de $|4.9| \%$. (56)

Por outro lado, o momento magnético de um sistema está relacionado com o emparelhamento dos elétrons na estrutura como um todo e, é calculado por:

$$
m_{T}=N_{u p}-N_{\text {down }}
$$

em que $N_{u p}$ é o número de elétrons com spin up $(+1 / 2)$ e $N_{\text {down }}$ é o número de elétrons com spin down $(-1 / 2)$. A hidroxila é a única molécula escolhida que possui um momento magnético não-nulo, $m_{T}=1 \mu_{B}$, o que condiz com o simples modelo de Lewis. Já a água e o etanol são chamados de sistema de camada fechada por apresentarem todos os elétrons emparelhados e, assim, um momento magnético nulo.

Devido a uma limitação da presente versão da implementação do FHI-aims, somente é possível obter os orbtais moleculares para sistemas de camada fechada. Sendo assim, é possível classificar os estados eletrônicos das moléculas de água e etanol. É possível observar na parte inferior da figura (3.2) os orbitais $1 s$ do oxigênio (água), além dos orbitais $1 s$ para ambos os carbonos nas estruturas trans e gauche do etanol. Na parte 
Figura 3.2 - Estados eletrônicos para as moléculas de água e etanol. Na parte inferior são encontrados os orbitais atômicos de oxigênio e carbono e, na parte superior se encontram os orbitais moleculares.

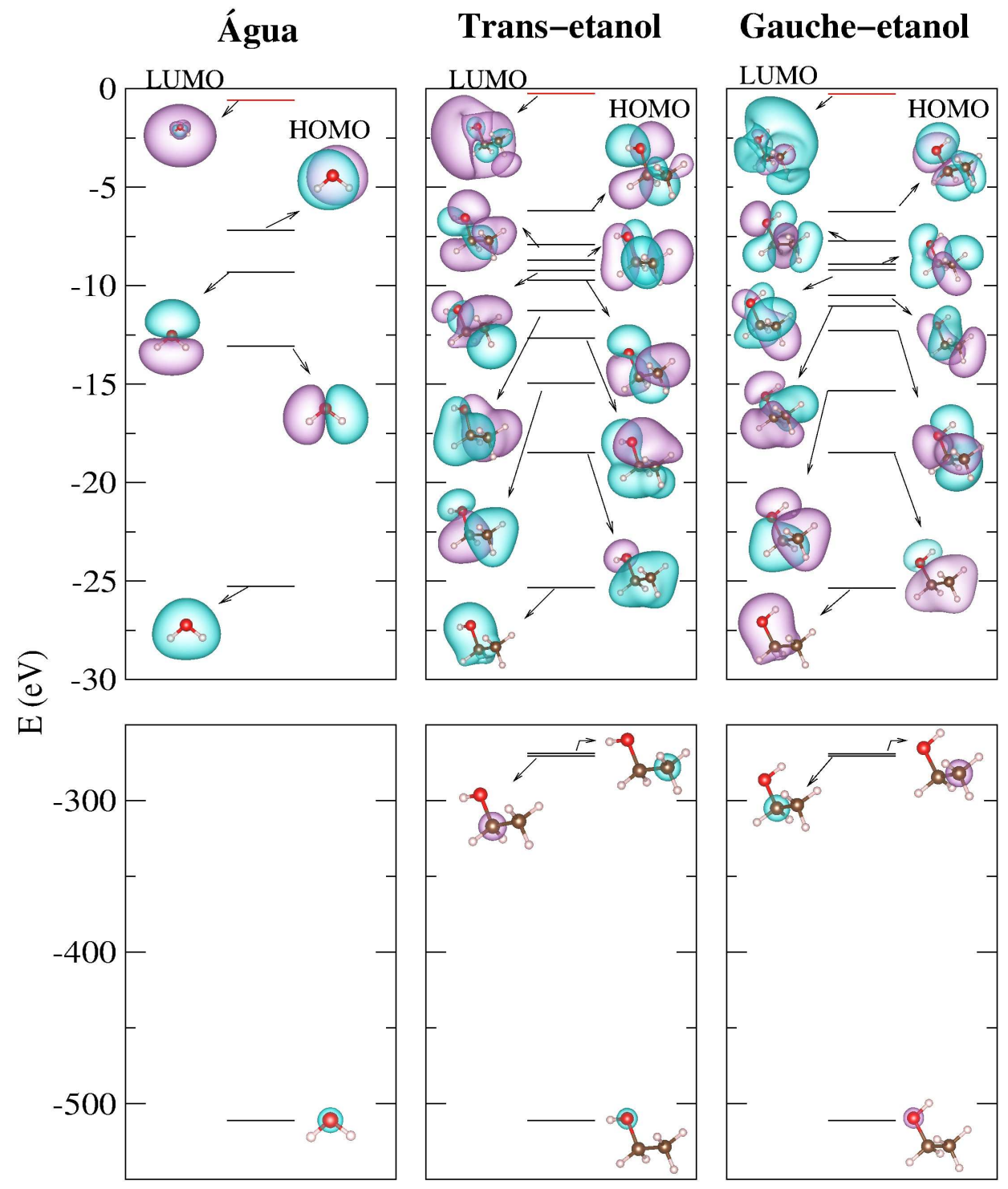

Fonte: Autoria própria.

superior da figura supracitada, observam-se os orbitais moleculares ligantes, não-ligantes e anti-ligantes. Para a molécula de água, seguindo a ordem crescente de energia, obsevam-se o orbital $2 s$ do oxgênio, dois orbitais ligantes, $\sigma$, o orbital $2 p_{z}$ não-ligante do oxigênio e, por fim, o primeiro orbital anti-ligante, $\sigma^{*}$. Sabendo que tanto o oxigênio como os átomos de carbono possuem hibridização $2 s p^{3}$ em ambos isômeros do etanol, têm-se na parte superior da figura (3.2), também de acordo com a ordem crescente de energia, os orbitais $\sigma_{\mathrm{C}-\mathrm{O}}, \sigma_{\mathrm{C}-\mathrm{C}}, \sigma_{\mathrm{O}-\mathrm{H}}$, seguidos de cinco $\sigma_{\mathrm{C}-\mathrm{H}}$, dois orbitais não-ligantes $2 s p^{3}$ do oxigênio e, por fim, o orbital anti-ligante $\sigma_{\mathrm{C}-\mathrm{O}}^{*}$. A partir da descrição anterior, é possível destacar que o orbital molecular ocupado de mais alta energia (highest occupied molecular orbital, HOMO) é não-ligante, enquanto o orbital molecular vazio de mais baixa energia (lowest unoccupied molecular orbital, LUMO) é anti-ligante tanto para a água, quanto para os 
isômeros do etanol. $(20,53)$ Esses orbitais são os que podem ser utilizados no processo de adsorção doando ou recebendo elétrons, em que utilizam, respectivamente, os orbitais HOMO e LUMO.

\section{Frequências vibracionais}

Por fim, foram calculados as frequências vibracionais para cada molécula. O código FHI-aims possui uma implementação que utiliza a diagonalização de matrizes Hessianas, contruídas a partir do método de aproximação de diferenças finitas, para calcular as frequências de vibração. Aplicam-se deslocamentos de $\pm 0.0010 \AA$ nas direções $x, y, z$ para cada átomo, para o cálculo da matriz de Hessian. A hidroxila, molécula diatômica, possui apenas um modo vibracional com frequência de $3737.76 \mathrm{~cm}^{-1},(56,58)$ proveniente do estiramento $\mathrm{O}-\mathrm{H}, \nu_{\mathrm{O}-\mathrm{H}}$. Ao se comparar os dados da literatura com os resultados obtidos, nota-se uma diminuição de $4 \%$ da frequência experimental. Já a água e o etanol são moléculas poliatômicas, não-lineares, que apresentam 3 e 21 modos vibracionais, respectivamente. A água pertence ao grupo de simetria $C_{2 v}$, para qual foram encontradas as frequências de vibração 3700, 3793 e $1595 \mathrm{~cm}^{-1}$, relacionadas aos modos de estiramento simétrico, estiramento assimétrico e torção, respectivamente. Ao se comparar os resultados calculados com dados da literatura, (56) notam-se desvios de $1.2 \%$ para estiramento simétrico, e $0.99 \%$ para o estiramento assimétrico. Não houve nenhum desvio na vibração de torção, o que pode sugerir que a sensibilidade que fez com que houvesse um desvio maior no cálculo dos ângulos dessa molécula, tenha proporcionado uma precisão maior no cálculo da vibração de torção.

Diferente da hidroxila e da água, o etanol é uma molécula orgânica e complexa, que possui 21 modos normais de vibração, dentre os quais destacam-se os estiramentos $\mathrm{O}-\mathrm{H}$, $\mathrm{C}-\mathrm{O}$ e $\mathrm{C}-\mathrm{H}$, que estão definidas nas chamadas regiões de impressão digital (fingerprint region), que especificam os grupos funcionais. A figura (3.3) mostra o espectro de absorção do etanol no infravermelho, em que as frequências de vibração foram obtidas através de cálculo DFT-PBE, que no FHI-aims é um cálculo de aproximação harmônica.

Observa-se que alguns modos vibracionais se destacam devido às suas intensidades, as quais são associadas às frequências de vibração em regiões de impressão digital. De acordo com Colthup, $(59,60)$ é possível identificar os principais grupos funcionais com regiões específicas de frequências, em que $\nu$ se refere às vibrações de estiramento e, $\delta$ às vibrações de torção. (61) Para a molécula de etanol, identificam-se os principais grupos funcionais sendo O-H ( $\nu$ entre 3590-3650 cm $\mathrm{cm}^{-1}$, com intensidade de absorção variável); C$\mathrm{H}\left(\nu\right.$ entre $2800-3000 \mathrm{~cm}^{-1}$, com forte intensidade, em que o estiramento assimétrico ocorre em uma frequência de vibração um pouco mais alta que o estiramento simétrico (62)); e C-O ( $\nu$ entre 1075-1000 $\mathrm{cm}^{-1}$, com alta intensidade). Assim, ao se comparar os dados calculados com as regiões experimentais, em que o espectro total é, normalmente, obtido entre 4000-400 $\mathrm{cm}^{-1}$, é possível constatar que ambos estão em pleno acordo. 
Figura 3.3 - Espectro das frequências vibracionais do trans-etanol obtido através de cálculos DFT-PBE.

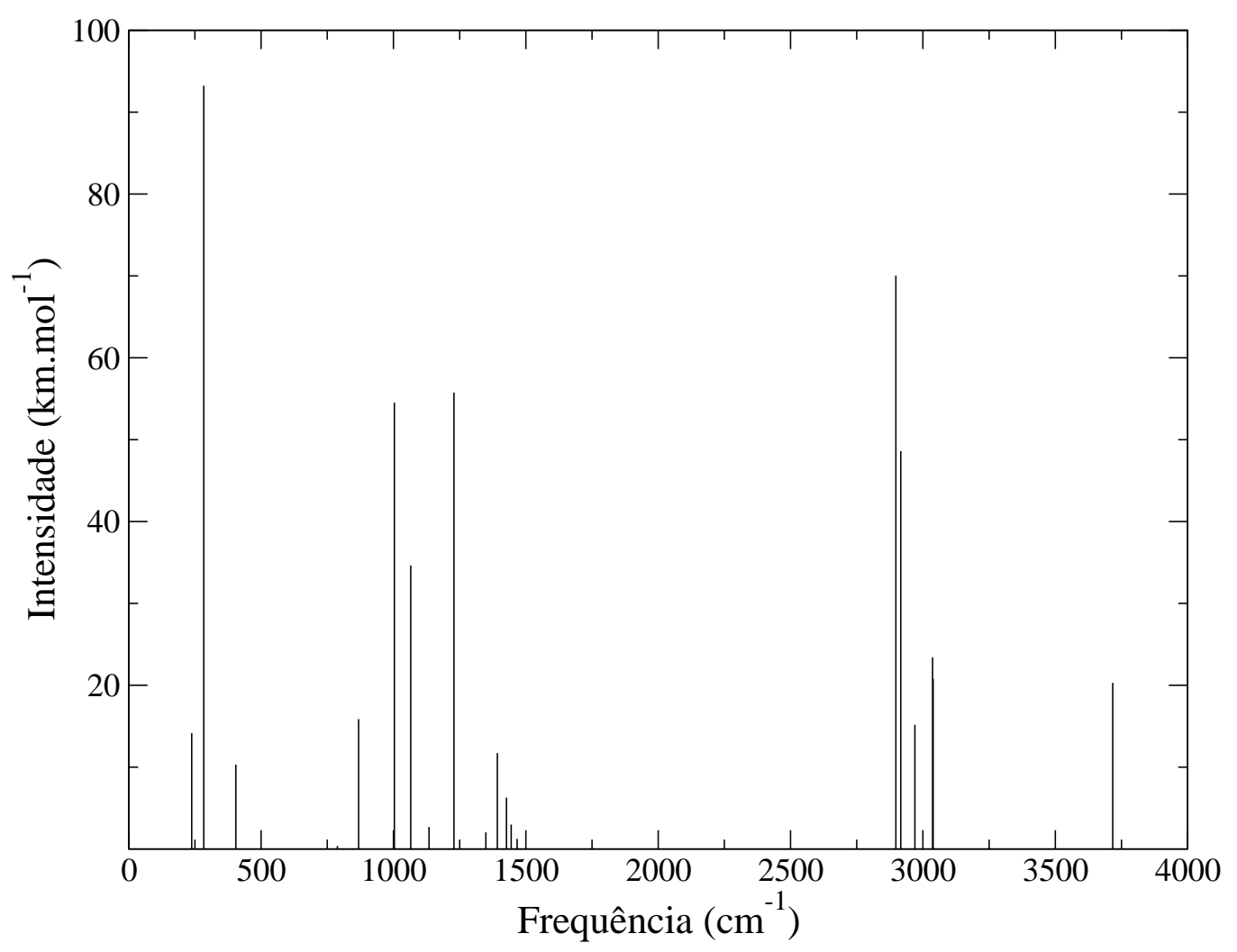

Fonte: Autoria própria.

\subsection{Clusters: $\mathrm{Ni}_{13}, \mathrm{Cu}_{13}, \mathrm{Pd}_{13}, \mathrm{Ag}_{13}, \mathrm{Pt}_{13}$ e $\mathrm{Au}_{13}$}

O estudo das estruturas de clusters contendo 13 átomos tem tido grandes esforços no que tange à busca das configurações de mínimo global, (63-68) o que corroborou diretamente no avanço do conhecimento da geometria e dos parâmetros energéticos que envolvem esses sistemas. As configurações utilizadas nesse trabalho foram obtidas através de um conjunto de estruturas iniciais conhecidas da literatura, (67) onde haviam desde arranjos completamente simétricos dos átomos, como ocorre nas formações icosaédrica e cuboctaédrica, bem como estruturas de baixa simetria.

O conjunto proveniente da literatura foi acrescido de estruturas geradas pelo algoritmo Basin-Hopping Monte Carlo revisado (RBHMC) (69), que é um algoritmo de otimização global que possui operadores locais e não-locais. Esses operadores atuam de forma a modificar a posição dos átomos dentro de uma região conhecida (esfera rígida) e, assim, providenciar novas configurações que abranjam toda superfície de energia potencial que descreve o sistema.

Para cada metal de transição, foram calculadas cerca de 60 configurações, iniciais a fim de se encontrar aquela de mais baixa energia. Dentre as configurações calculadas, destacam-se as que possuem alta simetria, icosaedro (ICO, com grupo espacial $I_{h}$ ), cuboctraedro (CUBO, $O_{h}$ ), bicamada hexagonal (hexagonal bilayer, HBL, $C_{3 v}$ ), biplanar 
(buckled-biplanar, BBP, $C_{3 v}$ ) e cubóide (double single cubic, DSC). Além disso, os testes para a seleção de função de base mostraram que a estrutura mais estável (LOW) não é equivalente para todos os elementos trabalhados, e por isso, também foi selecionada a estrutura icosaédrica, para que se pudesse observar as tendências no processo de adsorção.

As energia relativas foram calculadas em relação à estrutura mais estável, ou seja, de menor energia total $\left(E_{\text {tot }}^{\mathrm{LOW}}\right)$, de acordo com a seguinte equação:

$$
\Delta E_{t o t}=E_{t o t}^{i}-E_{t o t}^{\mathrm{LOW}},
$$

em que o termo $E_{\text {tot }}^{i}$ se refere à energia total do $i$-ésimo cluster. Assim, pode-se notar que, como as energias dos clusters são negativas, a energia relativa será positiva, uma vez que $E_{\text {tot }}^{\mathrm{LOW}}$ é maior em módulo.

Nota-se que as estruturas mais estáveis não possuem a mesma configuração para todos os elementos em um mesmo grupo. Assim sendo, como não se pode atribuir uma única tendência do processo de adsorção através de variações geométricas dos clusters, foram escolhidas as estruturas de menor energia e, também, as estruturas ICO para cada elemento. Especificamente para o ouro, é importante observar que nos cálculos DFT-PBE realizados nesse trabalho não foi considerado o efeito de acoplamento spin-órbita, no entanto, esse efeito se mostra importante para a determinação da estrutura $\mathrm{Au}_{13}$ mais estável. O ouro apresenta duas estruturas degeneradas, uma 2D e outra 3D, que irão se alternar na ordem de estabilidade, como apontam Piotrowski et al., (67) de forma que se optou pela seleção de ambas configurações para os cálculos de adsorção.

Para que se possa analisar as variações pós-adsorção, é necessário verificar as propriedades que caracterizam os clusters puros. As análises dos parâmetros geométricos, energéticos e eletrônicos dos clusters estão de acordo com a figura (3.6) e a tabela (3.2).

\section{Parâmetros geométricos}

Os parâmetros geométricos utilizados na análise dos clusters são baseados no conceito de número de coordenação efetiva (NCE). (70) Como os clusters de menor energia também possuem baixa simetria, o conceito de coordenação efetiva (CE) não é o mais adequado na sua descrição. Para se calcular a coordenação efetiva é definido um comprimento de ligação de corte $\left(d_{c u t}\right)$, de modo a se considerar todos os átomos $j$ a uma mesma distância do átomo $i$, ou seja, todos os comprimentos de ligação possuem o mesmo peso $\left(w_{i j}=1.0\right)$, o que é muito útil para sistemas simétricos. Contudo, para sistemas com baixa simetria é necessário se utilizar um parâmetro que varie os pesos dos comprimentos de ligação, tornando-os ponderados.

No caso do NCE são utilizados diferentes pesos para cada combinação $i j$, de forma que $w_{i j} \neq 1$.0. Esse conceito é baseado no fato de que átomos próximos se ligam mais fortemente, mas ainda há uma interação com átomos mais distantes que também é considerada. 
Figura 3.4 - Energia relativa (meV/átomo) para $\mathrm{Ni}_{13}, \mathrm{Pd}_{13}$ e $\mathrm{Pt}_{13}$ em que as estruturas com alta simetria e as de mais baixa energia são mostradas.

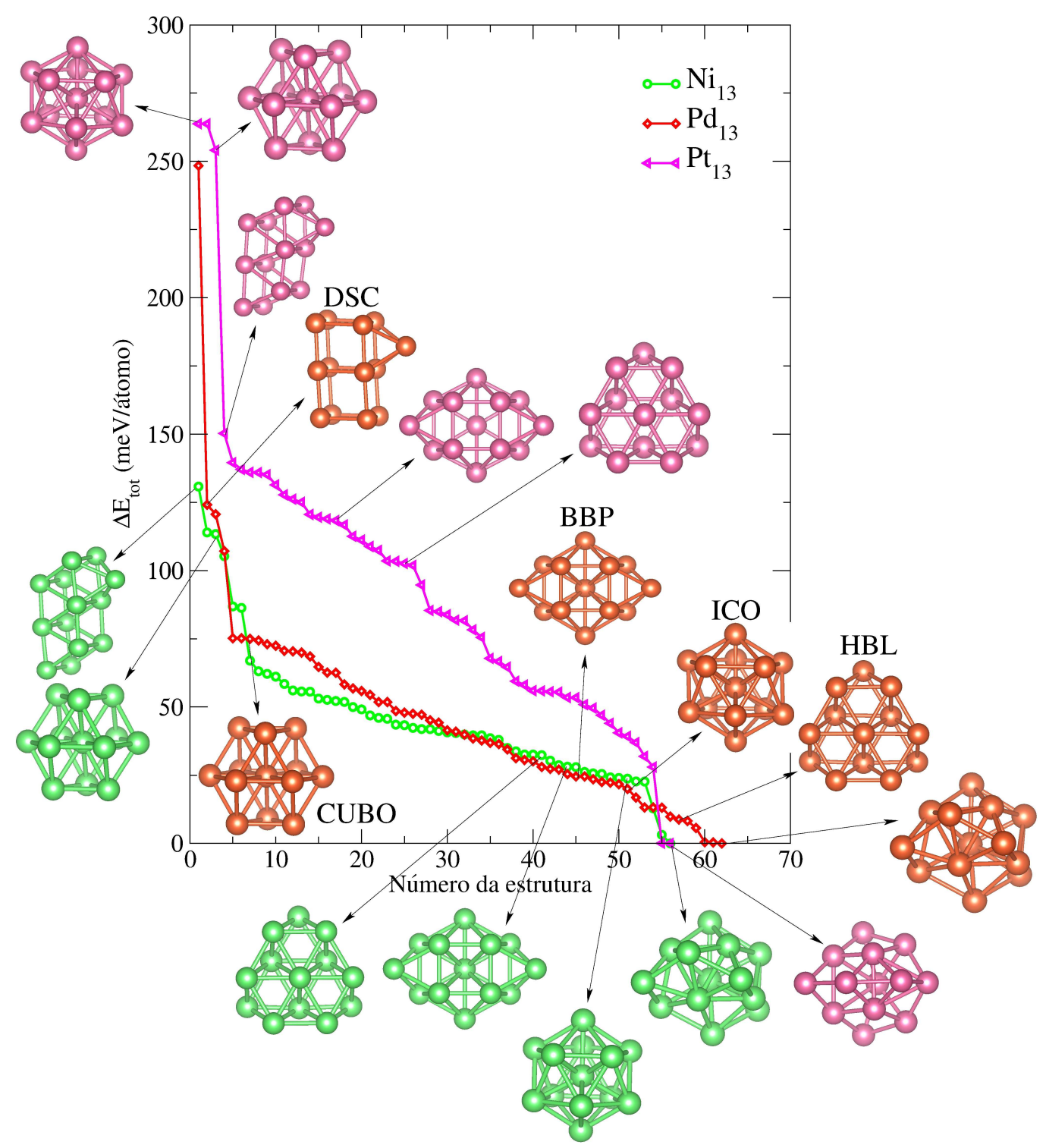

Fonte: Autoria própria.

Assim sendo, todos os pesos são calculados para cada átomo $i$, formando o comprimento de ligação ponderado $\left(d_{a v}^{i}\right)$. Dentre as diversas funções que podem ser utilizadas para realizar o cálculo dos pesos, e se obter o $\mathrm{NCE}_{i}$, neste projeto foi utilizada uma função exponencial de sexta potência, em que se seguem as equações:

$$
\mathrm{NCE}_{i}=\sum_{j} \exp \left[1-\left(\frac{d_{i j}}{d_{a v}^{i}}\right)^{6}\right]
$$

em que $d_{i j}$ é a distância entre os átomos $i$ e $j$, e o comprimento de ligação ponderado é 
Figura 3.5 - Energia relativa (meV/átomo) para $\mathrm{Cu}_{13}, \mathrm{Ag}_{13}$ e $\mathrm{Au}_{13}$ em que as estruturas com alta simetria e as de mais baixa energia são mostradas.

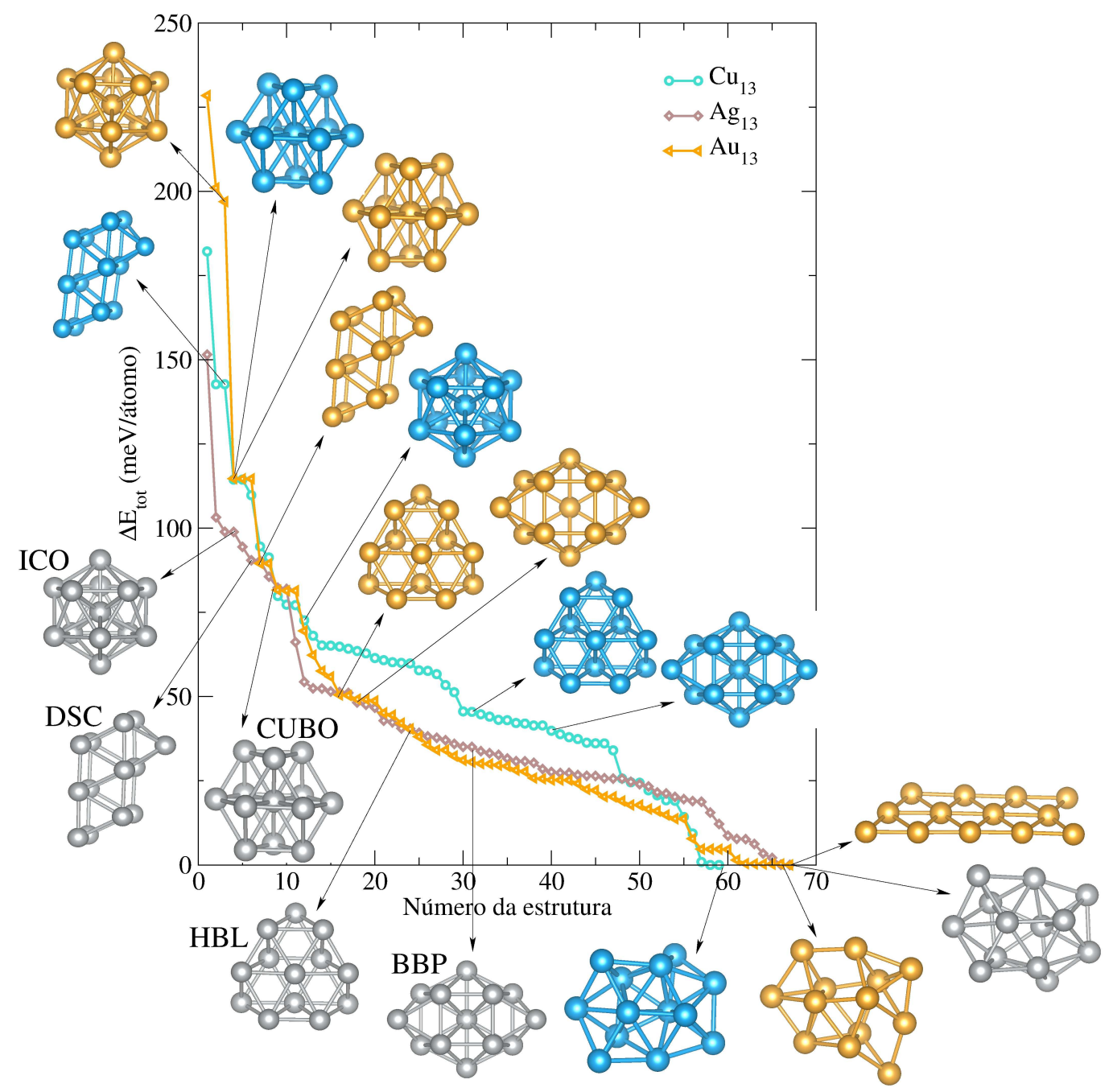

Fonte: Autoria própria.

definido como

$$
d_{a v}^{i}=\frac{\sum_{j} d_{i j} \exp \left[1-\left(\frac{d_{i j}}{d_{a v}^{i}}\right)^{6}\right]}{\sum_{j} \exp \left[1-\left(\frac{d_{i j}}{d_{a v}^{i}}\right)^{6}\right]},
$$

de forma que $d_{a v}^{i}$ é obtido auto-consistentemente, e nas análises posteriores foi utilizada como condição de convergência $\mid d_{a v}^{i}($ novo $)-d_{a v}^{i}($ antigo $)<0.00010 \mid$, sendo que a menor distância entre $i$ e $j$ foi utilizada como valor inicial do comprimento de ligação ponderado para o $i$-ésimo átomo.

A média NCE para dado sistema contendo $N$ átomos é calculada

$$
\mathrm{NCE}=\frac{1}{N} \sum_{N=1}^{N} \mathrm{NCE}_{i}
$$

Observa-se na figura (3.6) que nenhum cluster apresenta a configuração mais estável 


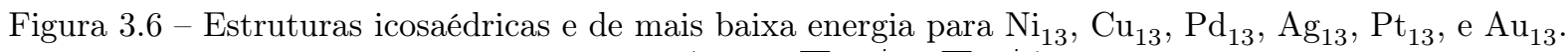
As cargas relativas de Mulliken $\left(\Delta Q=\sum_{i} Z_{A}^{i}-\sum_{i} q_{m}^{i}\right)$ são mostradas para os átomos não-equivalentes.
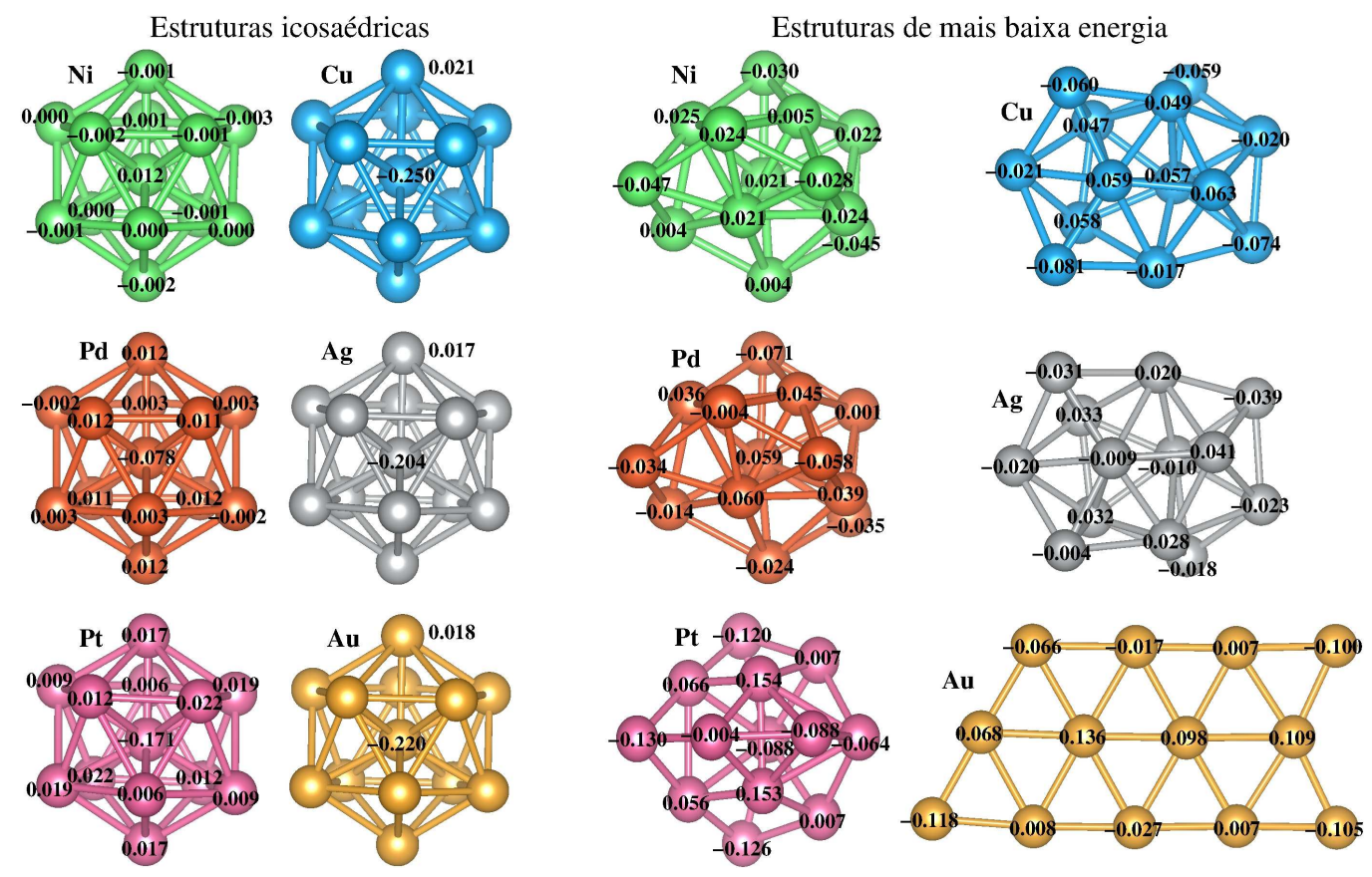

Fonte: Autoria própria.

como sendo a icosaédrica. É possível verificar ainda, que o NCE depende diretamente da configuração em que o cluster se apresenta e, que há uma preferência para estruturas mais abertas em todos os casos (NCE > 6.46, valor obtido para ICO ideal).

Pode-se notar, inicialmente, que para das estruturas icosaédricas o comprimento de ligação ponderado aumenta proporcionalmente com o número atômico, com exceção da platina, que destoa à tendência. Os dados obtidos para o número de coordenação efetiva também mostram que níquel, paládio e platina, metais de transição com orbitais $d$ semipreenchidos, distorcem a configuração icosaédrica ideal, enquanto cobre, prata e ouro mantém a simetria $I_{h}$, mostrando apenas uma pequena compressão ( $\mathrm{NCE}=6.40$ ).

Para as estruturas com mais baixa energia, verifica-se que todos os elementos preferem configurações mais abertas que a ICO, com valores de $d_{a v}$ e NCE menores que os apresentados pela estrutura de referência. Além disso, é possível observar a tendência entre as séries de elementos, em que $\mathrm{Ni}_{13}$ e $\mathrm{Cu}_{13}(3 d)$ possuem uma preferência a estruturas mais compactas; $\mathrm{Pd}_{13}$ e $\mathrm{Ag}_{13}(4 d)$ possuem comprimento de ligação e número de coorde-

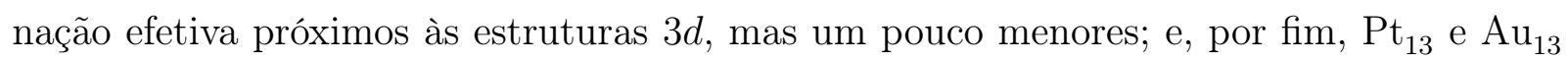
prevalecem em estruturas abertas, com NCE $<5.00$. Nota-se que, para ambos os casos ICO e LOW, menores comprimentos de ligação ocorrem para os elementos com orbitais $d$ semi-preenchidos, de forma que a estrutura eletrônica possui uma maior flexibilidade para se adequar de forma mais compacta. 
Tabela 3.2 - Propriedades dos clusters com 13 átomos. Comprimento de ligação ponderado $\left(d_{a v}\right.$, em $\left.\AA\right)$, número de coordenação efetiva (NCE, em número de vizinhos próximos), energia de ligação $\left(E_{b}\right.$, em eV/átomo) e momento magnético total $\left(m_{T}\right.$, em $\left.\mu_{B}\right)$.

\begin{tabular}{llcccc}
\hline & & $d_{a v}$ & $\mathrm{NCE}$ & $E_{b}$ & $m_{T}$ \\
\hline $\mathrm{Ni}_{13}$ & ICO & 2.40 & 6.38 & -3.13 & 8.00 \\
$\mathrm{Ni}_{13}$ & LOW & 2.37 & 5.67 & -3.15 & 10.00 \\
$\mathrm{Cu}_{13}$ & ICO & 2.50 & 6.40 & -2.27 & 5.00 \\
$\mathrm{Cu}_{13}$ & LOW & 2.46 & 5.70 & -2.35 & 1.00 \\
$\mathrm{Pd}_{13}$ & ICO & 2.74 & 6.36 & -2.32 & 8.00 \\
$\mathrm{Pd}_{13}$ & LOW & 2.68 & 5.66 & -2.34 & 8.00 \\
$\mathrm{Ag}_{13}$ & ICO & 2.88 & 6.40 & -1.60 & 5.00 \\
$\mathrm{Ag}_{13}$ & LOW & 2.83 & 5.65 & -1.70 & 1.00 \\
$\mathrm{Pt}_{13}$ & ICO & 2.72 & 6.37 & -3.65 & 2.00 \\
$\mathrm{Pt}_{13}$ & LOW & 2.59 & 4.28 & -3.91 & 2.00 \\
$\mathrm{Au}_{13}$ & ICO & 2.87 & 6.40 & -1.93 & 5.00 \\
$\mathrm{Au}_{13}$ & LOW3D & 2.78 & 4.94 & -2.13 & 1.00 \\
$\mathrm{Au}_{13}$ & LOW2D & 2.69 & 3.80 & -2.13 & 1.00 \\
\hline
\end{tabular}

\section{Parâmetros energéticos}

Através das figuras (3.4) e (3.5) é possível verificar a estabilidade dos clusters com configurações simétricas em relação às de menor energia. Dentre os metais estudados do grupo 10, a configuração $\mathrm{Pt}_{13}{ }^{\mathrm{ICO}}$ é a que possui a maior energia relativa ao se comparar à $\mathrm{Pt}_{13}{ }^{\mathrm{LOW}}$ (264 meV/átomo), enquanto níquel e paládio possuem uma diferença de $24 \mathrm{e}$ $20 \mathrm{meV} / a$ tomo, respectivamente. Assim, é possível compreender a tendência dos parâmetros geométricos, em que a configuração mais favorável da platina é mais aberta, desviando largamente da estrutura icosaédrica. Para o grupo 11, observam-se diferenças de energia relativa de 77, 99 e $197 \mathrm{meV} /$ átomo para as estruturas ICO de cobre, prata e ouro em relação às LOW, que mostram um aumento de energia relativa dada através da ordem $3 d<4 d<5 d$, conforme as estruturas se apresentem com configurações mais abertas.

Das propriedades energéticas que podem ser observadas, destaca-se a energia de ligação, uma vez que através dela é possível compreender como ocorrem os processos de formação e quebra das ligações existentes no sistema. Na tabela (3.2), nota-se que os clusters formados por elementos do grupo 11 apresentam a energia de ligação menores que seus respectivos antecessores periódicos, seguindo a ordem $\mathrm{Ni}_{13}>\mathrm{Cu}_{13}, \mathrm{Pd}_{13}>\mathrm{Ag}_{13}$ e $\mathrm{Pt}_{13}>\mathrm{Au}_{13}$. Isso se deve ao fato de que os elementos que possuem os orbitais $d$ completamente ocupados, por não disponibilizarem esses orbitais na formação de ligações covalentes. Também se observa uma tendência no aumento da magnitude das energias de ligação, $3 d>4 d<5 d$, a mesma que ocorre nas energias de coesão dos sólidos. Entretanto, notam-se desvios de energia ao se comparar as ligações que ocorrem nos clusters com as ligações que ocorrem nos sólidos que vão de $-44 \%\left(\mathrm{Au}_{13}\right)$ até $-29 \%\left(\mathrm{Ni}_{13}\right)$. (71) Esse resultado pode ser atrelado ao fato 
de que os clusters possuem uma preferência para estruturas abertas, divergindo dos seus respectivos bulks.

\section{Parâmetros eletrônicos}

Para se compreender a estrutura eletrônica dos clusters, foram analisados os momentos magnéticos e as cargas relativas de Mulliken. O momento magnético é uma propriedade que têm sido largamente pesquisada para os clusters, $(15,72-74)$ uma vez que o estudo e controle de materiais magnéticos é um ponto central de vários problemas, incluindo processos catalíticos. De acordo com Jena e Castleman Jr., (32) é possível verificar que efeitos de tamanho e a baixa coordenação dos átomos que constituem os clusters fazem com que o momento magnético dessas estruturas sejam maiores que seus respectivos bulks. É interessante notar que alguns clusters apresentam momentos magnéticos não-nulos, mesmo que seus análogos sólidos não apresentem magnetismo, como o $\mathrm{Cu}_{13}, \mathrm{Pd}_{13}, \mathrm{Pt}_{13}$ e $\mathrm{Au}_{13}$. As estruturas ICO de cobre, prata e ouro se destacam por apresentam $m_{T}=5.0 \mu_{B}$, que pode estar ligado ao parâmetro geométrico, enquanto suas configurações LOW possuem um pequeno momento magnético $\left(m_{T}=1.0 \mu_{B}\right)$ referente aos aspectos de confinamento quântico. Por outro lado, os clusters de níquel, paládio e platina possuem valores idênticos para seus clusters ICO e LOW, entretanto, $m_{T}^{\mathrm{Ni}_{13}}>m_{T}^{\mathrm{Pd}_{13}}>m_{T}^{\mathrm{Pt}_{13}}$, que já era esperado, uma vez que o níquel é um elemento ferromagnético na fase bulk; o paládio em fase sólida apresenta um caráter magnético, e a platina, que não possui ferromagnetismo em fase bulk, apresenta um pequeno momento magnético para $\mathrm{Pt}_{13}$.

Outro parâmetro a ser analisado se refere às cargas relativas de Mulliken. Na figura (3.6), as cargas indicadas nos átomos refletem a permanência ou distorção que ocorrem na geometria dos clusters icosaédricos. Os clusters de cobre, prata e ouro na configuração ICO possuem dois átomos não-equivalentes, o átomo central com carga relativa negativa e os que estão expostos ao vácuo, com cargas relativas positivas, em que suas cargas centrais seguem a ordem $\mathrm{Cu}_{13}{ }^{\mathrm{ICO}}>\mathrm{Ag}_{13}{ }^{\mathrm{ICO}}<\mathrm{Au}_{13}{ }^{\mathrm{ICO}}$, semelhante à energia de ligação. Há um compromisso entre o número de ligações (que estabiliza) e o aumento do átomo central, que desestabiliza a estrutura. Por outro lado, como já visto, os elementos da família 10 apresentam uma distorção da estrutura icosaédrica ideal, favorecendo uma variação de carga praticamente nula (comparável a átomos livres) para o níquel, já paládio e platina mantém grande parte da simetria, onde átomos em posições opostas possuem a mesma carga relativa. Para os clusters com baixa simetria, a distribuição de carga mostra que não há uma concentração eletrônica específica, como ocorre para o icosaédro, sendo que as cargas relativas são muito pequenas (com um máximo de $|0.074| e$ ) para os elementos $3 d$ e $4 d$, porém com um rearranjo um pouco maior de cargas em platina e ouro, isso porque os clusters formados por esses elementos possuem uma geometria mais aberta, influenciando, assim, a distribuição de cargas nas estruturas de forma mais heterogênea. 
Figura 3.7 - Frequências de vibração $\left(\mathrm{em} \mathrm{cm}^{-1}\right)$ para as configurações ICO e LOW dos $\mathrm{MT}_{13}$ clusters.

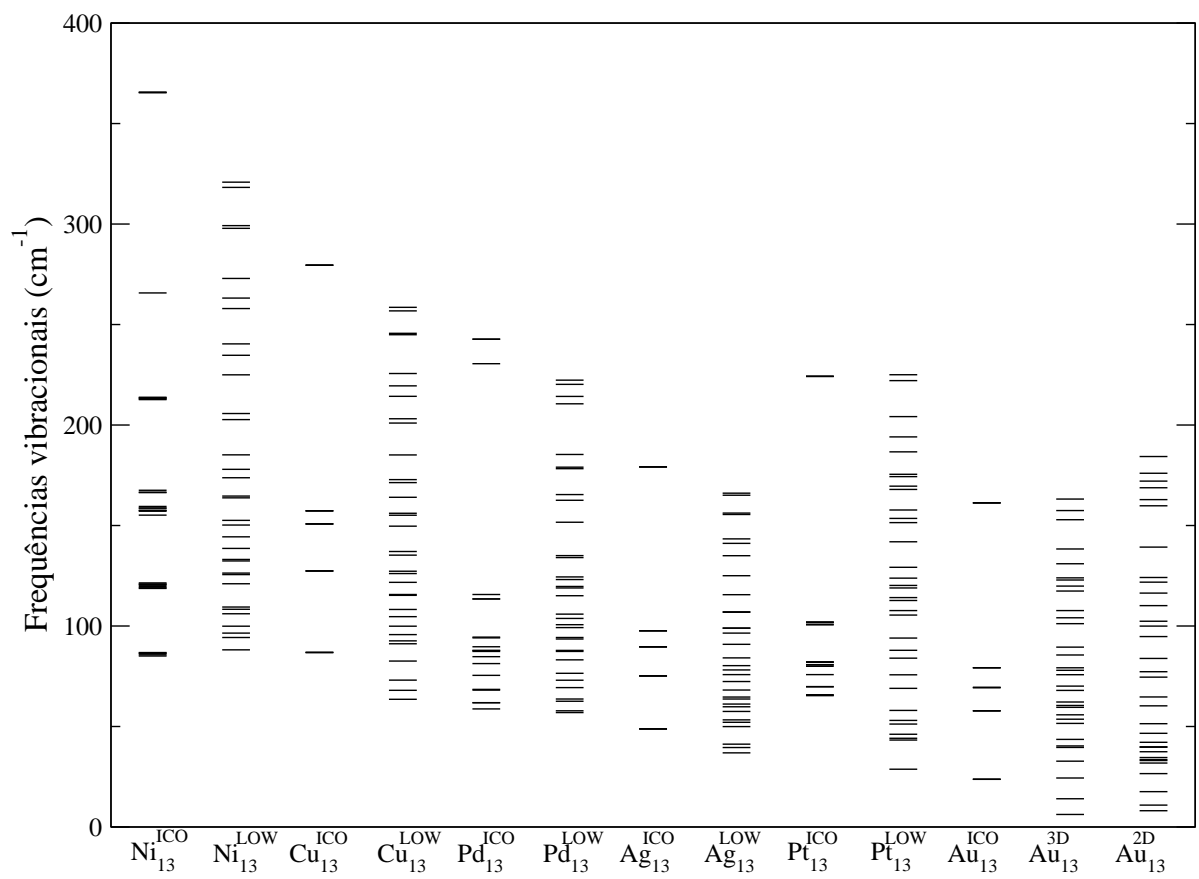

Fonte: Autoria própria.

\section{Frequências de vibração}

As frequências de vibração dos clusters foram obtidas para as configurações ICO e LOW, como mostra a figura (3.7). Observa-se, inicialmente, que todas as frequências de vibração são positivas, indicando que as configurações mostradas na figura (3.6) correspondem a mínimos locais (ICO) e globais assumidos (LOW), por isso, são estáveis para se considerar o estudo de adsorção de moléculas sobre os clusters. Caso os valores das frequências de vibração fossem negativos, estaria indicando que na construção da matriz de Hessian foram encontrados números imaginários, os quais denotam uma localização fora dos mínimos.

Dos cálculos vibracionais, ainda é possível observar que, ao se comparar os sistemas, as frequências de vibração máximas $\left(\nu_{\text {máx }}\right)$ diminuem com o aumento das massas atômicas, ou seja, $\nu_{\text {máx }}^{3 D}>\nu_{\text {máx }}^{4 D}>\nu_{\text {máx }}^{5 D}$. Mas também, quando a diferença entre as massas não é tão significativa, como ao se observar o cluster de cobre em relação ao cluster de níquel, pode-se aferir a predominância da constante de força para esses sistemas. Assim sendo, nota-se que as contantes de força seguem a ordem $\mathrm{Ni}_{13}{ }^{\mathrm{ICO}}>\mathrm{Cu}_{13}{ }^{\mathrm{ICO}}, \mathrm{Pd}_{13}{ }^{\mathrm{ICO}}>\mathrm{Ag}_{13}{ }^{\mathrm{ICO}}$ e $\mathrm{Pt}_{13}{ }^{\mathrm{ICO}}>\mathrm{Au}_{13}{ }^{\mathrm{ICO}}$, que pode ser correlacionada com a magnitude da energia de ligação.

\subsection{Sumário}

Através das análises apresentadas neste capítulo, foi possível obter as seguintes conclusões: 
- Todas as propriedades moleculares, geométricas, energéticas, eletrônicas e vibracionais foram descritas com grande precisão por DFT-PBE, com erros menores que $4.82 \%, 2.8 \%, 4.9 \%$, e $4 \%$, respectivamente.

- Observa-se que tanto a água quanto o etanol possuem os orbitais HOMO como sendo orbitais atômicos não-ligantes, provenientes do oxigênio, que condiz com resultados publicados na literatura.

- Quando se compara a complexidade sistêmica das moléculas $\left(\mathrm{OH}, \mathrm{H}_{2} \mathrm{O}\right.$ e $\mathrm{C}_{2} \mathrm{H}_{5} \mathrm{OH}$ e dos clusters $\mathrm{MT}_{13}$, observa-se que esses últimos são mais difíceis de serem avaliados, devido à necessidade de se realizar uma busca pelo mínimo global de energia utilizando um grande número de configurações, e devido ao fato de todos os sistemas apresentarem momento magnético. Os resultados obtidos reproduzem dados publicados anteriormente por outros grupos e pelo grupo de teoria quântica de nanomateriais, e portanto, demostrando clara precisão dos procedimentos utilizados.

- Através do conjunto de testes de convergência em função do número de funções base foi possível selecionar os conjuntos LT2 para a descrição dos clusters, e os conjuntos LT3 para a descrição das moléculas nos sistemas de adsorção. 


\section{Capítulo 4}

\section{Resultados: Sistemas adsorvidos}

Este capítulo está separado em cinco seções: (4.1) Geração de estruturas de adsorção; (4.2) adsorção de $\mathrm{OH} / \mathrm{MT}_{13} ;$ (4.3) adsorção de $\mathrm{H}_{2} \mathrm{O} / \mathrm{MT}_{13} ;$ (4.4) adsorção de $\mathrm{C}_{2} \mathrm{H}_{5} \mathrm{OH} / \mathrm{MT}_{13}$; (4.5) discussão e sumário.

\subsection{Geração de estruturas de adsorção}

No capítulo anterior foram obtidas as estruturas mais estáveis para os clusters $\mathrm{MT}_{13}$, além de um grande número de isômeros com energias mais elevadas para cada sistema. Em vista disso, há uma grande quantidade de estruturas atômicas, entretanto, devido ao custo computacional, foram selecionadas somente as estruturas mais importantes: estrutura de energia mais baixa $(\mathrm{LOW})$ para cada $\mathrm{MT}_{13}$ cluster e um isômero de mais alta energia. As configurações de mais baixa energia possuem baixa simetria e são distintas entre os diferentes sistemas, e portanto, uma investigação dos efeitos eletrônicos sobre as propriedades de adsorção fica comprometida devido às diferenças nas estruturas. Assim sendo, para minimizar este problema, a configuração icosaédrica (ICO), a qual possui energia mais alta, mas também possui alta simetria, foi selecionada para entender os efeitos eletrônicas sobre as propriedades de adsorção.

Um dos maiores desafios no estudo da adsorção de moléculas sobre clusters está na determinação do sítio de adsorção de mais baixa energia. Quando se observam superfícies de alto empacotamento, MT(111), (30) nota-se a existência de três sítios de adsorção de alta simetria: o primeiro ocorre sobre um único átomo e é chamado sítio top; o segundo faz uma ponte entre dois átomos, por isso, é chamado de sítio bridge; e, por fim, há o sítio hollow, localizado no "buraco" formado por três átomos. Esses mesmos sítios de adsoção podem ser encontrados na estrutura de um cluster icosaédrico, como mostra a figura (4.1).

Por outro lado, ao se trabalhar com clusters de baixa simetria, em que todos os átomos são não-equivalentes, a quantidade de sítios de adsorção aumenta exponencialmente. Ainda de acordo com a figura (4.1), observa-se que para uma estrutura similar à $\mathrm{Cu}_{13}{ }^{\mathrm{LOW}}$, por exemplo, somente para sítios top há treze possibilidades. Ao se ampliar para os demais 
Figura 4.1 - Sítios de adsorção para estruturas de 13 átomos (a) icosaédrica e (b) com baixa simetria. Para o icosaedro, destacam-se (a1) top; (a2) bridge e (a3) hollow. Na estrutura de baixa simetria são mostrados somente os sítios top.

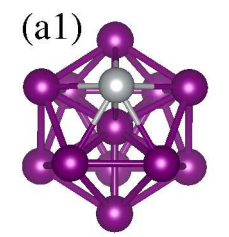

(b)
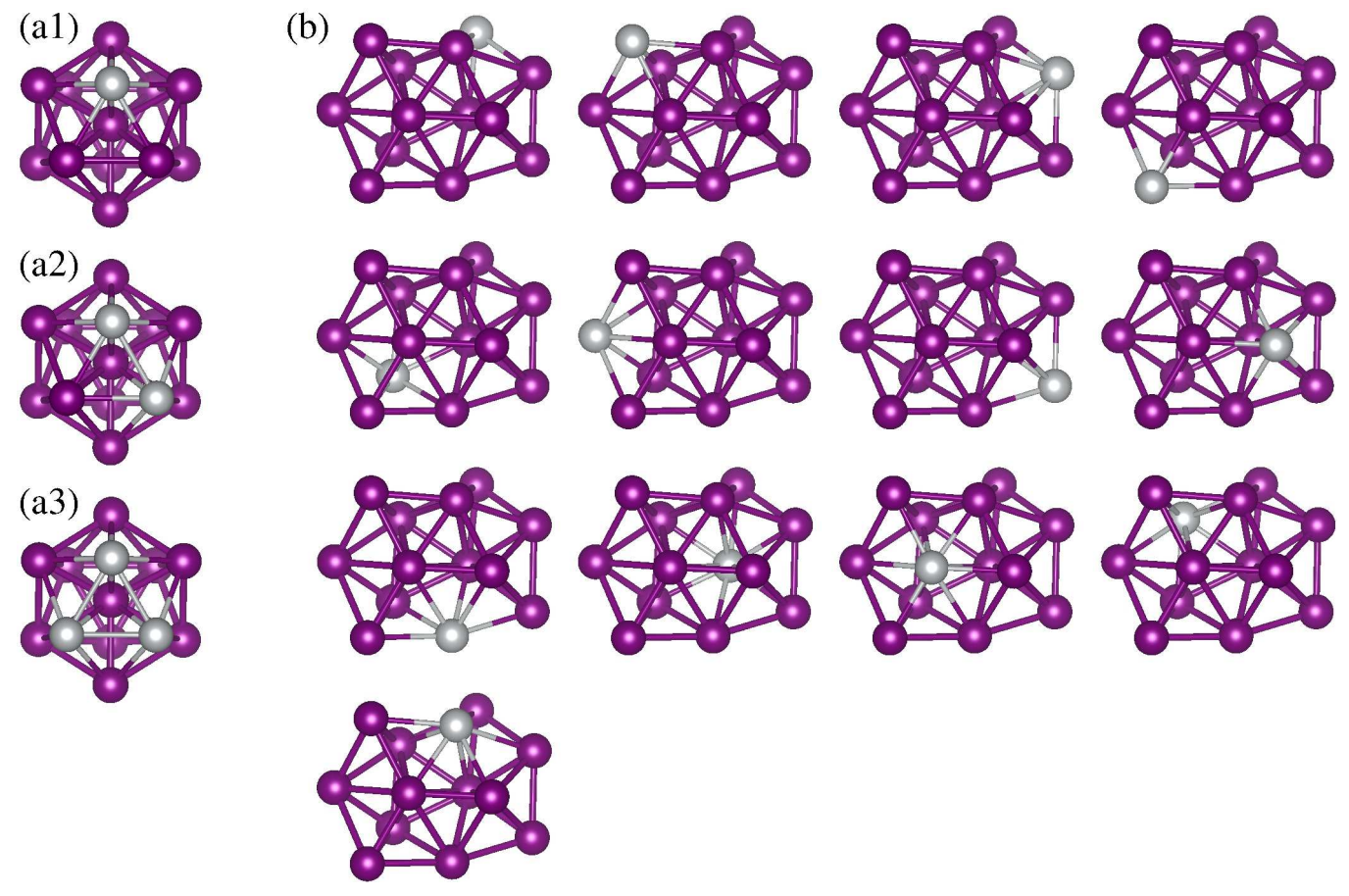

Fonte: Autoria própria.

sítios existentes, são incluídos 38 sítios bridge e 22 sítios hollow, totalizando, assim, 73 sítios de adsorção, além de todas as demais configurações possíveis. Dessa forma, observa-se o grande desafio de se abranger todos os sítios de adsorção para uma estrutura com baixa simetria, sem privilegiar previamente nenhum deles. Ademais, neste trabalho são utilizadas as moléculas hidroxila, água e etanol, sendo essa última ponto chave de interesse, uma vez que é necessário analisá-la através das diferentes ligações que podem ocorrer e suas respectivas orientações. Portanto, é possível concluir que a seleção das configurações iniciais para adsorção de $\mathrm{OH}, \mathrm{H}_{2} \mathrm{O}$ e $\mathrm{C}_{2} \mathrm{H}_{5} \mathrm{OH}$ sobre os clustes escolhidos no presente trabalho é um grande desafio.

Assim sendo, para determinar a configuração de energia mais baixa é necessário realizar o cálculo para milhares de configurações, entretanto, cálculos ab initio possuem um grande custo computacional e, consequentemente, é proibitivo o cálculo de milhares de configurações. E, é sabido que algoritmos de otimização local aplicados à estruturas similares fornecerão estruturas finais muito similares ou idênticas, de forma que pertencem ao mesmo mínimo local ou são mínimos locais próximos no espaço de fase. Portanto, técnicas de análise comparativa podem ser utilizadas para verificar a similaridade entre diferentes configurações estruturais, e assim, os cálculos ab initio foram realizados somente para um conjunto restrito de estruturas não similares, obtidas através da análise de similaridade.

Neste trabalho, foi utilizado o seguinte critério de similaridade: duas configurações iniciais, $\alpha$ e $\beta$, geradas aleatóriamente são similares se a função $S(\alpha, \beta)$ fornecer um valor 
Figura 4.2 - Curva de energia potencial hipotética que ilustra a aplicação do critério de similaridade.

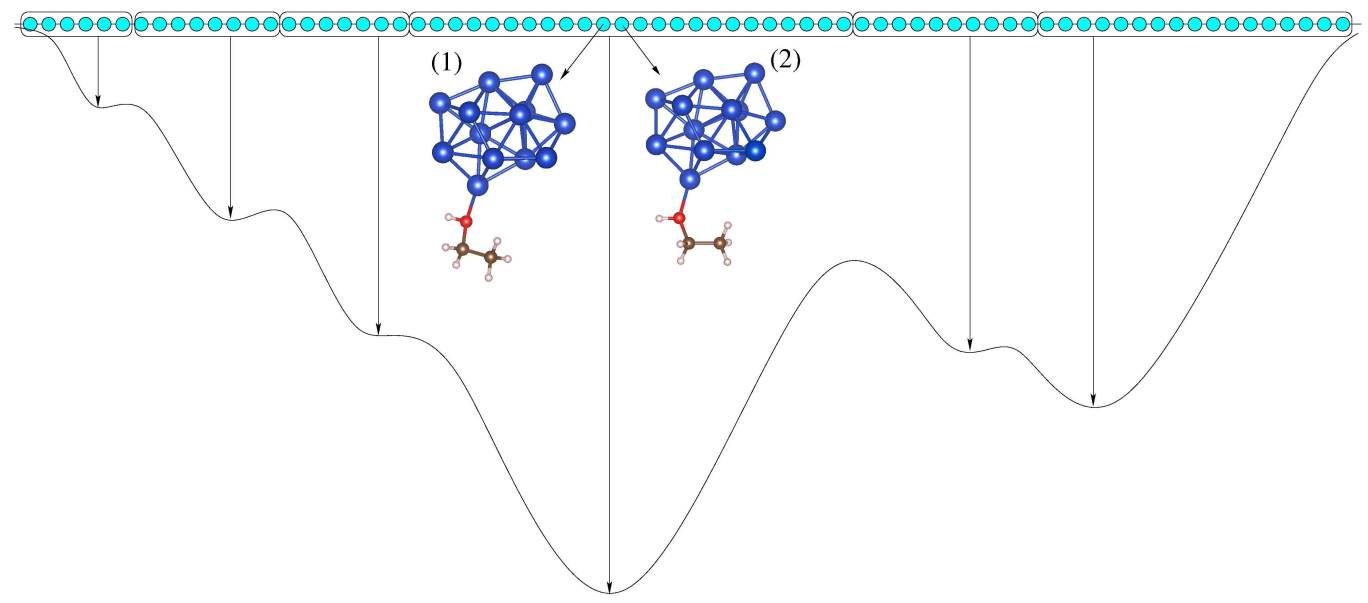

Fonte: Autoria própria.

inferior ao critério de similaridade (parâmetro), onde $S(\alpha, \beta)$ é dado por

$$
S(\alpha, \beta)=\frac{\sum_{i=1}^{N}\left[\left(\overrightarrow{d_{i}^{\alpha}}-{\overrightarrow{d_{i}^{\beta}}}^{\beta}\right) \cdot\left(\overrightarrow{d_{i}^{\alpha}}-{\overrightarrow{d_{i}^{\beta}}}^{\beta}\right)\right]}{\sum_{i=1}^{N}\left[\left(\overrightarrow{d_{i}^{\alpha}}\right) \cdot\left(\overrightarrow{d_{i}^{\alpha}}\right)+\left(\overrightarrow{d_{i}^{\beta}}\right) \cdot\left(\vec{d}_{i}^{\beta}\right)\right]},
$$

em que $\vec{d}_{i}$ é um vetor que contém a posição de todos os átomos do sistema com origem no centro de gravidade do cluster. A figura (4.2) ilustra a aplicação do critério de similaridade, uma vez que é possível observar que, para uma curva de energia potencial, várias configurações levam ao mesmo mínimo local e, por isso, pode-se selecionar apenas uma delas para a realização do cálculo ab initio.

Basicamente, esta definição é uma modificação da métrica de Euclides para fornecer como resultado um número admensional e, assim, possuir uma dependência menor em relação ao tamanho da partícula. Este algoritmo é relativamente simples, e segue as seguintes etapas descritas sucintamente:

I. Primeiramente são selecionadas as estruturas do cluster e da molécula.

II. Defini-se a distância mínima e máxima entre o cluster e a molécula.

III. Um valor de corte é fornecido para separar as diferentes estruturas entre similares e não-similares.

IV. Utilizando números aleatórios, 50 milhões de configurações são geradas, as quais diferem somente na posição, orientação, e distância da molécula em relação ao cluster.

V. Todas as configurações geradas são comparadas entre si utilizando a equação de similaridade definida anteriormente. Estruturas similares são removidas do conjunto gerado, e este processo é excecutado para todas as configurações. 
Tabela 4.1 - Parâmetros de adsorção para $\mathrm{OH} / \mathrm{MT}_{13}$. Energia de adsorção $\left(E_{a d}\right.$, em eV), comprimento de ligação O-MT ( $d_{\mathrm{O}-\mathrm{MT}}$, em $\AA$ ), variações de número de coordenação efetiva e comprimento de ligação ponderado ( $\Delta \mathrm{NCE}$ e $\Delta d_{a v}$, ambos em \%), frequência de vibração $\mathrm{O}-\mathrm{H}\left(\nu_{\mathrm{O}-\mathrm{H}}, \mathrm{em} \mathrm{cm}^{-1}\right)$, e as cargas relativas de Mulliken para oxigênio e hidrogênio $(\Delta Q$, em $e$ ).

\begin{tabular}{llccrrrrr}
\hline & & $E_{a d}$ & $d_{\mathrm{O}-\mathrm{MT}}$ & $\Delta \mathrm{NCE}$ & $\Delta d_{a v}$ & $\nu_{\mathrm{O}-\mathrm{H}}$ & $\Delta Q(\mathrm{O})$ & $\Delta Q(\mathrm{H})$ \\
\hline $\mathrm{OH}$ & & - & - & - & - & 3588 & -0.260 & 0.260 \\
\hline $\mathrm{Ni}_{13}$ & ICO & -4.10 & 2.01 & -0.62 & 0.21 & 3616 & -0.417 & 0.268 \\
$\mathrm{Ni}_{13}$ & LOW & -4.11 & 1.91 & -0.84 & 0.00 & 3667 & -0.421 & 0.214 \\
$\mathrm{Cu}_{13}$ & ICO & -3.64 & 1.97 & -0.97 & 0.16 & 3692 & -0.421 & 0.148 \\
$\mathrm{Cu}_{13}$ & LOW & -3.89 & 1.94 & -4.33 & 0.30 & 3697 & -0.426 & 0.165 \\
$\mathrm{Pd}_{13}$ & ICO & -2.94 & 2.12 & -0.78 & -0.17 & 3663 & -0.332 & 0.160 \\
$\mathrm{Pd}_{13}$ & LOW & -3.06 & 2.12 & -0.04 & 0.06 & 3667 & -0.352 & 0.162 \\
$\mathrm{Ag}_{13}$ & ICO & -3.05 & 2.33 & -1.68 & 0.08 & 3686 & -0.553 & 0.177 \\
$\mathrm{Ag}_{13}$ & LOW & -3.25 & 2.22 & -4.04 & -0.40 & 3708 & -0.519 & 0.141 \\
$\mathrm{Pt}_{13}$ & ICO & -3.42 & 2.13 & -35.36 & -5.17 & 3654 & -0.317 & 0.149 \\
$\mathrm{Pt}_{13}$ & LOW & -3.62 & 2.14 & -7.27 & -0.68 & 3649 & -0.341 & 0.145 \\
$\mathrm{Au}_{13}$ & ICO & -3.12 & 1.99 & -23.92 & -3.74 & 3686 & -0.471 & 0.179 \\
$\mathrm{Au}_{13}$ & LOW3D & -3.12 & 1.99 & -1.43 & -0.38 & 3685 & -0.484 & 0.183 \\
$\mathrm{Au}_{13}$ & LOW2D & -3.11 & 2.16 & 5.54 & 0.91 & 3666 & -0.380 & 0.152 \\
\hline
\end{tabular}

Após a aplicação da equação de similaridade, as 50 milhões de configurações são reduzidas a um conjunto contendo entre $1-5$ centenas de configurações. Este conjunto reduzido, por sua vez, é analisado novamente para remover estruturas químicamente não favoráveis. Por exemplo, sabe-se que $\mathrm{OH}$ interage com superfícies metálicas através do átomo de oxigênio e, portanto, configurações contendo o átomo de hidrogênio em contato direto com a superfície podem não ser energeticamente favoráveis, verificado através dos cálculos aqui realizados. Os cálculos ab initio foram realizados somente para o conjunto final de configurações.

Assim sendo, este trabalho envolve o estudo da adsorção de sistemas moleculares sobre clusters contendo milhões de estruturas, as quais são avalidas de forma hierárquica através de diferentes ferramentas computacionais com o objetivo de se obter um conjunto de dados representativo para que, assim, a interação de sistemas moleculares com clusters metálicos possa ser analisada de forma eficiente.

\subsection{Adsorção de hidroxila sobre $\mathrm{MT}_{13}$}

Os dados referentes aos resultados da adsorção de $\mathrm{OH} / \mathrm{MT}_{13}$ se encontram nas figuras (4.3) e (4.4), e na tabela (4.1). A análise da adsorção de $\mathrm{OH} / \mathrm{MT}_{13}$ é feita de acordo com os sítios mencionados anteriormente, a energia de adsorção, além dos parâmetros estruturais, que incluem as modificações geométricas dos clustes e da molécula. Por fim, observam-se as variações da densidade de estados e da carga relativa da molécula e, também, a variação vibracional. 
Figura 4.3 - Estruturas de mais baixa energia para $\mathrm{OH} / \mathrm{MT}_{13}$. Para os casos particulares $\mathrm{OH} / \mathrm{Pt}_{13}{ }^{\mathrm{ICO}}$, $\mathrm{OH} / \mathrm{Au}_{13}{ }^{\mathrm{ICO}}, \mathrm{OH} / \mathrm{Au}_{13}{ }^{3 \mathrm{D}}$, e $\mathrm{OH} / \mathrm{Au}_{13}{ }^{2 \mathrm{D}}$, ocorreram distorções das configurações iniciais ao longo da otimização.
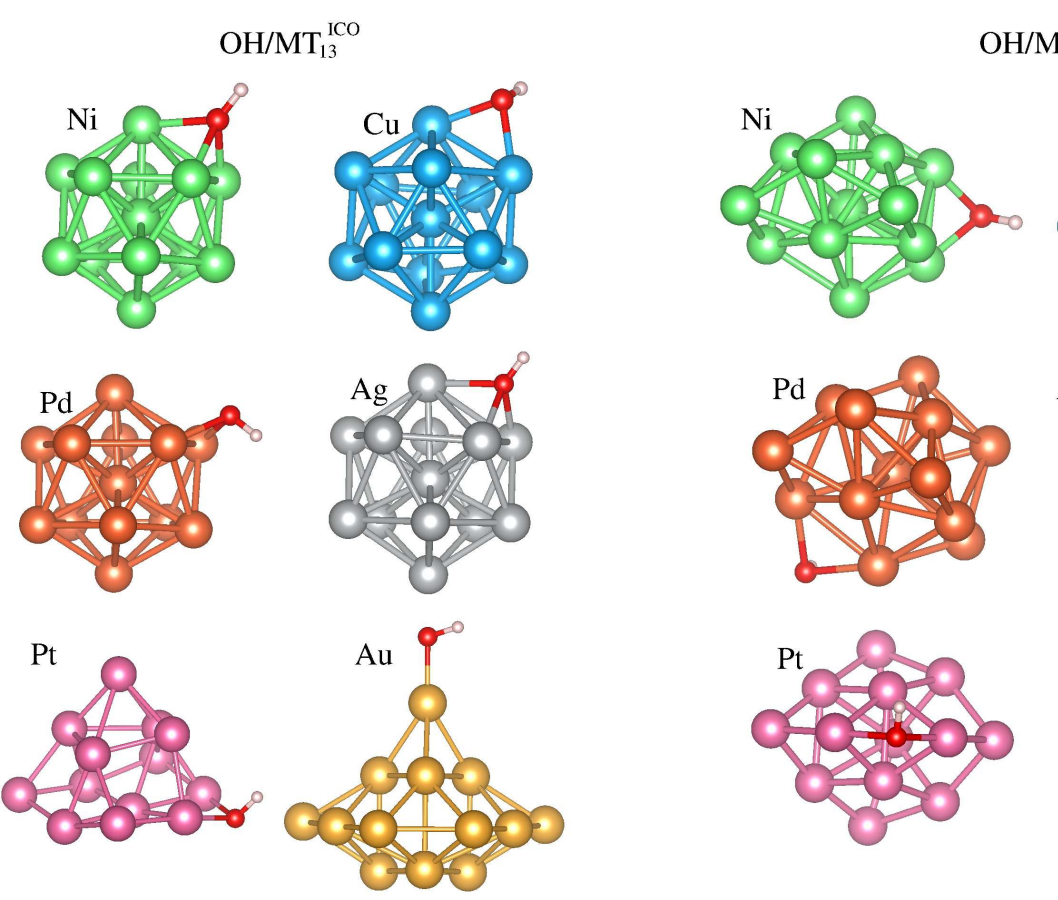

$\mathrm{H} / \mathrm{MT}_{13}^{\text {LOW }}$
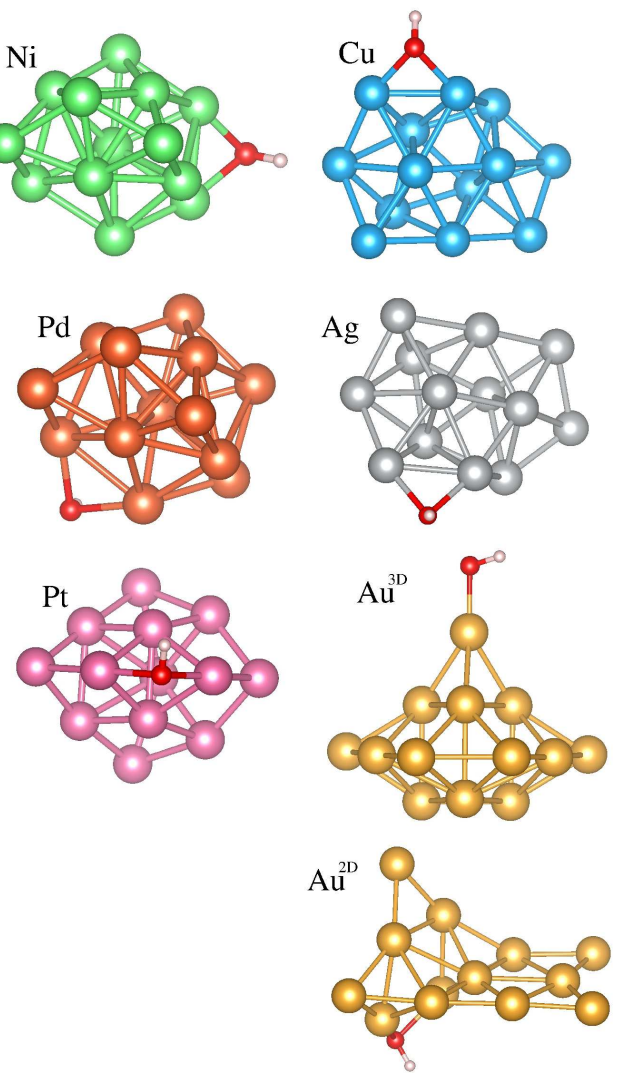

Fonte: Autoria própria.

\section{Sítios de adsorção}

Observa-se na figura (4.3), a qual mostra as configurações mais estáveis para a adsorção de hidroxila sobre os clusters $\mathrm{MT}_{13}$, que as configurações iniciais de $\mathrm{Pt}_{13}{ }^{\mathrm{ICO}} \mathrm{e}$ $\mathrm{Au}_{13}{ }^{\mathrm{ICO}}$ sofreram deformações estruturais ao longo das otimizações, de modo a perderem completamente a configuração ICO após adsorção. Ressalta-se que as estruturas de mais baixa energia também apresentam deformações, em que a estrutura final obtida a partir

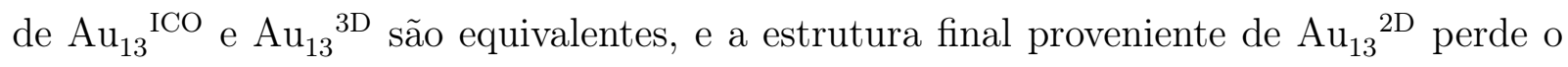
aspecto planar. Essas variações tão abruptas de geometria podem ser responsáveis pelas exceções apresentadas para os clusters de ouro.

Observa-se que a adsorção de $\mathrm{OH}$ sobre os clusters ocorre preferencialmente com o átomo de oxigênio apontando diretamente para o cluster sobre os seguintes sítios de adsorção: sítio hollow sobre $\mathrm{Ni}_{13}{ }^{\mathrm{ICO}}$ e $\mathrm{Ag}_{13}{ }^{\mathrm{ICO}}$, ou seja, o átomo de O está fazendo três ligações com cluster. Nos demais casos, o $\mathrm{OH}$ se aproxima do clusters e se liga através do sítio brigde a $\mathrm{Cu}_{13}{ }^{\mathrm{ICO}}, \mathrm{Pd}_{13}{ }^{\mathrm{ICO}}, \mathrm{Pt}_{13}{ }^{\mathrm{ICO}}, \mathrm{Ni}_{13}{ }^{\text {LOW }}, \mathrm{Cu}_{13}{ }^{\mathrm{LOW}}, \mathrm{Pd}_{13}{ }^{\mathrm{LOW}}, \mathrm{Ag}_{13}{ }^{\text {LOW }}, \mathrm{Pt}_{13}{ }^{\mathrm{LOW}}$, e $\mathrm{Au}_{13}{ }^{2 \mathrm{D}}$, enquanto o sítio de menor coordenação foi obtido somente para $\mathrm{Au}_{13}{ }^{\mathrm{ICO}} \mathrm{e} \mathrm{Au}_{13}{ }^{3 \mathrm{D}}$, que convergiram para a mesma estrutura após otimização. Portanto, existe uma maior 
Figura 4.4 - Projeção da densidade de estados para os orbitais $s$ e $p$ do hidrogênio e do oxigênio puros e após adsorção. A energia do HOMO foi definida como origem.

Hidroxila
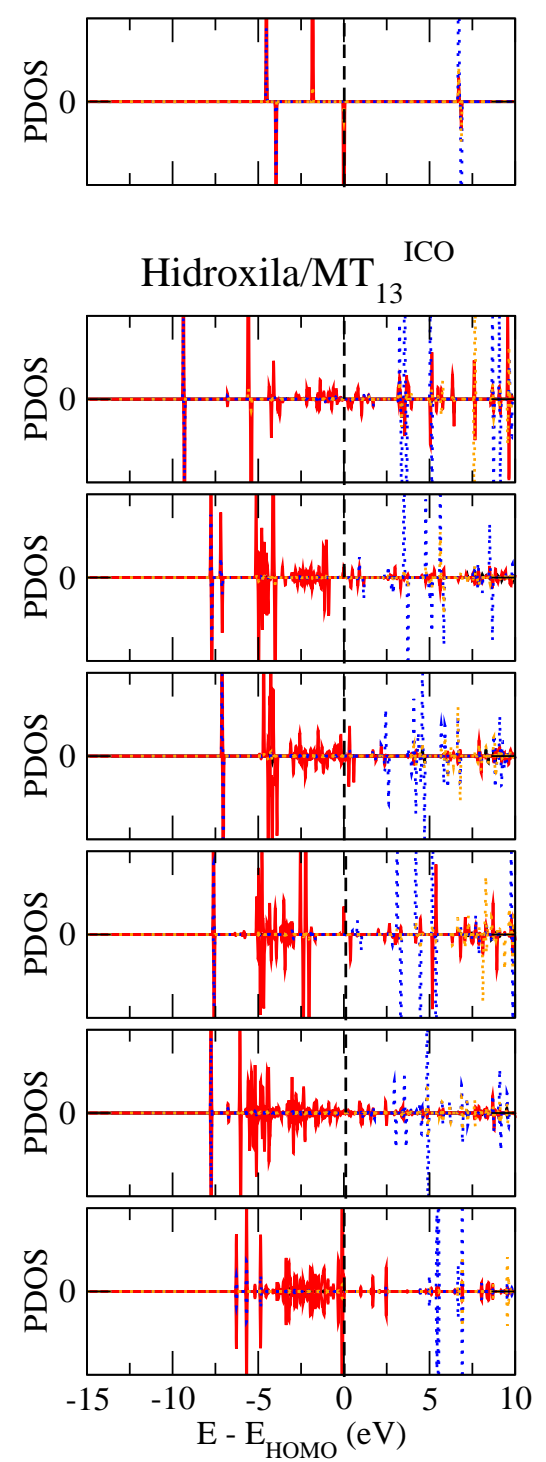

Hidroxila
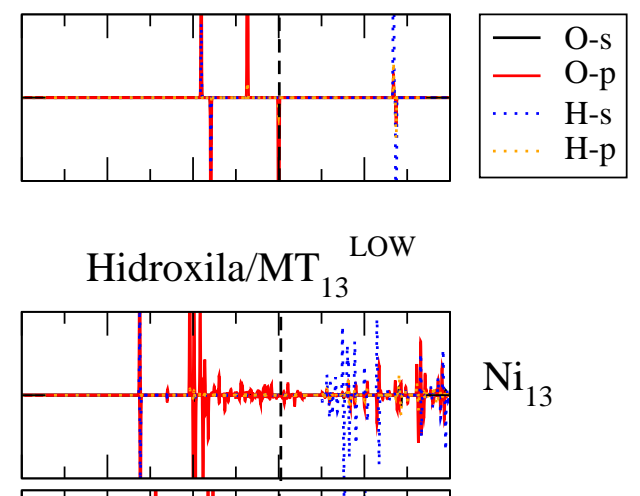

$\mathrm{Ni}_{13}$
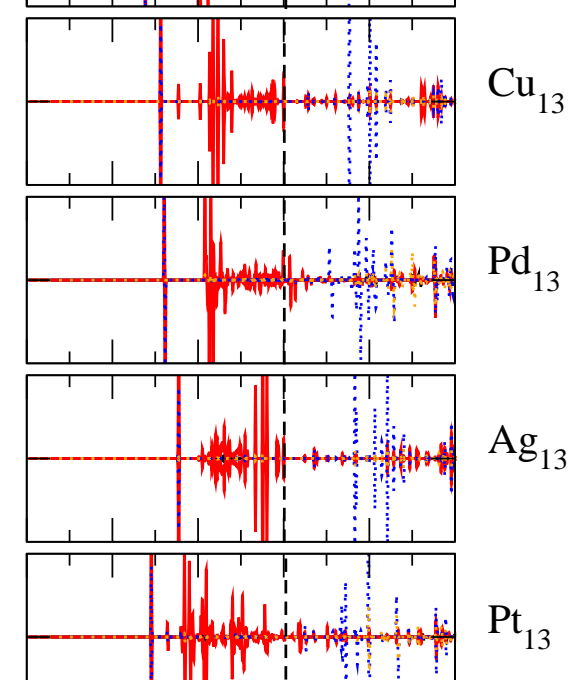

$\mathrm{Pt}_{13}$

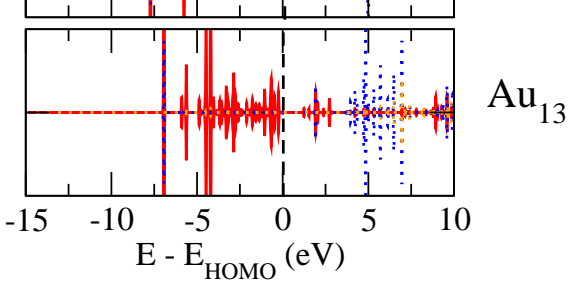

Fonte: Autoria própria.

preferência por sítios bridge, enquanto o sítio top foi obtido somente para uma única configuração. A preferência por sítios de maior coordenação pode estar relacionada à distribuição espacial da densidade de carga na região próxima ao átomo de oxigênio, em particular, à distribuição espacial da densidade do carga dos estados HOMO e dos pares de Lewis.

\section{Energia de adsorção}

A energia de adsorção é uma propriedade energética que determina a magnitude da interação, no caso, entre a molécula que está sendo adsorvida e o adsorvente, clusters 
$\mathrm{MT}_{13}$. A enegia de adsorção $\left(E_{a d}\right)$ é calculada por

$$
E_{a d}=E_{t o t}^{\text {molécula } / \mathrm{MT}_{13}}-\left(E_{\text {tot }}^{\text {molécula }}+E_{\text {tot }}^{\mathrm{MT}_{13}}\right)
$$

em que $E_{\text {tot }}^{\text {molécula } / \mathrm{MT}_{13}}$ é a energia total do sistema adsorvido, e $E_{\text {tot }}^{\text {molécula }}$ e $E_{\text {tot }}^{\mathrm{MT}_{13}}$ são referentes às energias dos sistemas isolados, da molécula e do clusters, respectivamente.

A tabela (4.1) apresenta os valores para a energia de adsorção de $\mathrm{OH} / \mathrm{MT}_{13}$, em que se pode observar uma variação energética entre $-4.11 \mathrm{eV}\left(\mathrm{OH} / \mathrm{Ni}_{13}\right)$ e $-2.94 \mathrm{eV}\left(\mathrm{OH} / \mathrm{Pd}_{13}\right)$, que classifica os processos como adsorções químicas. (75) Isso pode ser explicado dada a alta reatividade do radical hidroxila e a disponibilidade de elétrons encontrada nos clusters de metais de transição.

Nota-se que a diferença da energia de adsorção $\mathrm{OH} / \mathrm{MT}_{13}^{\mathrm{LOW}}$ e $\mathrm{OH} / \mathrm{MT}_{13}^{\mathrm{ICO}}$ varia entre $0.01 \mathrm{eV}\left(\mathrm{Ni}_{13}\right)$ e $0.25 \mathrm{eV}\left(\mathrm{Cu}_{13}\right)$. Isso pode ser explicado pelo fato de que as estruturas LOW já possuem um número de coordenação efetiva menor, mostrando estruturas mais abertas e que possuem uma maior flexibilidade para rearranjo da estrutura eletrônica, de acordo com a adsorção. Os clusters icosaédricos formados por treze átomos fazem parte do conjunto de clusters conhecidos como números mágicos, dada a alta estabilidade geométrica atribuída à esse número. Dessa forma, os clusters inicialmente icosaédricos tendem a apresentar energias de adsorção $\mathrm{OH} / \mathrm{MT}_{13}^{\mathrm{ICO}}$ menores. No caso da platina e do ouro, as energias relativas para os clusters ICO são muito altas, o que favoreceu a deformação da estrutura inicial. Os clusters adquiriram novas estruturas $\left(\mathrm{ICO}^{*}\right) \mathrm{com}$ energias relativas de $16.4 \mathrm{eV} /$ átomo para $\mathrm{Pt}_{13}{ }^{\mathrm{ICO} *}$ e $7.8 \mathrm{eV} /$ átomo para $\mathrm{Au}_{13}{ }^{\mathrm{ICO} *}$, menores que a energia relativa para as estruturas ICO, mas ainda maiores que a energia dos clusters $\mathrm{MT}_{13}^{\mathrm{LOW}}$.

Observa-se que há uma tendência para energia de adsorção, na ordem $-E_{a d}^{\mathrm{Ni}_{13}}>-E_{a d}^{\mathrm{Pd}_{13}}$ e $-E_{a d}^{\mathrm{Cu}_{13}}>-E_{a d}^{\mathrm{Ag}_{13}}$, porém $-E_{a d}^{\mathrm{Pd}_{13}}<-E_{a d}^{\mathrm{Pt}_{13}}$ e $-E_{a d}^{\mathrm{Ag}_{13}}<-E_{a d}^{\mathrm{Au}_{13}}$, em que o desvio do comportamento linear para a energia de adsorção de $\mathrm{OH}$ sobre platina e ouro pode estar associada à potencialização da atividade catalítica desses sistemas na escala em questão. Ao se comparar elementos da mesma série, nota-se que $-E_{a d}^{\mathrm{Ni}_{13}}>-E_{a d}^{\mathrm{Cu}_{13}}$ e $-E_{a d}^{\mathrm{Pt}_{13}}>-E_{a d}^{\mathrm{Au}_{13}}$, enquanto $-E_{a d}^{\mathrm{Pd}_{13}}<-E_{a d}^{\mathrm{Ag}_{13}}$, apontando para a relevância do elemento.

Por fim, ressalta-se a exceção vista para $\mathrm{OH} / \mathrm{Au}$, em que as configurações iniciais ICO e 3D se distorcem para a mesma estrutura de cluster, fazendo com que tenham a mesma energia de adsorção. Por outro lado, a configuração inicial 2D do ouro perde sua planaridade e, ao se otimizar a estrutura distorcida, obtém-se a mesma conformação final apresentada por $\mathrm{Au}^{\mathrm{ICO} *}$ e $\mathrm{Au}^{3 \mathrm{D} *}$. Assim, a energia de adsorção desses sistemas é tão próxima. Em um primeiro momento, considera-se o aumento de $7.8 \mathrm{eV}$ e $7.5 \mathrm{eV}$ para os clusters 2D e 3D, respectivamente. Porém, é possível identificar que os mínimos locais para a superfície de energia potencial do cluster $\mathrm{Au}_{13}$ são muito próximos, e que a estrutura final obtida após adsorção da hidroxila é a mais favorável. 


\section{Parâmetros estruturais}

Existe um grande número de comprimentos de ligações e ângulos que poderiam ser analisados para entender os efeitos da adsorção de $\mathrm{OH}$ sobre os clusters, entretanto, este procedimento não é o mais eficiente. Neste trabalho, são utilizados três parâmetros estruturais, os quais contêm todos os efeitos envolvidos: $(i)$ a variação do número de coordenação efetiva dos clusters; $(i i)$ a variação dos comprimentos de ligação ponderados dos clusters; e (iii) a distância de ligação entre o átomo ligante e o cluster.

Os parâmetros estruturais encontrados para avaliar a adsorção de $\mathrm{OH} / \mathrm{MT}_{13}$ estão disponíveis na tabela (4.1). Nessas análises, são utilizados os conceitos de número de coordenação efetiva e comprimento de ligação ponderado, além da distância entre o átomo de oxigênio, o qual se liga à estrutura, e o cluster $\left(d_{\mathrm{O}-\mathrm{TM}}\right)$. Pode-se calcular a variação estrutural do cluster utilizando a variação de número de coordenação efetiva ( $\triangle \mathrm{NCE}$ ) e do comprimento de ligação ponderado $\left(\Delta d_{a v}\right)$ após a adsorção. Para ambas as propriedades mencionadas, foi calculado

$$
\Delta X=\frac{\left(X^{D}-X^{A}\right) \times 100 \%}{X^{A}}
$$

onde $X$ é NCE ou $d_{a v}$, e $X^{A}$ e $X^{D}$ se referem aos valores da propriedade antes (sistema isolado) e depois da adoção.

Observa-se que, para os clusters $3 d$ de $4 d$, são apresentadas as variações $\Delta d_{a v}<|1| \%$, de forma que os comprimentos de ligação entre os átomos não variaram significativamente; e, também, que as variações de NCE foram entre $-0.04 \%$ e $-4.33 \%$, mostrando a preferência de estruturas mais abertas. Já $\Delta d_{a v}$ e $\Delta$ NCE para os clusters de platina e ouro definem mudanças drásticas nas geometrias iniciais, com ênfase nos configurações icosaédricas que perdem completamente sua forma, tornando-se estruturas mais abertas com menores números de coordenação efetiva e menores comprimentos de ligação ponderada. $\mathrm{O}$ único cluster que aumentou sua coordenação foi o $\mathrm{Au}_{13}{ }^{2 \mathrm{D}}$, e perdeu seu aspecto planar. Logo, os comprimentos de ligação que ocorrem entre o átomo de oxigênio e os clusters $\mathrm{MT}_{13}$ são inversamente proporcionais às energias de adsorção, de forma que quanto mais próxima a molécula estiver do cluster (menor $d_{\mathrm{O}-\mathrm{TM}}$ ), maior será a sobreposição dos orbitais da molécula com os orbitais do clusters e, consequentemente, maior será a energia de adsorção.

\section{Parâmetros eletrônicos}

Para compreender a estrutura eletrônica dos sistemas de adsorção $\mathrm{OH} / \mathrm{MT}_{13}$ foram feitos cálculos da densidade dos estados para a projeção $s$ e $p$ para o oxigênio e o hidrogênio, como mostra a figura (4.4), em que o HOMO foi definido no zero de energia. A parte superior da figura mostra as projeções para a molécula isolada. A ligação $\mathrm{O}-\mathrm{H}$ ocorre 
através do orbital $1 s$ do hidrogênio com um orbital $p$ do oxigênio, visto sua completa sobreposição nas energias mais baixas. Após os processos de adsorção, é possível observar que o orbital HOMO não é mais definido pelo orbital O- $p$ e que em todos os casos de $\mathrm{OH} / \mathrm{MT}_{13}$ houve uma hibridização dos orbitais $\mathrm{O}-p$ com os metais, visto através dos novos desdobramentos.

Nota-se que os clusters que já possuíam baixa simetria antes da adsorção $\left(\mathrm{MT}_{13}^{\mathrm{LOW}}\right)$ facilitam o processo de relaxação, os quais proporcionam um rearranjo da estrutura eletrônica maior, em que os orbitais O- $p$ sofrem maiores hibridizações quando comparadas às modificações ocorridas para as estruturas icosaédricas. Essas modificações possuem um papel chave no processo de adsorção, uma vez que permitem o desdobramento dos estados $\mathrm{H}-s$, os quais se aproximam do HOMO e, também, fazem com que ocorra um deslocamento dos estados que determinam a ligação O-H. Pode-se observar que quanto maior o deslocamento do orbital $\sigma_{\mathrm{O}-\mathrm{H}}$ quando comparado ao PDOS da molécula em fase gasosa, maior a energia de adsorção do sistema.

Também foi realizada a análise das cargas relativas de Mulliken, como mostra a tabela (4.1). São apresentadas as cargas dos átomos de hidrogênio e oxigênio na hidroxila isolada e após o processo de adsorção. A carga relativa para o $i$-ésimo átomo em um sistema é dada por

$$
\Delta Q(i)=Z^{i}-q^{i}
$$

onde $q^{i}$ é a carga eletrônica total sobre o átomo $i$ e $Z^{i}$ é seu número atômico. Assim, quando $\Delta Q(i)<0$ o átomo recebeu carga, caso contrário, doou.

Os resultados apontam para uma transferência de carga proveniente do hidrogênio para o oxigênio na hidroxila isolada, dada pela diferença de eletronegatividade que existe entre os elementos $(\mathrm{H}=2.20$ e $\mathrm{O}=3.44)$. (56) E, ao se analisar as cargas de $\mathrm{H}$ e $\mathrm{O}$ após a adsorção, nota-se que a quantidade doada pelo hidrogênio tende a diminuir a transferência para todos os casos, com exceção do $\mathrm{OH} / \mathrm{Ni}_{13}{ }^{\mathrm{ICO}}$, o qual é o único sistema que apresenta baixa hibridização dos orbitais O- $p$. Ressalta-se que a quantidade de carga recebida pelo oxigênio é maior do que a doada pelo hidrogênio em todos os casos, de forma que o oxigênio recebe carga eletrônica proveniente do cluster. Observa-se que a maior carga relativa sobre o $\mathrm{O}$ ocorre quando $\mathrm{OH} / \mathrm{Ag}_{13}{ }^{\mathrm{ICO}}$, em que a hidroxila se encontra no sítio hollow e o oxigênio apresenta uma alta hibridização dos seus estados $p$.

\section{Frequências vibracionais}

Todos os sistemas $\mathrm{OH} / \mathrm{MT}_{13}$ apresentaram frequências de vibração positivas para os $3 N-6$ modos vibracionais, de modo que as configurações da figura (4.3) são mínimos locais. Para se analisar as modificações ocorridas na molécula, observa-se que $\nu_{\mathrm{O}-\mathrm{H}}$ aumenta após a adsorção (blue shift), em que a intensidade do deslocamento de frequência está diretamente relacionado com a carga relativa sobre os átomos oxigênio e hidrogênio. Observa-se que 
quanto maior a carga sobre o átomo O, maior será o deslocamento. Porém, para sistemas que apontam para a mesma carga no oxigênio, como o caso de $\mathrm{OH} / \mathrm{Ni}_{13}{ }^{\mathrm{LOW}}$ e OH$/ \mathrm{Cu}_{13}{ }^{\mathrm{ICO}}$, em que ambos têm o sítio bridge de adsorção preferencial, nota-se que a intensidade de $\nu_{\mathrm{O}-\mathrm{H}}$ é maior quando o cluster possui uma maior transferência de carga para a molécula.

\subsection{Adsorção de água sobre $\mathrm{MT}_{13}$}

A fim de se avaliar os parâmetros envolvidos na adsorção de água sobre clusters de metais de transição contendo treze átomos, esta seção é separada em: (i) sítios de adsorção; (ii) energia de adsorção; (iii) parâmetros estruturais; $(i v)$ densidade de estados; $(v)$ diferença de densidade e transferência de carga; e (vi) correções de van der Waals.

\section{Sítios de adsorção}

Pode-se acompanhar a evolução das configurações água/ $\mathrm{MT}_{13}$ de acordo com as figuras (4.5) e (4.6), em que se identificam as configurações de adsorção de menor energia, que possuem como estruturas iniciais os clusters ICO e LOW, respectivamente. Nota-se que água se liga próxima ao topo de um único átomo, sendo que a interação com os clusters ocorre, via oxigênio. Para os clusters ICO é possível se calcular o ângulo $\mathrm{MT}^{c} \mathrm{MT}^{s} \mathrm{O}$, em que $\mathrm{MT}^{c}$ é o átomo central e $\mathrm{MT}^{s}$ é o átomo da superfície do icosaedro. Caso o oxigênio estivesse exatamento sobre o átomo, seria encontrado um ângulo de $180^{\circ}$, entretanto, os resultados apontam que, para as estruturas que se mantiveram icosaédricas, $\mathrm{Ni}_{13}{ }^{\mathrm{ICO}}$, $\mathrm{Cu}_{13}{ }^{\mathrm{ICO}}, \mathrm{Pd}_{13}{ }^{\mathrm{ICO}}$ e $\mathrm{Ag}_{13}{ }^{\mathrm{ICO}}$, o átomo de oxigênio apresentou desvios de $11^{\circ}, 6^{\circ}, 18^{\circ}$ e $14^{\circ}$, respectivamente. Além dos clusters de menor energia, com baixa simetria, os clusters inicialmente ICO de platina e ouro sofreram deformações que impossibilitaram a realização uma análise quantitativa dos desvios que a molécula de água apresenta sobre o sítio de adsorção. Entretanto, uma análise visual aponta para a localização da água sobre um único átomo do cluster.

Diferente das análises geométricas em relação às superfícies MT(111), que possuem um plano através do qual é possível inferir a variação dos ângulos de rotação e inclinação da molécula, $(20,30)$ os clusters não apresentam uma região específica que possa ser utilizada como parâmetro quantitativo para identificar o posicionamento da molécula. Entretando, é possível observar uma posição em relação ao átomo com a molécula se liga e, assim, vê-se que molécula se encontra aproximadamente paralela a este, em que os átomos de hidrogênio não se distanciam do cluster. Fazendo uma extrapolação das ideias que Michaelides e colaboradores (20) desenvolveram para adsorção de água sobre superfícies de metais nobres, é possível relacionar esse paralelismo aproximado da molécula de água em relação ao cluster à predominância das interações covalentes comparadas às eletrostáticas. Detalhes sobre o processo de transferência de carga são encontrados adiante. 
Figura 4.5 - Configurações de mais baixa energia para água/ $\mathrm{MT}_{13}^{\mathrm{ICO}}$ e etanol $/ \mathrm{MT}_{13}^{\mathrm{ICO}}$. Os comprimentos de ligação O-MT e H-MT estão em $\AA$, e os números subscritos às estruturas ligadas através do hidrogênio mostram a diferença de energia em relação às estruturas ligadas através do oxigênio $\left(\Delta E_{t o t}, \mathrm{em} \mathrm{meV} /\right.$ átomo).
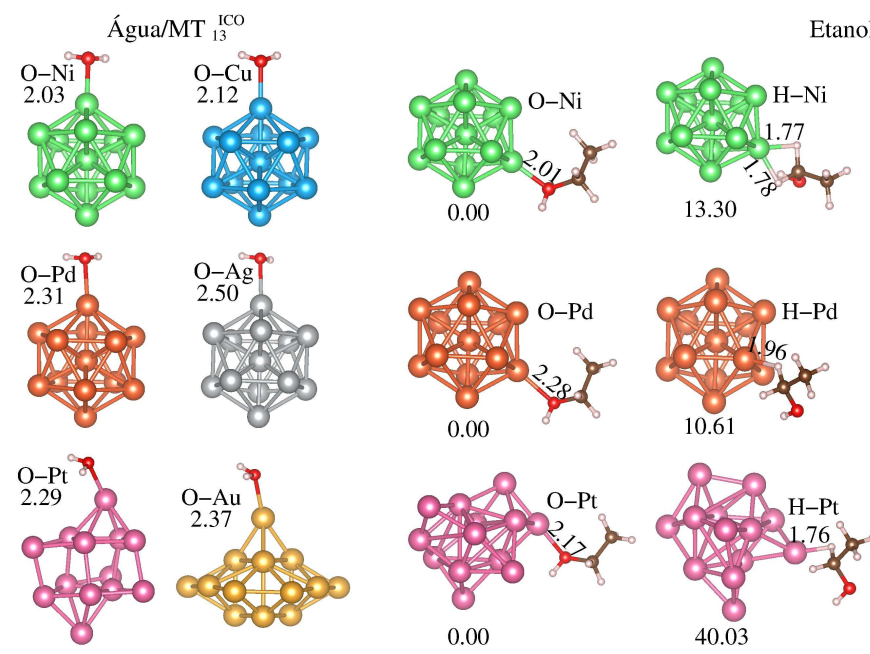

Etanol/MT ICO $_{13}$
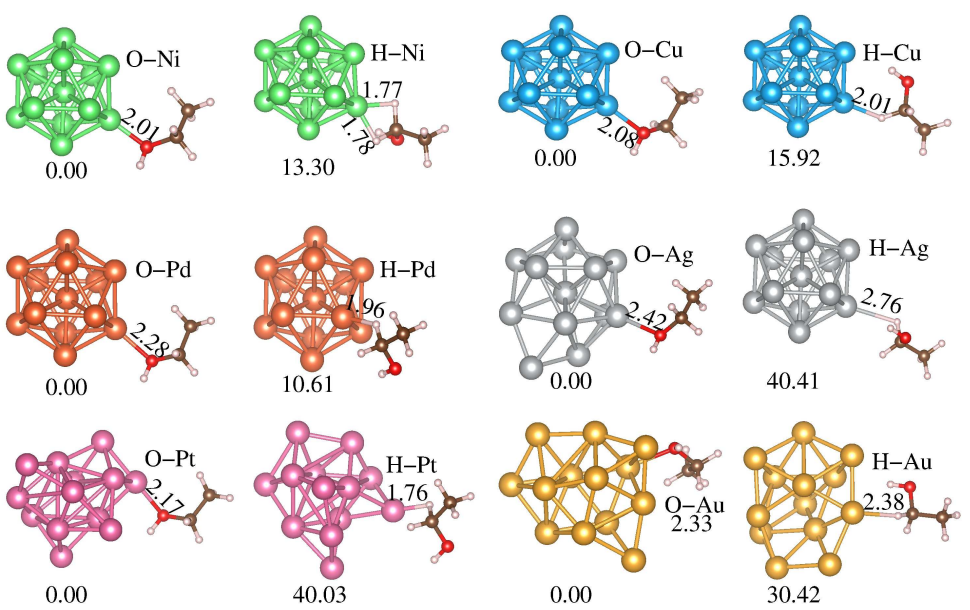

Fonte: Autoria própria.

\section{Energia de adsorção}

Do mesmo modo que a energia de adsorção foi calculada para $\mathrm{OH} / \mathrm{MT}_{13}$, foram obtidos os parâmetros relacionados à magnitude da interação da molécula de água com os clusters. Os resultados obtidos para as energias de adsorção $\mathrm{H}_{2} \mathrm{O} / \mathrm{MT}_{13}$ podem ser encontrados na tabela (4.2). A fim de se fazer um parelalo de ideias entre os processos de adsorção de água sobre superfícies compactas de metais de transição e clusters $\mathrm{MT}_{13}$, foram utilizados resultados prévios acerca da adsorção de moléculas sobre superfícies compactas. (30)

Observa-se, também, que as energias de adsorção obtidas através de DFT-PBE para a água sobre superfícies MT(111) apresentam uma tendência, a qual obedece à ordem $-E_{a d}^{3 d}>-E_{a d}^{4 d}>-E_{a d}^{5 d}$. Por outro lado, a adsorção de água sobre os clusters apresenta uma ordem energética divergente, de modo que $-E_{a d}^{3 d}>-E_{a d}^{4 d}$, porém $-E_{a d}^{4 d}<-E_{a d}^{5 d}$, ou seja, $\mathrm{Pt}_{13}$ e $\mathrm{Au}_{13}$ fogem à tendência, o que pode estar atrelado às propriedades que se modificam nesses metais e são regidas por efeitos de tamanho, aumentando o poder catalítico de ambos.

Os valores apresentados para a adsorção sobre MT(111) e sobre $\mathrm{MT}_{13}$ apontam para uma interação mais forte da molécula de água sobre os metais com orbitais $d$ semipreenchidos, os quais proporcionam um rearranjo da densidade eletrônica que corrobora para um aumento na energia de adsorção. Ressalta-se que a magnitude da interação de água com $\mathrm{MT}_{13}$ é muito maior quando comparada à sua interação com MT(111), em que se destaca o caso do ouro devido à baixa coordenação dos átomos que constituem o cluster $(\mathrm{NCE}=3.80)$. 
Figura 4.6 - Configurações de mais baixa energia para água/ $\mathrm{MT}_{13}^{L O W}$ e etanol $/ \mathrm{MT}_{13}^{L O W}$. Os comprimentos de ligação O-MT e H-MT estão em A, e os números subscritos às estruturas ligadas através do hidrogênio mostram a diferença de energia em relação às estruturas ligadas através do oxigênio $\left(\Delta E_{t o t}\right.$, em meV/átomo).
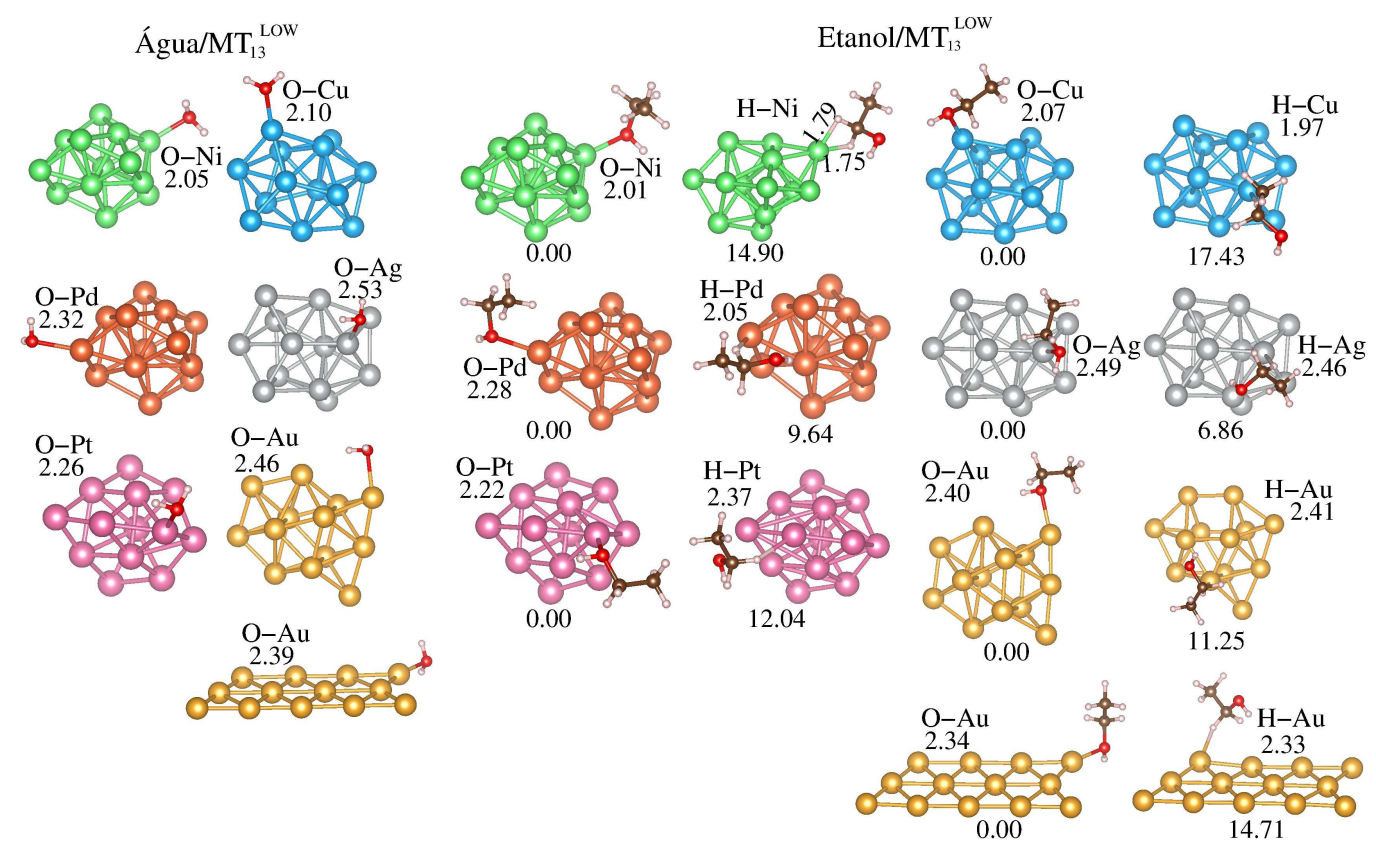

Fonte: Autoria própria.

\section{Parâmetros estruturais}

Utilizando dos mesmos parâmetros que foram aplicados à análise de $\mathrm{OH} / \mathrm{MT}_{13}$, foram calculadas as variações de NCE e $d_{a v}$ dos clusters, bem como a distância O-MT. Para a adsorção de água sobre os clusters $\mathrm{MT}_{13}$ ocorreram variações entre $-0.01 \%<\Delta \mathrm{NCE}<$ $0.04 \%$ e $0.00 \%<\Delta d_{a v}<0.01 \%$ para os clusters $3 d$ e $4 d$ e $5 d^{\mathrm{LOW}}$. Essa pequenas variações apontam para a baixa interação que ocorre entre a água e os clusters. Por outro lado, na figura (4.5) é possível visualizar as deformações ocorridas nos clusters ICO de platina e ouro. Ambos os $\mathrm{MT}_{13}^{\mathrm{ICO}}$ tiveram mudanças estruturais envolvendo uma variação de $\mathrm{NCE}$ de $-33.0 \%$ e $-23.3 \%$, e uma variação de $d_{a v}$ de $-4.8 \%$ e $-3.6 \%$, respectivamente para platina e ouro.

Em relação aos comprimentos de ligação do oxigênio com os clusters têm-se, como esperado, que quanto menor $d_{\mathrm{O}-\mathrm{MT}}$, mais próxima estará a molécula dos clusters, e maior será a energia de adsorção. Ademais, a distância molécula-cluster aumenta com a ocupação dos estados $d$, por exemplo, $d_{\mathrm{O}-\mathrm{MT}}^{\mathrm{Ni}_{13} \mathrm{ICO}}<d_{\mathrm{O}-\mathrm{MT}}^{\mathrm{Cu}_{13}{ }_{\mathrm{ICO}}}$, e a mesma tendência é encontrada ao se comparar os demais clusters, como mostra a tabela (4.2).

\section{Densidade de estados}

As figuras (4.7) e (4.8) apresentam, respectivamente, o cálculos da densidade de estados para as projeções dos estados $s$ e $p$ para os átomos da água isolada (parte superior) e após 
Tabela 4.2 - Energia de adsorção $\left(E_{a d}\right.$, em meV) e comprimentos de ligação O-MT $\left(d_{\mathrm{O}-\mathrm{MT}}\right.$, em $\left.\AA\right)$ de água e etanol sobre as configurações icosaédricas* e de mais baixa energia dos clusters de metais de transição, calculados através de PBE-DFT e DFT com correções de van der Waals. Os resultados para superfícies de alto empacotamento foram retirados da literatura**.

\begin{tabular}{|c|c|c|c|c|c|c|c|c|}
\hline & \multicolumn{4}{|c|}{$\mathrm{H}_{2} \mathrm{O} / \mathrm{MT}_{13}$} & \multicolumn{4}{|c|}{$\mathrm{C}_{2} \mathrm{H}_{5} \mathrm{OH} / \mathrm{MT}_{13}$} \\
\hline & $E_{a d}$ & $E_{a d}^{+ \text {vdw }}$ & $d_{\mathrm{O}-\mathrm{MT}}$ & $d_{\mathrm{O}-\mathrm{MT}}^{+\mathrm{vdW}}$ & $E_{a d}$ & $E_{a d}^{+\mathrm{vdw}}$ & $d_{\mathrm{O}-\mathrm{MT}}$ & $d_{\mathrm{O}-\mathrm{MT}}^{+\mathrm{vdW}}$ \\
\hline $\mathrm{Ni}_{13}{ }^{\mathrm{ICO}}$ & -670 & -770 & 2.03 & 2.02 & -761 & -1008 & 2.01 & 2.00 \\
\hline $\mathrm{Ni}_{13}$ LOW & -627 & -731 & 2.05 & 2.05 & -717 & -985 & 2.01 & 2.00 \\
\hline $\mathrm{Ni}(111)$ & -285 & & 2.18 & & -290 & & 2.14 & \\
\hline $\mathrm{Cu}_{13}{ }^{\mathrm{ICO}}$ & -449 & -525 & 2.12 & 2.10 & -526 & -723 & 2.08 & 2.07 \\
\hline $\mathrm{Cu}_{13}$ LOW & -461 & -513 & 2.10 & 2.07 & -546 & -721 & 2.07 & 2.07 \\
\hline $\mathrm{Cu}(111)$ & -175 & & 2.37 & & -174 & & 2.32 & \\
\hline $\mathrm{Pd}_{13}$ ICO & -404 & -462 & 2.31 & 2.32 & -471 & -601 & 2.28 & 2.27 \\
\hline $\mathrm{Pd}_{13}$ LOW & -410 & -445 & 2.32 & 2.32 & -487 & -596 & 2.28 & 2.28 \\
\hline $\operatorname{Pd}(111)$ & -254 & & 2.41 & & -266 & & 2.39 & \\
\hline $\mathrm{Ag}_{13} \mathrm{ICO}$ & -255 & -300 & 2.50 & 2.51 & $-387^{*}$ & $-500^{*}$ & $2.42^{*}$ & $2.47^{*}$ \\
\hline $\mathrm{Ag}_{13} \mathrm{LOW}$ & -270 & -349 & 2.53 & 2.56 & -317 & -515 & 2.49 & 2.49 \\
\hline $\operatorname{Ag}(111)$ & -138 & & 2.69 & & -136 & & 2.69 & \\
\hline $\mathrm{Pt}_{13} \mathrm{ICO}$ & $-535^{*}$ & $-598^{*}$ & $2.29^{*}$ & $2.30^{*}$ & $-837^{*}$ & $-999^{*}$ & $2.17^{*}$ & $2.18^{*}$ \\
\hline $\mathrm{Pt}_{13}$ LOW & -576 & -624 & 2.26 & 2.26 & -695 & -840 & 2.22 & 2.22 \\
\hline $\operatorname{Pt}(111)$ & -215 & & 2.47 & & -237 & & 2.39 & \\
\hline $\mathrm{Au}_{13}{ }^{\mathrm{ICO}}$ & $-470^{*}$ & $-490^{*}$ & $2.37^{*}$ & $2.37^{*}$ & $-322^{*}$ & $-513^{*}$ & $2.33^{*}$ & $2.31^{*}$ \\
\hline $\mathrm{Au}_{13}$ LOW3D & -333 & -374 & 2.46 & 2.46 & -390 & -498 & 2.40 & 2.39 \\
\hline $\mathrm{Au}_{13}{ }^{\mathrm{LOW} 2 \mathrm{D}}$ & -392 & -411 & 2.39 & 2.40 & -471 & -544 & 2.34 & 2.35 \\
\hline $\mathrm{Au}(111)$ & -109 & & 2.82 & & -115 & & 2.77 & \\
\hline
\end{tabular}

*As configurações marcadas com asterisco indicam os clusters icosaédricos que sofreram deformações após o processo de adsorção.

${ }^{* *}$ Referência (30).

adsorção sobre as estruturas $\mathrm{MT}_{13}{ }^{\mathrm{ICO}}$ e $\mathrm{MT}_{13}{ }^{\mathrm{LOW}}$ (parte inferior).

De acordo com as projeções apresentadas, observa-se inicialmente que os principais estados da água são provenientes de H- $s$ e O- $p$, em que a sobreposição desses estados define a ligação O-H. O HOMO na molécula isolada é definido pelo orbital O- $p$ não-ligante. No átomo de hidrogênio livre não se tem o orbital $p$, contudo, pode acontecer uma população no estado H- $p$ devido à hibridização dos estados eletrônicos após a adsorção, por isso, esses estados também são vistos nas figuras mencionadas.

Observa-se que após a interação da molécula de água com os clusters houve desdobramentos dos estados H- $s$ e H-p, e é possível apontar a ocorrência de um deslocamento dos estados que descrevem a ligação O-H em relação ao HOMO. Entretanto, os deslocamentos ocorridos são muito próximos, de forma que apenas essa análise não é suficiente para diferenciar a magnitude das interações. Para isso, foram utilizadas análises de diferença de densidade e cargas relativas sobre os átomos $\mathrm{O}$ e $\mathrm{H}$. 
Figura 4.7 - Densidade de estados para os orbitais moleculares. Moléculas em fase gasosa e após adsorção molécula/ $\mathrm{MT}_{13}^{\mathrm{ICO}}$.

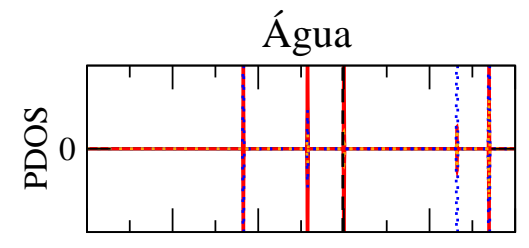

Água/MT ${ }_{13}$ ICO
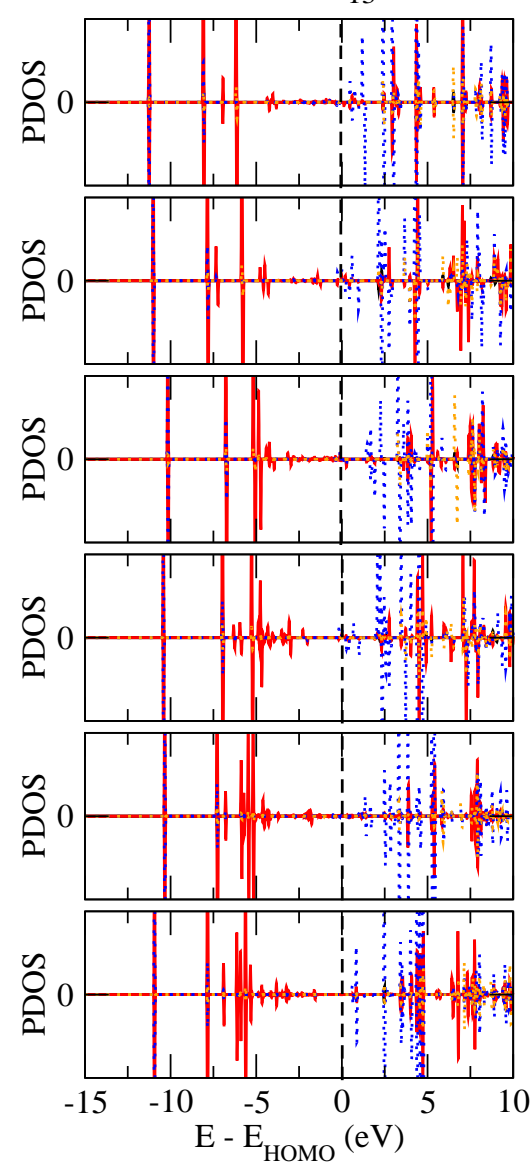

Etanol

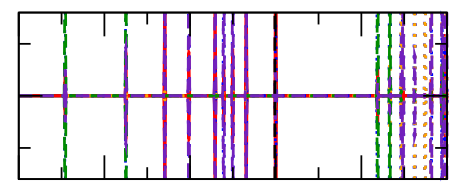

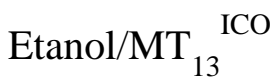
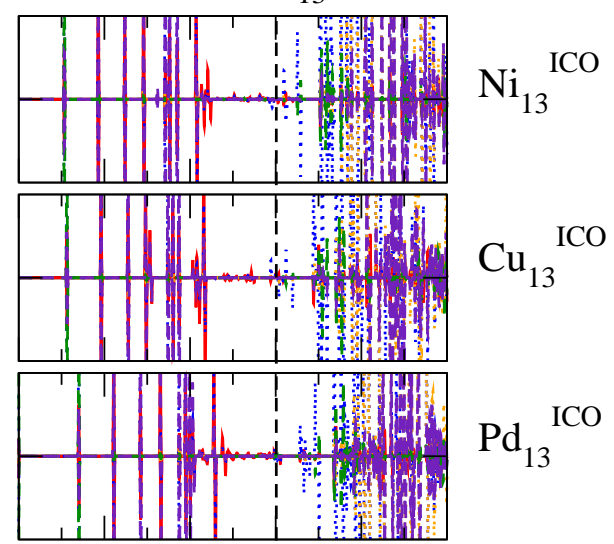

$\mathrm{Pd}_{13}{ }^{\mathrm{ICO}}$

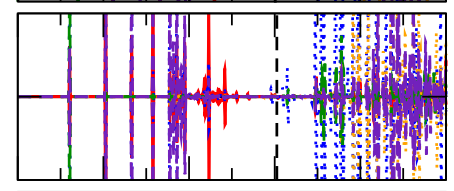

$\operatorname{Ag}_{13}{ }^{I C O}$

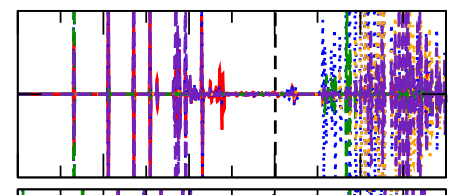

$\mathrm{Pt}_{13}{ }^{\mathrm{ICO}}$

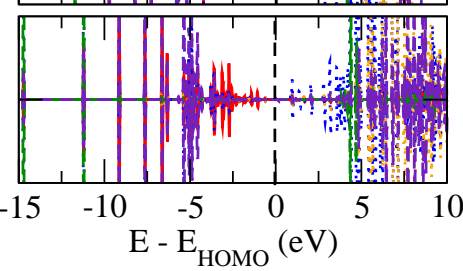

$\mathrm{Au}_{13}{ }^{\mathrm{ICO}}$

Fonte: Autoria própria.

\section{Diferença de densidade e análise de Mulliken}

Para se identificar os orbitais envolvidos no processo de adsorção, bem como ocorreu o rearranjo da densidade eletrônica sobre os sistemas e as tranferências de carga envolvidas, foram utilizadas as análises de diferença de densidade e as cargas relativas de Mulliken.

A diferença de densidade $\left(\rho^{\text {diff }}\right)$ é um cálculo que utiliza a diferença de densidade eletrônica entre o sistema adsorvido $\left(\rho^{\text {molécula/MT }} \mathrm{MT}_{13}\right)$ e os entes que o forma (molécula, $\rho^{\text {molécula }}$, e cluster, $\rho^{\mathrm{MT}_{13}}$ ), dada por

$$
\rho^{\text {diff }}=\rho^{\text {molécula } / \mathrm{MT}_{13}}-\left(\rho^{\text {molécula }}+\rho^{\mathrm{MT}_{13}}\right) .
$$


Figura 4.8 - Densidade de estados para os orbitais moleculares. Moléculas em fase gasosa e após adsorção molécula/MT $\mathrm{MTW}_{13}^{\mathrm{LOW}}$.
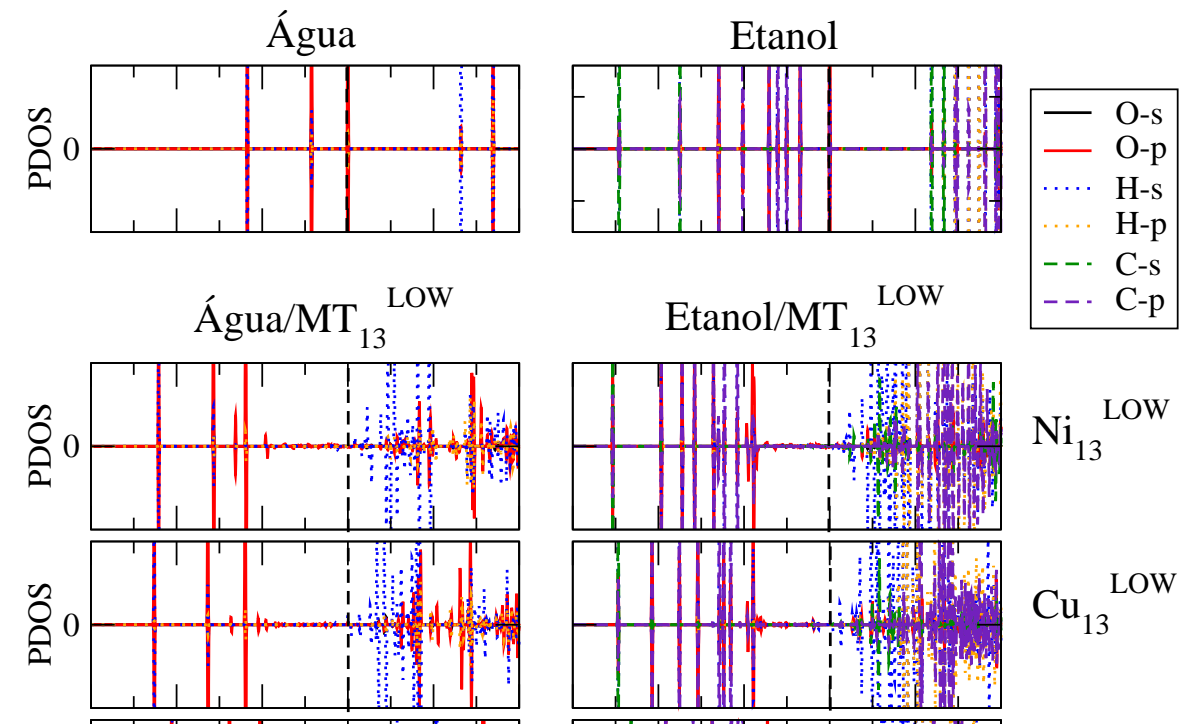

$$
\mathrm{Ni}_{13}{ }^{\text {LOW }}
$$

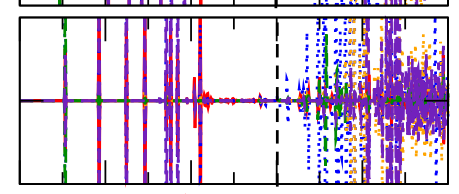

$$
\mathrm{Cu}_{13}^{\text {LOW }}
$$
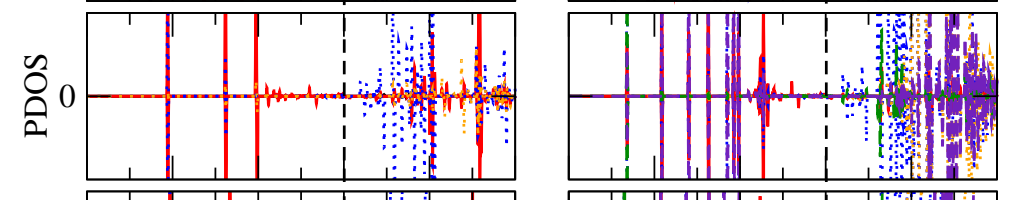

$$
\operatorname{Pd}_{13}^{\text {LOW }}
$$
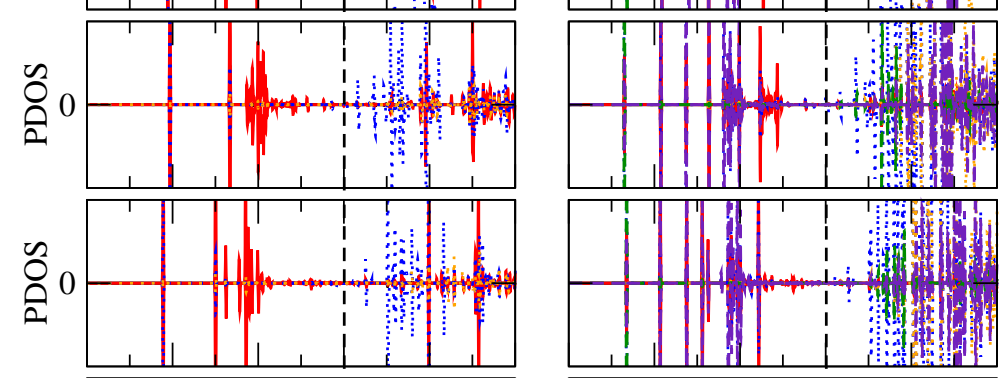

$\operatorname{Ag}_{13}$ LOW

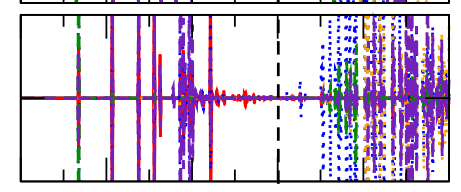

$\mathrm{Pt}_{13}^{\text {LOW }}$
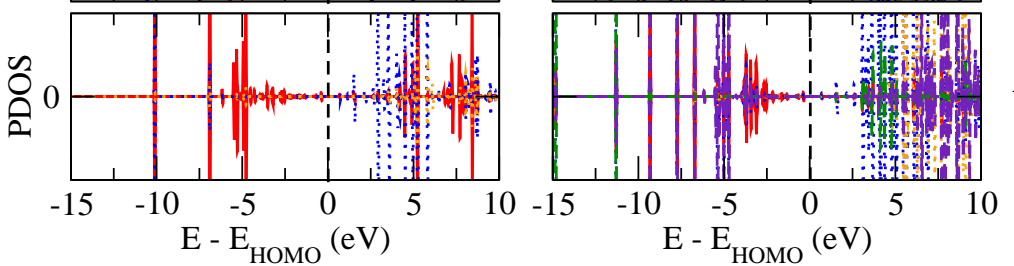

$\mathrm{Au}_{13}^{2 \mathrm{D}}$

Fonte: Autoria própria.

As figuras (4.9) e (4.10) apresentam as diferenças de densidade para a água sobre os clusters ICO e LOW, respectivamente. As regiões em azul mostram onde houve um aumento de densidade, e as regiões em lilás mostram os locais em que ocorreu um decréscimo de densidade eletrônica. Nas figuras, é visível a interação dos orbitais $d_{z^{2}}$ dos metais com o orbital HOMO da água. Em todos os casos, nota-se um aumento da densidade exatamente sobre o átomo de oxigênio, enquanto suas vizinhanças apresentam uma perda de carga. Ressalta-se a redistribuição da densidade eletrônica sobre os clusters de metais de transição com orbitais $d$ semi-preenchidos, que está de acordo com a maior energia de adsorção sobre os mesmos.

A relação das cargas relativas de Mulliken são apresentadas para os átomos $\mathrm{O}$ e H na tabela (4.3). Nota-se que para todos os sistemas adsorvidos há uma quantidade menor de 
Figura 4.9 - Diferença de densidade eletrônica para água e etanol sobre $\mathrm{MT}_{13}^{\mathrm{ICO}}$.

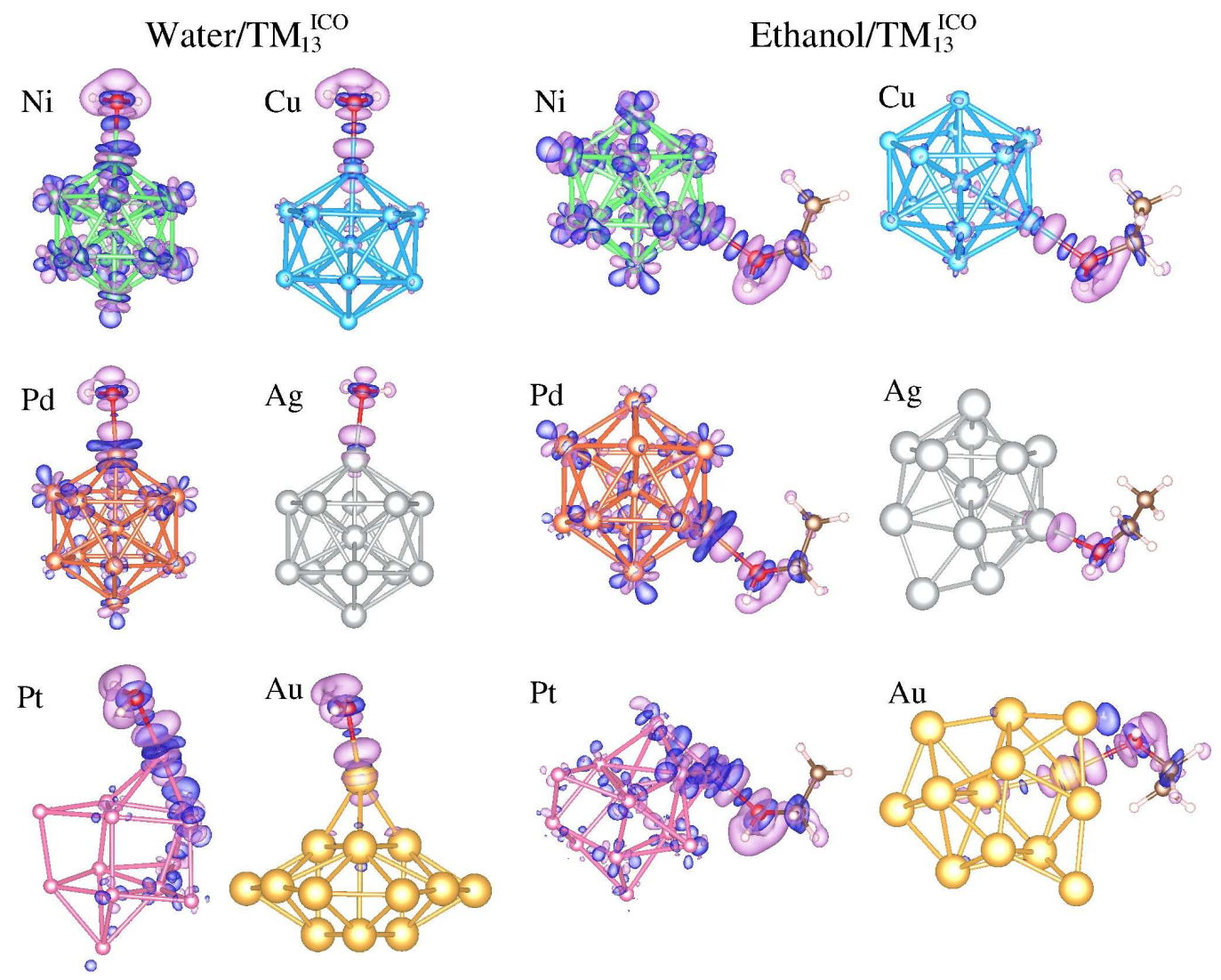

Fonte: Autoria própria.

carga sobre o oxigênio que a doada pelos hidrogênios, de forma que há uma transferência de carga da molécula para os clusters. A quantidade de carga transferida ocorre na ordem de $0.1 e$, com exceção para $\mathrm{H}_{2} \mathrm{O} / \mathrm{Ag}_{13}$, em que as quantidades são de 0.037 e e 0.046 e para ICO e LOW, condizente com a baixa interação e menor energia de adsorção. Estendendo as ideias de Michaelides e colaboradores (20) para o nível de clusters, é possível verificar que a água atua como doadora de elétrons para o substrato, favorecendo a adsorção nos sítios top.

\section{Análise vibracional}

Através das frequências de vibração características da água é possível identificar variações energéticas entre as ligações $\mathrm{O}-\mathrm{H}$ ao se considerar os deslocamentos nas frequências após adsorção. Na tabela (4.4) são identificados os modos de vibração simétrico $\left(\nu_{\mathrm{s}}\right)$, assimétrico $\left(\nu_{\mathrm{as}}\right)$ e de torção $\left(\delta_{\mathrm{HOH}}\right)$ para a água. Os resultados apontam para uma diminuição das frequências de vibração (red shift), que mostram um enfraquecimento das ligações $\mathrm{O}$ H. O deslocamento para frequências mais baixas condiz com o decréscimo de energia da molécula, seguindo o mesmo padrão que os comprimentos de ligação $d_{\mathrm{O}-\mathrm{MT}}$. 
Figura 4.10 - Diferença de densidade eletrônica para água e etanol sobre $\mathrm{MT}_{13}^{\mathrm{LOW}}$.
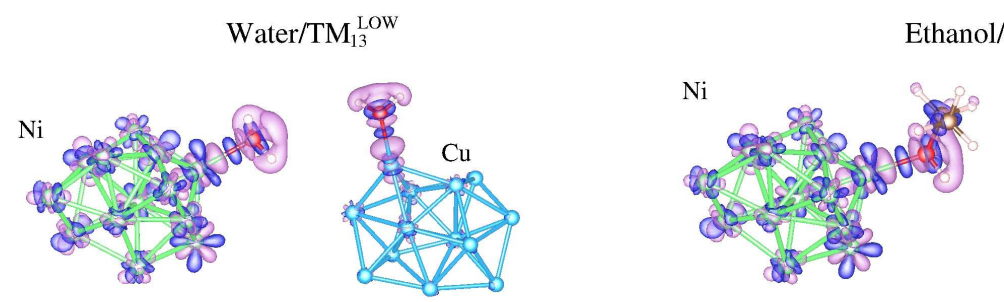
Ethanol/TM $\mathrm{TM}_{13}^{\mathrm{LOW}}$
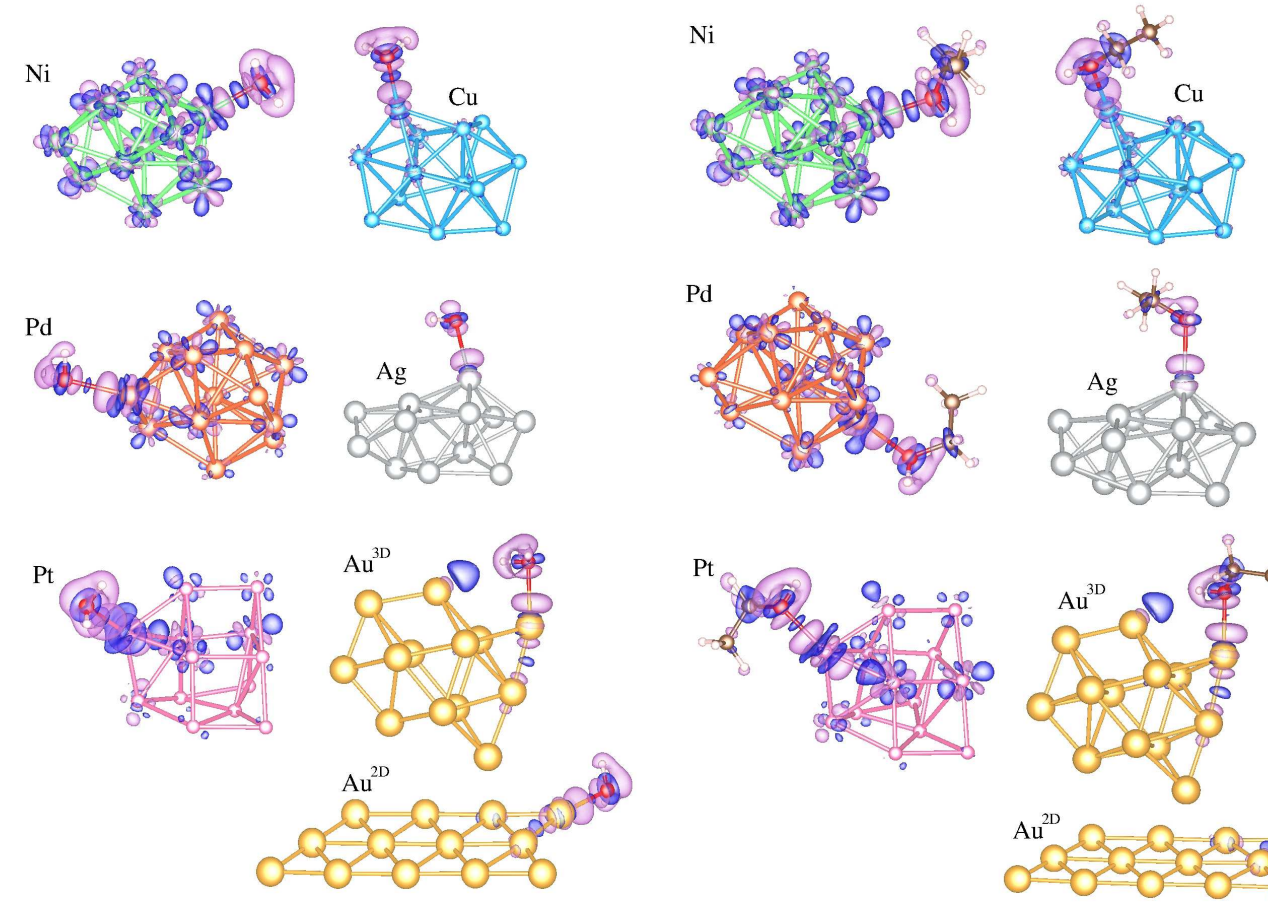

Fonte: Autoria própria.

\section{Correções de van der Waals}

Através das correções de vdW, como mostra a tabela (4.2), observa-se um aumento da energia de adsorção que varia de $4.3 \%$ a $16.6 \%$ para a maioria dos clusters. No entanto, o aumento na energia de adsorção sobre os clusters de Ag foram de $17.6 \%$ (ICO) e $29.3 \%$ (LOW). Assim, é possível observar que a maior diferença ocorreu para o sistema com menor energia de adsorção. Por outro lado, não é possível identificar uma dependência entre o elemento constituinte do cluster e o fator de aumento gerado pela correção de vdW.

\subsection{Adsorção de etanol sobre $\mathrm{MT}_{13}$}

A análise para adsorção de etanol sobre $\mathrm{MT}_{13}$ é feita de forma análoga à análise para adsorção de água. Nessa seção é possível encontrar os sítios de adsorção para o etanol, bem como sua energia de adsorção sobre os clusters. São apresentados os parâmetros estruturais, a densidade de estados, a diferença de densidade e análise de Mulliken, além das frequências vibracionais e correção de van der Waals.

\section{Sítios de adsorção}

Ao se propor um sítio preferencial para adsorção do etanol é relevante notar que existem duas vias pelas quais esse processo pode ocorrer, uma é utilizando o grupo hidroxila, 
Tabela 4.3 - Cargas relativas de Mulliken $(\Delta Q$, em $e$ ), para os átomos $\mathrm{O}$ e $\mathrm{H}$ da água, e $\mathrm{C}, \mathrm{H}, \mathrm{O}$ do etanol.

\begin{tabular}{|c|c|c|c|c|c|c|c|}
\hline & \multicolumn{2}{|c|}{$\mathrm{H}_{2} \mathrm{O}$} & \multicolumn{5}{|c|}{$\mathrm{C}_{2} \mathrm{H}_{5} \mathrm{OH}$} \\
\hline & $\Delta Q(\mathrm{O})$ & $\Delta Q(\mathrm{H})$ & $\Delta Q\left(\mathrm{C}^{1}\right)$ & $\Delta Q\left(\mathrm{C}^{2}\right)$ & $\Delta Q(\mathrm{O})$ & $\Delta Q\left(\mathrm{H}^{\mathrm{O}}\right)$ & $\Delta Q\left(\mathrm{H}^{\mathrm{C}}\right)$ \\
\hline Molécula & -0.357 & 0.357 & 0.187 & 0.008 & -0.398 & 0.174 & 0.029 \\
\hline $\mathrm{Ni}_{13}{ }^{\mathrm{ICO}}$ & -0.193 & 0.261 & 0.164 & 0.045 & -0.303 & 0.130 & 0.021 \\
\hline $\mathrm{Ni}_{13}$ LOW & -0.183 & 0.277 & 0.181 & 0.042 & -0.288 & 0.144 & 0.012 \\
\hline $\mathrm{Cu}_{13}{ }^{\mathrm{ICO}}$ & -0.174 & 0.254 & 0.151 & 0.034 & -0.295 & 0.131 & 0.061 \\
\hline $\mathrm{Cu}_{13}$ LOW & -0.186 & 0.300 & 0.163 & 0.050 & -0.293 & 0.141 & 0.041 \\
\hline $\mathrm{Pd}_{13}$ ICO & -0.195 & 0.296 & 0.156 & 0.049 & -0.299 & 0.145 & 0.049 \\
\hline $\mathrm{Pd}_{13} \mathrm{LOW}$ & -0.190 & 0.304 & 0.175 & 0.039 & -0.301 & 0.155 & 0.046 \\
\hline $\mathrm{Ag}_{13} \mathrm{ICO}$ & -0.223 & 0.260 & 0.163 & 0.032 & -0.354 & 0.151 & 0.046 \\
\hline $\mathrm{Ag}_{13}$ LOW & -0.212 & 0.258 & 0.161 & 0.017 & -0.350 & 0.145 & 0.042 \\
\hline $\mathrm{Pt}_{13} \mathrm{ICO}$ & -0.151 & 0.288 & 0.158 & 0.016 & -0.243 & 0.128 & 0.114 \\
\hline $\mathrm{Pt}_{13}$ LOW & -0.130 & 0.282 & 0.147 & 0.038 & -0.263 & 0.147 & 0.088 \\
\hline $\mathrm{Au}_{13} \mathrm{ICO}$ & -0.189 & 0.322 & 0.148 & 0.028 & -0.288 & 0.125 & 0.104 \\
\hline $\mathrm{Au}_{13}$ LOW3D & -0.202 & 0.243 & 0.162 & 0.009 & -0.306 & 0.099 & 0.113 \\
\hline $\mathrm{Au}_{13}$ LOW2D & -0.188 & 0.302 & 0.165 & 0.024 & -0.309 & 0.162 & 0.109 \\
\hline
\end{tabular}

e a outra é pelos hidrogênios do grupo CH. De modo semelhante à água, para os clusters que se mantiveram icosaédricos é possível realizar uma análise quantitativa do desvio do átomo de oxigênio sobre o átomo ligante do cluster. As figuras (4.5) e (4.6) mostram a adsorção de $\mathrm{C}_{2} \mathrm{H}_{5} \mathrm{OH} / \mathrm{MT}_{13}$. O ângulo $\mathrm{MT}^{c} \mathrm{MT}^{s} \mathrm{O}$ calculado para etanol sobre $\mathrm{Ni}_{13}{ }^{\mathrm{ICO}}$, $\mathrm{Cu}_{13}{ }^{\mathrm{ICO}}$, e $\mathrm{Pd}_{13}{ }^{\mathrm{ICO}}$ apresenta desvios de $8^{\circ}, 6^{\circ}$ e $12^{\circ}$. Para os demais sistemas é possível, através de uma avaliação visual, apontar que também ocorrem através dos sítios top, preferencialmente via oxigênio. Entretanto, também é possível encontrar a molécula de etanol se ligando aos clusters via hidrogênio proveniente dos grupos $\mathrm{CH}$, com energias relativas na ordem de $k T$ (aproximadamente $25.67 \mathrm{meV}$ ), o que pode indicar um papel importante na quebra das ligações $\mathrm{C}-\mathrm{C}$, já que essas configurações são prováveis a temperatura ambiente.

\section{Energia de adsorção}

Os valores para as energias de adsorção $\mathrm{C}_{2} \mathrm{H}_{5} \mathrm{OH} / \mathrm{MT}_{13}$ podem ser encontrados na tabela (4.2). Observa-se que as energias de adsorção para o etanol seguem o mesmo padrão apresentado pela água, ou seja, $-E_{a d}^{3 d}>-E_{a d}^{4 d}$, mas $-E_{a d}^{4 d}<-E_{a d}^{5 d}$. Ao se comparar os resultados obtidos para etanol sobre os clusters com os dados da literatura para adsorção de etanol sobre MT(111) (30), nota-se que as energias de adsorção são maiores para o primeiro caso em que $E_{a d} \approx 0.5 \mathrm{eV}$, equanto para superfícies esse valor não ultrapassa $290 \mathrm{meV}($ etanol/Ni(111)).

O etanol apresenta uma maior intensidade de interação com os metais que possuem orbitais $d$ semi-preenchidos, consequentemente, uma menor interação com os metais com orbitais $d$ completamente preenchidos. Nota-se que os clusters de platina e ouro formam uma exceção, de modo que suas propriedades catalíticas são modificadas, em que a estru- 
Tabela 4.4 - Frequências de vibração, em $\mathrm{cm}^{-1}$, da água e do etanol após adsorção.

\begin{tabular}{|c|c|c|c|c|c|c|c|}
\hline & \multicolumn{3}{|c|}{$\mathrm{H}_{2} \mathrm{O}$} & \multicolumn{4}{|c|}{$\mathrm{C}_{2} \mathrm{H}_{5} \mathrm{OH}$} \\
\hline & $\nu_{\mathrm{s}}$ & $\delta_{\mathrm{HOH}}$ & $\nu_{\mathrm{as}}$ & $\nu_{\mathrm{O}-\mathrm{H}}$ & $\nu_{s \mathrm{C}-\mathrm{H}}$ & $\nu_{a s \mathrm{C}-\mathrm{H}}$ & $\nu_{\mathrm{C}-\mathrm{O}}$ \\
\hline Molécula & 3700 & 1595 & 3793 & 3717 & 2897 & 2916 & 1003 \\
\hline $\mathrm{Ni}_{13} \mathrm{ICO}$ & 3611 & 1563 & 3703 & & & & \\
\hline $\mathrm{Ni}_{13}$ LOW & 3613 & 1568 & 3702 & 3653 & 2947 & 2959 & 998 \\
\hline $\mathrm{Cu}_{13} \mathrm{ICO}$ & 3638 & 1576 & 3735 & 3677 & 2949 & 2955 & 1004 \\
\hline $\mathrm{Cu}_{13}^{13}$ LOW & 3630 & 1572 & 3730 & 3676 & 2949 & 2955 & 1002 \\
\hline $\mathrm{Pd}_{13} \mathrm{ICO}$ & 3647 & 1578 & 3740 & & & & \\
\hline $\mathrm{Pd}_{13}$ LOW & 3657 & 1580 & 3752 & & & & \\
\hline $\mathrm{Ag}_{13} \mathrm{ICO}$ & 3656 & 1585 & 3754 & & & & \\
\hline $\mathrm{Ag}_{13}$ LOW & 3651 & 1587 & 3744 & & & & \\
\hline $\mathrm{Pt}_{13} \mathrm{ICO}$ & 3616 & 1572 & 3711 & 3566 & 2966 & 2963 & 999 \\
\hline $\mathrm{Pt}_{13}$ LOW & 3617 & 1571 & 3720 & 3654 & 2958 & 2962 & 996 \\
\hline $\mathrm{Au}_{13} \mathrm{ICO}$ & 3657 & 1580 & 3753 & 3560 & 2950 & 2967 & 1005 \\
\hline $\mathrm{Au}_{13}$ LOW3D & 3482 & 1573 & 3708 & 3501 & 2945 & 2965 & 1011 \\
\hline $\mathrm{Au}_{13}$ LOW2D & 3656 & 1578 & 3757 & 3688 & 2968 & 2952 & 1005 \\
\hline
\end{tabular}

tura $\mathrm{Pt}_{13}$ amplia a capacidade catalítica da platina, e no caso do ouro ocorre o aparecimento dessa propriedade, divergindo completamente da fase de bulk. Esse fato pode estar relacionado com a exposição dos átomos que configuram os clusters, os quais apresentam um número de coordenação efetiva pequeno.

\section{Parâmetros estruturais}

Através das variações de NCE e $d_{a v}$ dos clusters, e também da distância de ligação $d_{\mathrm{O}-\mathrm{MT}}$ é possível traçar um panorâma das mudanças geométricas que ocorrem após adsorção de etanol $/ \mathrm{MT}_{13}$. O número de coordenação efetiva varia entre -0.09 e $0.17 \%$ para $\mathrm{Ni}_{13}, \mathrm{Cu}_{13}$ e $\mathrm{Pd}_{13}$, e apresenta pequenas modificações (menores que 1\%) para as estruturas LOW de Ag, Pt e Au. Entretanto, as demais estruturas ICO apresentam altas deformações, em que $\triangle \mathrm{NCE}=-13.6 \%\left(\mathrm{Ag}_{13}{ }^{\mathrm{ICO}}\right),-32.1 \%\left(\mathrm{Pt}_{13}{ }^{\mathrm{ICO}}\right)$, e $-24.9 \%\left(\mathrm{Au}_{13}{ }^{\mathrm{ICO}}\right)$. Ressalta-se que todas as estruturas ICO se tornaram mais abertas, mas por outro lado as estruturas LOW diminuíram seu NCE, fazendo com que a estrutura fosse mais compacta. Há uma exceção apresentada pela configuração 2D $\mathrm{Au}_{13}$, que mostra um aumento dos comprimentos de ligação atrelado a uma diminuição de NCE, consequentemente tornando a estrutura ainda mais aberta. Nota-se ainda que os comprimentos de ligação do oxigênio com os clusters são inversamente proporcionais à magnitude da energia de adsorção, obedecendo ao padrão de $d_{\mathrm{O}-\mathrm{MT}}$ ser menor para clusters formandos pelos metais com ocupação incompleta dos orbitais $d$, como se observa na tabela (4.2). 


\section{Densidade de estados}

A análise do cálculo da densidade de estados foi feitaao se considerar a projeção dos estados $s$ e $p$ para os átomos $\mathrm{C}, \mathrm{H}$ e $\mathrm{O}$ na molécula isolada e após adsorção, como mostram as figuras (4.7) e (4.8). Observa-se um desdobramento dos estados referentes a $\mathrm{C}$ e $\mathrm{H}$ com energias maiores que o HOMO, os quais se aproximam da origem, devido à interação com o cluster. Já os estados ligados do carbono não apresentam nenhuma modificação, além do deslocamento ocasionado pela interação. Por outro lado, é possível apontar que a variação dos estados O-p possuem uma relação direta com a energia de adsorção. Nota-se que quanto maior o deslocamento desses estados para energias abaixo do HOMO, maior será a energia de adsorção.

\section{Diferença de densidade e análise de Mulliken}

Análogo ao processo direcionado para a compreensão das propriedades eletrônicas da água adsorvida sobre os clusters, também é possível encontrar a diferença de densidade para a molécula de etanol sobre os clusters $\mathrm{MT}_{13}$ nas figuras (4.9) e (4.10), e a variação das cargas relativas de Mulliken mais adiante.

Nota-se que há um aumento de carga sobre o átomo de oxigênio e, também, sobre o carbono que está diretamente ligado a ele $\left(\mathrm{C}^{1}\right)$, sendo que a região que os envolve doa densidade eletrônica. Nas figuras, é possível observar que os clusters interagem com a molécula via orbital $d_{z^{2}}$ e, o etanol utiliza o orbital HOMO, omde é possível observar que o grupo hidroxila é praticamente paralelo ao átomo do cluster em que está ligado. Ao se comparar as diferenças de densidade sobre os clusters, nota-se que há um rearranjo de cargas muito maior para os clusters com orbitais $d$ semi-preenchidos, condizente com as tendências apresentadas pela energia de adsorção.

Sendo o etanol uma molécula mais complexa, é necessário um critério mais cuidadoso para se compreender as transferências de carga no processo de adsorção que a envolve. Inicialmente, observa-se que a quantidade de carga total da molécula após a adsorção é menor do que a molécula isolada em todos os casos, apontando para uma transferência de carga da molécula para o cluster. A quantidade de carga transferida da molécula varia $0.015 e<\Delta Q<0.173 e$, que reflete a baixa interação entre etanol e $\mathrm{MT}_{13}$. Na tabela (4.3) é possível observar as cargas relativas para os diferentes átomos presentes na molécula. Nota-se que os átomos pertencentes ao etanol que estão ligados ao oxigênio diminuem a carga doada, porém os hidrogênios do grupo $\mathrm{CH}$ e o $\mathrm{C}^{2}$ estabilizam a molécula, perdendo densidade eletrônica. Apesar de ainda receber carga, o oxigênio apresenta cargas relativas menores do que o valor presente para a molécula isolada. 


\section{Análise vibracional}

Para a análise vibracional do etanol foram selecionadas as frequências de vibração apresentadas nas regiões de impressão digital, sendo $\nu_{\mathrm{O}-\mathrm{H}}$, o estiramento $\mathrm{O}-\mathrm{H} ; \nu_{s \mathrm{C}-\mathrm{H}}$, o estiramento simétrico $\mathrm{C}-\mathrm{H} ; \nu_{a s \mathrm{C}-\mathrm{H}}$, o estiramento assimétrico $\mathrm{C}-\mathrm{H}$; e, $\nu_{\mathrm{C}-\mathrm{O}}$, o estiramento $\mathrm{C}-\mathrm{O}$. Observa-se na tabela (4.4) que as maiores variações ocorrem para $\nu_{\mathrm{O}-\mathrm{H}}$ (red shift) e $\nu_{s \mathrm{C}-\mathrm{H}}$ (blue shift), apontando para um enfraquecimento da ligação $\mathrm{O}-\mathrm{H}$, equanto há um fortalecimento das ligações $\mathrm{C}-\mathrm{H}$, após a adsorção.

\section{Correções de van der Waals}

A tabela (4.2) apresenta os valores para a energia de adsorção, bem como a distância $d_{\mathrm{O}-\mathrm{MT}}$, após as correções de van der Waals. É possível observar um aumento da energia de adsorção entre aproximadamente 20-30\%, exceto para etanol $/ \mathrm{Ag}_{13}$ LOW, o qual teve um acréscimo de $62.5 \%$ com as correções de vdW, que pode estar atrelado ao fato de que esse sistema apresentava a menor interação.

\subsection{Discussão e sumário}

O desenvolvimento de catalisadores mais eficientes que possam atuar no processo de reforma a vapor do etanol, para operarem a baixas temperaturas e pressão atmosférica, dependem diretamente da compreensão do mecanismo de interação de moléculas de água e etanol com esses catalisadores. Uma vez que o entendimento das propriedades energéticas e estruturais de clusters mágicos contendo treze átomos tem tido grandes eforços, providenciando um panorama sólido para compreensão desses sistemas, (67) é possível agora contribuir para o entendimento da interação das moléculas de etanol e água sobre clusters $\mathrm{MT}_{13}\left(\mathrm{Ni}_{13}, \mathrm{Cu}_{13}, \mathrm{Pd}_{13}, \mathrm{Ag}_{13}, \mathrm{Pt}_{13}\right.$ e $\left.\mathrm{Au}_{13}\right)$. As propriedades de adsorção para água e etanol sobre os clusters foram comparadas às propriedades obtidades para essas moléculas sobre superfícies compactas MT(111), (30) a fim de facilitar a compreensão do processo. Para também auxiliar na

Inicialmente, observa-se que água e etanol se ligam preferencialmente aos sítios top através do átomo de oxigênio, sendo que o etanol também apresenta configurações pelas quais se liga pelo átomo de hidrogênio proveniente do grupo $\mathrm{CH}$. Esses isômeros para o etanol que ocorrem via H-MT apresentam energias mais altas, mas são prováveis a temperatura ambiente. O posicionamento do grupo $\mathrm{OH}$ na interação com os clusters é similar com o encontrado para as superfícies para água e etanol, em que O-H é praticamente paralelo ao substrato. O radical hidroxila, apesar de também se ligar ao cluster via oxigênio, possui uma preferência para os sítios bridge, e apresenta uma dependência geométrica e em relação ao elemento com o qual se liga, de forma que é possível se encontrar $\mathrm{OH}$ interagindo com o cluster através dos sítios hollow, e especificamente no caso do ouro, sítio 
top.

Para a energia de adsorção de água e etanol sobre clusters segue a ordem $-E_{a d}^{\mathrm{Ni}_{13}}>$ $-E_{a d}^{\mathrm{Pd}_{13}}$ e $-E_{a d}^{\mathrm{Cu}_{13}}>-E_{a d}^{\mathrm{Ag}_{13}}$, mas $-E_{a d}^{\mathrm{Pd}_{13}}<-E_{a d}^{\mathrm{Pt}_{13}}$ e $-E_{a d}^{\mathrm{Ag}_{13}}<-E_{a d}^{\mathrm{Au}_{13}}$, que diverge da tendência apresentada para superfícies, em que $-E_{a d}^{\mathrm{Ni}_{13}}>-E_{a d}^{\mathrm{Pd}_{13}}>-E_{a d}^{\mathrm{Pt}_{13}} \mathrm{e}-E_{a d}^{\mathrm{Cu}_{13}}>$ $-E_{a d}^{\mathrm{Ag}_{13}}>-E_{a d}^{\mathrm{Au}_{13}}$. Através dessas tendências é possível compreender a proporcionalidade inversa dos comprimentos de ligação O-MT, os quais diminuem com o aumento da energia de adsorção. A mudança de tendência para o processo de adsorção sobre os clusters pode ser explicada com base no aumento da atividade catalítica dos metais de transição em escala nanométrica, especialmente nos casos apresentados de $\mathrm{Pt}_{13}$ e $\mathrm{Au}_{13}$, onde a energia de adsorção para adsorção da água (etanol) sobre os clusters aumenta em um fator de 2.68 e 3.60 (2.93 e 4.10), respectivamente, em relação à energia de adsorção sobre MT(111). Podese correlacionar a intensificação dos valores referentes à energia de adsorção sobre $\mathrm{Au}_{13}{ }^{2 \mathrm{D}}$ à baixa coordenação dos átomos que configuram o cluster. As diferenças de densidade mostram que clusters de metais de transição com orbitais $d$ semi-ocupados proporcionam um maior rearranjo das cargas no sistema, refletindo em maiores energias de adsorção quando comparados aos clusters com orbitais $d$ totalmente ocupados.

Observa-se que a projeção dos estados O- $p$ são de suma importância na compreensão das magnitudes da energia de adsorção, já que foi possível identificar que esta propriedade possui uma relação direta ao deslocamento desses estados para níveis com energias mais baixas, distanciando-se do HOMO. Além disso, devido às diferenças encontradas nos orbitais utilizados na adsorção, têm-se que o radical $\mathrm{OH}$ recebe carga proveniente do cluster, enquanto água e etanol utilizam seus orbitais HOMO transferindo densidade eletrônica para o cluster. Esse transferência de cargas reflete nas frequências de vibração das moléculas, que para hidroxila se vê um aumento de frequência (blue shift), ou seja, um aumento da força molecular da ligação, condizendo com o aumento de energia sobre a molécula e estabilização da ligação O-H. Por outro lado, água e etanol apresentam um decréscimo das frequências de vibração associadas ao oxigênio (red shift), o que proporciona um enfraquecimento das ligações $\mathrm{O}-\mathrm{H}$ e $\mathrm{C}-\mathrm{O}$.

Por fim, foi encontrado que as correções de vdW para adsorção de água e etanol não geram modificações estruturais significativas. A energia de adsorção após aplicação de vdW apresenta um fator de acréscimo que varia entre 1.04 e 1.29 para água, e de 1.15 a 1.62 para o etanol, em que os comprimentos de ligação O-MT descrescem em um máximo de $0.03 \AA$, o que significa que as correções de vdW não possuem importância considerável para os sistemas aqui tratados. 


\section{Capítulo 5}

\section{Conclusões}

Neste trabalho foram realizados cálculos utilizando DFT para adsorção de hidroxila, água e etanol sobre clusters de metais de transição $\mathrm{MT}_{13}$, que possibilitaram as análises apresentadas anteriormente, através das quais é possível concluir que:

- A interação de $\mathrm{OH}$ com os clusters é mais forte do que a água e o etanol devido ao seu elétron desemparelhado. Existe uma preferência por sítios de maior coordenação, a qual pode estar relacionada à distribuição espacial da densidade de carga na região próxima ao átomo de oxigênio.

- Água e etanol se ligam aos clusters preferencialmente via oxigênio pelo sítio top. Entretanto, o etanol ainda apresenta a possibilidade de se ligar ao cluster através do hidrogênio do grupo CH com isômeros de maior energia relativa, porém que são prováveis de existirem a temperatura ambiente, o que pode indicar o favorecimento da quebra da ligação C-C.

- Ao comparar a adsorção das moléculas de água e etanol sobre clusters e sobre MT(111), nota-se que a energia de adsorção é maior no primeiro caso, especialmente em relação ao ouro, dada ao baixo número de coordenação efetiva de sua configuração mais estável (2D).

- Pode-se observar que as moléculas de água e etanol utilizam seus orbitais HOMO para interagirem com os orbitais $d_{z^{2}}$ do cluster, onde ocorre uma pequena transferência de carga da molécula para cluster, refletindo a baixa interação.

- As correções de van der Waals acarretam pequenas variações estruturais, porém influenciam um aumento na energia de adsorção de água e etanol sobre $\mathrm{MT}_{13}$ que variam entre $5 \%$ e $62 \%$. 


\section{Referências}

1 KAŠPAR, J.; FORNASIERO, P.; HICKEY, N. Automotive catalytic converters: Current status and some perspectives. Catal. Today, v. 77, p. 419-449, 2003. doi:10.1016/S0920-5861(02)00384-X.

2 GONZALEZ, E. R. Electrocatálise e poluição ambiental. Quim. Nova, v. 23, p. 262-266, 2000. doi:http://dx.doi.org/10.1590/S0100-40422000000200019.

3 DRESSELHAUS, M. S.; THOMAS, I. L. Alternative energy technologies. Nature, v. 414, p. 332-337, 2001. doi:10.1038/35104599.

4 NI, M.; LEUNG, D. Y. C.; LEUNG, M. K. H. A review on reforming bio-ethanol for hydrogen production. Int. J. Hydrogen Energy, v. 32, p. 3238-3247, 2007. doi:10.1016/j.ijhydene.2007.04.038.

5 MATTOS, L. V.; JACOBS, G.; DAVIS, B. H.; NORONHA, F. B. Production of hydrogen from ethanol: Review of reaction mechanism and catalyst deactivation. Chem. Rev., v. 112, p. 4094-4123, 2012. doi:10.1021/cr2000114.

6 DELUGA, G. A.; SAlGE, J. R.; SCHMIDT, L. D.; VERYKIOS, X. E. Renewable hydrogen from ethanol by authothermal reforming. Science, v. 303, p. 993-997, 2004. doi:10.1126/science.1093045.

7 SHENG, P. Y.; IDRISS, H. Ethanol reactions over $\mathrm{Au}-\mathrm{Rh} / \mathrm{CeO}_{2}$ catalysts: Total decomposition and $\mathrm{H}_{2}$ formation. J. Vac. Sci. Technol., A, v. 22, p. 1652-1658, 2004. doi:http://dx.doi.org/10.1116/1.1705591.

8 PETKOVIC, L. M.; RASHKEEV, S. N.; GINOSAR, D. M. Ethanol oxidation on metal oxide-supported platinum catalysts. Catal. Today, v. 147, p. 107-114, 2009. doi:10.1016/j.cattod.2009.02.015.

9 IOANNIDES, T.; NEOPHYTIDES, S. Efficieny of a solid polymer fuel cell operating on ethanol. J. Power Sources, v. 91, p. 150-156, 2000.

doi:10.1016/S0378-7753(00)00473-0.

10 CHIANG, H. N.; WANG, C. C.; CHENG, Y. C.; JIANG, J. C.; HSIEH, H. M. Density functional theory study of ethanol decomposition on $3 \mathrm{Ni} / \mathrm{Al}_{2} \mathrm{O}_{3}(0001)$ surface. Langmuir, v. 26, p. 15845-15851, 2010. doi:10.1021/la101492g. 
11 HARYANTO, A.; FERNANDO, S.; MURALI, N.; ADHIKARI, S. Current status of hydrogen production techniques by steam reforming of ethanol: A review. Energy Fuels, v. 19, p. 2098-2106, 2005. doi:10.1021/ef0500538.

12 KHODAKOV, A.; OLTHOF, B.; BELL, A. T. Structure and catalytic properties of supported vanadium oxides: Support effects on oxidative dehydrogenation reactions. J. Catal., v. 181, p. 205-216, 1999. doi:http://dx.doi.org/10.1006/jcat.1998.2295.

13 BAÑARES, M. A.; MARTÍNEZ-HUERTA, M. V.; GAO, X.; FIERRO, J. L. G.; WACHS, I. E. Dynamic behavior of supported vanadia catalysts in the selective oxidation of ethane. in situ Raman, UV-Vis DRS and reactivity studies. Catal. Today, v. 61, p. 295-301, 2000. doi:http://dx.doi.org/10.1016/S0920-5861(00)00388-6.

14 WACHS, I. E. Recent conceptual advances in the catalysis science of mixed metal oxide catalytic materials. Catal. Today, v. 100, p. 79-94, 2005. doi:http://dx.doi.org/10.1016/j.cattod.2004.12.019.

15 ALONSO, J. A. Electronic and atomic structure, and magnetism of transition-metal clusters. Chem. Rev., v. 100, p. 637-677, 2000. doi:10.1021/cr980391o.

16 HARUTA, M. Size and support dependency in the catalysis by gold. Catal. Today, v. 36, p. 153-166, 1997. doi:10.1016/S0920-5861(96)00208-8.

17 VALDEN, M.; LAI, X.; GOODMAN, D. W. Onset of catalytic activity of gold clusters on titania with the appearance of nonmetallic properties. Science, v. 281, p. 1647-1650, 1998. doi:10.1126/science.281.5383.1647.

18 LOPEZ, N.; NØRSKOV, J. K. Theoretical study of the $\mathrm{Au} / \mathrm{TiO}_{2}(110)$ interface. Surf. Sci., v. 515, p. 175-186, 2002. doi:http://dx.doi.org/10.1016/S0039-6028(02)01873-3.

19 VAJDA, S.; PELLIN, M. J.; GREELEY, J. P.; MARSHALL, C. L.; CURTISS, L. A.; BALlENTINE, G. A.; ELAM, J. W.; CATILLON-MUCHERIE, S.; REDFERN, P. C.; MEHMOOD, F.; ZAPOL, P. Subnanometre platinum clusters as highly active and selective catalysts for the oxidative dehydrogenation of propane. Nat. Mater., v. 8, p. 213-216, 2009. doi:10.1038/nmat2384.

20 MiChaElides, A.; RANEA, V. A.; DE AndRES, P. L.; KING, D. A. General model for water monomer adsorption on close-packed transition and noble metal surfaces. Phys. Rev. Lett., v. 90, p. 216102(1)-216102(4), 2003. doi:http://dx.doi.org/10.1103/PhysRevLett.90.216102. 
21 ITO, M. Structures of water at electrified interfaces: Microscopic understanding of electrode potential in electric double layers on electrode surfaces. Surf. Sci. Rep., v. 63, p. 329-389, 2008. doi:10.1016/j.surfrep.2008.04.002.

22 CARRASCO, J.; KLIMEŠ, J.; MICHAELIDES, A. The role of van der waals forces in water adsorption on metals. J. Chem. Phys., v. 138, p. 024708(1)-024708(9), 2013. doi:10.1063/1.4773901.

23 HAMADA, I.; LEE, K.; MORIKAWA, Y. Interaction of water with a metal surface: Importance of van der Waals forces. Phys. Rev. B, v. 81, p. 115452(1)-115452(6), 2010. doi:10.1103/PhysRevB.81.115452.

24 TERESHCHUK, P.; DA SILVA, J. L. F. Density functional investigation of the adsorption of ethanol-water mixture on the Pt(111) surface. J. Phys. Chem. C, v. 117, p. 16942-16952, 2013. doi:10.1021/jp403352u.

25 MICHAELIDES, A. Density functional theory simulations of water/metal interfaces: Waltzing waters, a novel 2D ice phase, and more. Appl. Phys. A, v. 85, p. 415-425, 2006. doi:10.1007/s00339-006-3695-9.

26 ÁRNADÓTTIR, L.; STUVE, E. M.; JÓNSSON, H. Adsorption of water monomer and clusters on platinum(111) terrace and related steps and kinks i. configurations, energies, and hydrogen bonding. Surf. Sci., v. 604, p. 1978-1986, 2010. doi:10.1016/j.susc.2010.08.007.

27 HENDERSON, M. A. The interaction of water with solid surfaces: fundamental aspects revisited. Surf. Sci. Rep., v. 46, p. 1-308, 2002. doi:http://dx.doi.org/10.1016/S0167-5729(01)00020-6.

28 MENG, S.; WANG, E. G.; GAO, S. Water adsorption on metal surfaces: a general picture from density functional theory studies. Phys. Rev. B, v. 69, p. 195404(1)-195404(13), 2004. doi:10.1103/PhysRevB.69.195404.

29 CARRASCO, J.; HODGSON, A.; MICHAELIDES, A. A molecular perspective of water at metal interfaces. Nat. Mater., v. 11, p. 667-674, 2012. doi:10.1038/nmat3354.

30 TERESHCHUK, P.; DA SILVA, J. L. F. Ethanol and water adsorption on close-packed $3 d, 4 d$, and $5 d$ transition-metal surfaces: A density functional theory investigation with van der waals correction. J. Phys. Chem. C, v. 116, p. 24695-24705, 2012. doi:10.1021/jp308870d. 
31 YANG, M.-M.; BAO, X.-H.; LI, W.-X. First principle study of ethanol adsorption and formation of hydrogen bond on $\mathrm{Rh}(111)$ surface. J. Chem. Phys., v. 111, p. 7403-7410, 2007. doi:10.1021/jp0686184.

32 JENA, P.; CASTLEMAN Jr., A. W. Nanoclusters: a bridge across disciplines. Amsterdan: Elsevier, 2010. 576p.

33 BORN, M.; OPPENHEIMER, J. R. 1. Zur Quantentheorie der Molekeln. Ann. Phys., v. 84, p. 457-484, 1927. doi:10.1002/andp.19273892002.

34 In: WILSON, S.; DIERCKSEN, G. (Eds.) Methods in computational molecular physics. 1992. p. 19-46.

35 FORDE, N. R.; MYERS, T. L.; BUTLER, L. J. Chemical reaction dynamics when the Born-Oppenheimer approximation fails: Understanding which changes in the electronic wavefunction might be restricted. Faraday Discuss., v. 108, p. 221-242, 1997. doi:10.1039/A705851I.

36 HARTREE, D. The wave mechanics of an atom with a non-Coulomb central field. Part I. Theory and methods. Math. Proc. Cambridge Philos. Soc., v. 24, p. 89-110, 1928. doi:10.1017/S0305004100011919.

37 FOCK, V. „Selfconsistent field” mit austausch für natrium. Z. f. Physik, v. 62, n. 11-12, p. 795-805, 1930. doi:10.1007/BF01330439.

38 SZABO, A.; OSTLUND, N. S. Modern quantum chemistry: introduction to advanced electronic structure theory. Mineola: Dover Publications, 1996. 466p.

39 PARR, R. G.; YANG, W. Density-functional theory of atoms and molecules. Oxford: Oxford University, 1989. 352p.

40 HOHENBERG, P.; KOHN, W. Inhomogeneous electron gas. Phys. Rev., v. 136, p. B864-B871, 1964. doi:10.1103/PhysRev.136.B864.

41 KOHN, W.; SHAM, L. J. Self-consistent equations including exchange and correlation effects. Phys. Rev., v. 140, p. A1133-A1138, 1965. doi:10.1103/PhysRev.140.A1133.

42 DREIZLER, R. M.; GROSS, E. K. U. Density functional theory. Berlin: Springer-Verlag, 1990. 302p.

43 LEVINE, I. N. Quantum chemistry. 5th ed. Englewood Cliffs: Prentice Hall, 2000. 566p. 
44 CEPERLEY, D. M.; ALDER, B. J. Ground state of the electron gas by a stochastic method. Phys. Rev. Lett., v. 45, p. 566-569, 1980.

doi:http://dx.doi.org/10.1103/PhysRevLett.45.566.

45 VOSKO, S. H.; WILK, L.; NUSAIR, M. Accurate spin-dependent electron liquid correlation energies for local spin density calculations: a critical analysis. Can. J. Phys., v. 58, p. 1200-1211, 1980. doi:10.1139/p80-159.

46 BYLANDER, D. M.; KLEINMAN, L. Why the local-spin-density approximation fails to predict the energy bands of Gd correctly. Phys. Rev. B, v. 49, p. 1608-1611, 1994. doi:http://dx.doi.org/10.1103/PhysRevB.49.1608.

47 LANGRETH, D. C.; PERDEW, J. P. Theory of nonuniform electronic systems. i. analysis of the gradient approximation and a generalization that works. Phys. Rev. B, v. 21, p. 5469-5493, 1980. doi:http://dx.doi.org/10.1103/PhysRevB.21.5469.

48 PERDEW, J. P.; ChEVARY, J. A.; VOSKO, S. H.; JACKSON, K. A.; PEDERSON, M. R.; SINGH, D. J.; FIOLHAIS, C. Atoms, molecules, solids, and surfaces:

Applications of the generalized gradient approximation for exchange and correlation PW91 reference. Phys. Rev. B, v. 46, p. 6671-6687, 1992.

doi:10.1103/PhysRevB.46.6671.

49 PERDEW, J. P.; BURKE, K.; ERNZERHOF, M. Generalized gradient approximation made simple. Phys. Rev. Lett., v. 77, p. 3865-3868, 1996. doi:10.1103/PhysRevLett.77.3865.

50 BEDOLlA, P. O.; FELDBAUER, G.; WOLlOCH, M.; EDER, S. J.; DOÖRR, N.; MOHN, P.; REDINGER, J.; VERNES, A. Effects of van der Waals interactions in the adsorption of isooctane and ethanol on Fe(100) surfaces. J. Phys. Chem. C, v. 118, p. 17608-17615, 2014. doi:dx.doi.org/10.1021/jp503829c.

51 TKATCHENKO, A.; SCHEFFLER, M. Accurate molecular van der Waals iteractions from ground-state electronic density and free-atom reference data. Phys. Rev. Lett., v. 102, p. 073005(1)-073005(4), 2009.

doi:http://dx.doi.org/10.1103/PhysRevLett.102.073005.

52 BLUM, V.; GEHRKE, R.; HANKE, F.; HAVU, P.; HAVU, V.; REN, X.; REUTER, K.; SCHEFFLER, M. Ab initio molecular simulations with numeric atom-centered orbitals. Comput. Phys. Commun., v. 180, p. 2175-2196, 2009.

doi:10.1016/j.cpc.2009.06.022. 
53 NING, C. G.; LUO, Z. H.; HUANG, Y. R.; HAJGATÓ, B.; MORINI, F.; LIU, K.; ZHANG, S. F.; DENG, J. K.; DELEUZE, M. S. Investigation of the molecular conformations of ethanol using electron momentum spectroscopy. J. Phys. B: At. Mol. Opt. Phys., v. 41, p. 175103 (11pp), 2008.

doi:http://iopscience.iop.org/0953-4075/41/17/175103.

54 HARMONY, M. D.; LAURIE, V. W.; KUCZKOWSKI, R. L.; SCHWENDEMAN, R. H.; RAMSAY, D. A.; LOVAS, F. J.; LAFFERTY, W. J.; MAKI, A. G. Molecular structures of gas-phase polyatomic molecules determined by spectroscopic methods. J. Phys. Chem. Ref. Data, v. 8, p. 619-721, 1979. doi:10.1063/1.555605.

55 PATNAIK, P. Handbook of inorganic chemicals. New York: McGraw-Hill, 2003. 1086p.

56 LIDE, D. R. CRC handbook of chemistry and physics. Boca Raton: CRC, 2005. Disponível em: <http://www.hbcpnetbase.com>. Acesso em: 3 abr. 2015.

57 PEARSON, J. C.; BRAUER, C. S.; DROUIN, B. J. The asymmetric top-asymmetric frame internal rotation spectrum of ethyl alcohol. J. Mol. Spectrosc., v. 251, p. 394-409, 2008. doi:10.1016/j.jms.2008.05.007.

58 HERZBERG, G. Molecular spectra and molecular structure I. spectra of diatomic molecules. 2nd ed. Malabar: Robert E. Krieger Publishing, 1989. 732p.

59 COLThUP, N. B. Spectra-structure correlations in the infra-red region. J. Opt. Soc. America, v. 40, p. 397-400, 1950. doi:10.1364/JOSA.40.000397.

60 COLTHUP, N. B.; DALY, L. H.; WIBERLEY, S. E. Introduction to infrared and raman spectroscopy. San Diego: Academic Press, 1990. 547p.

61 HARRIS, D. C.; BERTOLUCCI, M. D. Symmetry and spectroscopy: an introduction to vibrational and electronic spectroscopy. New York: Dover Publications, 1978. 576p.

62 DURIG, J. R.; BUCY, W. E.; WURREY, C. J.; CARREIRA, L. A. Raman spectra of gases. xvi. torsional transitions in ethanol and ethanethiol. J. Phys. Chem., v. 79, p. 988-993, 1975. doi:10.1021/j100577a009.

63 CHANG, C. M.; CHOU, M. Y. Alternative low-symmetry structure for 13-atom metal clusters. Phys. Rev. Lett., v. 93, p. 133401(1)-133401(4), 2004.

doi:10.1103/PhysRevLett.93.133401. 
64 LONGO, R. C.; GALLEGO, L. J. Structures of 13-atom clusters of fcc transition metals by ab initio and semiempirical calculations. Phys. Rev. B, v. 74, p. 193409(1)-193409(4), 2006. doi:10.1103/PhysRevB.74.193409.

65 SUN, Y.; ZHANG, M.; FOURNIER, R. Periodic trends in the geometric structures of 13-atom metal clusters. Phys. Rev. B, v. 77, p. 075435(1)-075435(8), 2008. doi:10.1103/PhysRevB.77.075435.

66 CHOU, J. P.; CHEN, H. Y. T.; HSING, C. R.; CHANG, C. M.; CHENG, C.; WEI, C. M. 13-atom metallic clusters studied by density functional theory: Dependence on exchange-correlation approximations and pseudopotentials. Phys. Rev. B, v. 80, p. 165412(1)-165412(10), 2009. doi:10.1103/PhysRevB.80.165412.

67 PIOTROWSKI, M. J.; PIQUINI, P.; DA SILVA, J. L. F. Density functional theory investigation of $3 d, 4 d$, and $5 d$ 13-atom metal clusters. Phys. Rev. B, v. 81, p. 155446(1)-155446(14), 2010. doi:10.1103/PhysRevB.81.155446.

68 CHOU, J. P.; HSING, C. R.; WEI, C. M.; CHENG, C.; CHANG, C. M. Ab initio random structure search for 13-atom clusters of fcc elements. J. Phys.: Condens. Matter, v. 25, p. 125305 (7p), 2013. doi:10.1088/0953-8984/25/12/125305.

69 RONDINA, G. G.; Da Silva, J. L. F. Revised basin-hopping monte carlo algorithm for structure optimization of clusters and nanoparticles. J. Chem. Inf. Model., v. 53, n. 9, p. 2282-2298, 2013. doi:10.1021/ci400224z.

70 DA SILVA, J. L. F. Effective coordination concept applied for phase change $(\mathrm{GeTe})_{\mathrm{m}}\left(\mathrm{Sb}_{2} \mathrm{Te}_{3}\right)_{\mathrm{n}}$ compounds. J. Appl. Phys., v. 109, p. 023502(1)-023502(6), 2011. doi:http://dx.doi.org/10.1063/1.3533422.

71 KITTEL, C. Introduction to solid state physics. New York: John Wiley, 1996. 704p.

72 AGUILERA-GRANJA, F.; MONTEJANO-CARRIZALEZ, J. M.; GUIRADO-LÓPEZ, R. A. Magnetic properties of small $3 d$ and $4 d$ transition metal clusters: The role of a noncompact growth. Phys. Rev. B, v. 73, p. 115422(1)-115422(10), 2006. doi:10.1103/PhysRevB.73.115422.

73 FUTSCHEK, T.; HAFNER, J.; MARSMAN, M. Stable structural and magnetic isomers of small transition-metal clusters from the Ni group: An ab-initio density-functional study. J. Phys.: Condens. Matter, v. 18, p. 9703-9748, 2006. doi:10.1088/0953-8984/18/42/016. 
74 BŁONSKI, P.; HAFNER, J. Magneto-structural properties and magnetic anisotropy of small transition-metal clusters: A first-principles study. J. Phys.: Condens.

Matter, v. 23, p. 136001 (19p), 2011. doi:10.1088/0953-8984/23/13/136001.

75 International Union of Pure and Applied Chemistry. Chemisorption and physisorption, 2002. Disponível em:

$<$ http://old.iupac.org/reports/2001/colloid_2001/manual_of_s_and_t/node16.html $>$. Acesso em: 24 abr. 2015.

76 ATKINS, P.; JONES, L. Princípios de química: questionando a vida moderna e o meio ambiente. Porto Alegre: Bookman, 2001. 1048p. 


\section{Apêndice A}

\section{Teoria do funcional da densidade: Teoremas}

Este apêndice foi desenvolvido para auxiliar estudantes que buscam compreender o formalismo matemático da teoria do funcional da densidade.

\section{A.1 Primeiro teorema de Hohenberg-Kohn}

Demonstração. Considera-se que, inicialmente, existam dois potenciais externos $V_{\text {ext }}(\mathbf{r})$ e $V^{\prime}$ ext $(\mathbf{r})$ relacionados, respectivamente, aos Hamiltonianos $\hat{H}$ e $\hat{H}^{\prime}$ que atuam sobre as respetivas funções de onda $\varphi$ e $\varphi^{\prime}$. Ao se assumir que ambos levam à mesma densidade eletrônica do estado fundamental $\rho(\mathbf{r})$, faz-se

$$
\langle\varphi|H| \varphi\rangle=E_{0} \quad \text { e } \quad\left\langle\varphi^{\prime}\left|H^{\prime}\right| \varphi^{\prime}\right\rangle=E_{0}^{\prime}
$$

Primeramente, assume-se $\langle\varphi|H| \varphi\rangle=E_{0}$. Ao se aplicar o Hamiltoniano $H$ na função $\varphi^{\prime}$, obtém-se

$$
\langle\varphi|H| \varphi\rangle=E_{0} \quad<\left\langle\varphi^{\prime}|H| \varphi^{\prime}\right\rangle=\left\langle\varphi^{\prime}\left|H^{\prime}\right| \varphi^{\prime}\right\rangle+\left\langle\varphi^{\prime}\left|H-H^{\prime}\right| \varphi^{\prime}\right\rangle
$$

onde

$$
\left\langle\varphi^{\prime}\left|H^{\prime}\right| \varphi^{\prime}\right\rangle+\left\langle\varphi^{\prime}\left|H-H^{\prime}\right| \varphi^{\prime}\right\rangle=E_{0}^{\prime}+\int \rho(\mathbf{r})\left[V_{e x t}(\mathbf{r})-V_{e x t}^{\prime}(\mathbf{r})\right] d \mathbf{r} .
$$

Utilizando o mesmo procedimento à segunda equação de A.1, ocorre que

$$
\left\langle\varphi^{\prime}\left|H^{\prime}\right| \varphi^{\prime}\right\rangle=E_{0}^{\prime} \quad\left\langle\left\langle\varphi\left|H^{\prime}\right| \varphi\right\rangle=\langle\varphi|H| \varphi\rangle+\left\langle\varphi\left|H^{\prime}-H\right| \varphi\right\rangle\right.
$$

em que

$$
\langle\varphi|H| \varphi\rangle+\left\langle\varphi\left|H^{\prime}-H\right| \varphi\right\rangle=E_{0}-\int \rho(\mathbf{r})\left[V_{e x t}(\mathbf{r})-V_{e x t}^{\prime}(\mathbf{r})\right] d \mathbf{r}
$$


Assim, das equações A.3 e A.5, se encontra que

$$
\begin{gathered}
E_{0}<E_{0}^{\prime}+\int \rho(\mathbf{r})\left[V(\mathbf{r})-V^{\prime}(\mathbf{r})\right] d \mathbf{r} \quad \mathrm{e} \\
E_{0}^{\prime}<E_{0}-\int \rho(\mathbf{r})\left[V(\mathbf{r})-V^{\prime}(\mathbf{r})\right] d \mathbf{r},
\end{gathered}
$$

de forma que ao serem somadas, chega-se em $\left(E_{0}+E_{0}^{\prime}\right)<\left(E_{0}+E_{0}^{\prime}\right)$, que é um absurdo. Assim, é garantido que as considerações iniciais são impossíveis de serem satisfeitas. Por isso, pode-se afirmar que $V_{\text {ext }}(\mathbf{r})$ é funcional único de $\rho(\mathbf{r})$.

\section{A.2 Segundo teorema de Hohenberg-Kohn}

A energia total do sistema, escrita como um funcional da densidade eletrônica, é dada por

$$
E[\rho(\mathbf{r})]=\langle\psi|H| \psi\rangle=\langle\psi|T+U| \psi\rangle+\left\langle\psi\left|V_{\text {ext }}\right| \psi\right\rangle=F_{H K}[\rho]+\int V_{e x t}(\mathbf{r}) \rho(\mathbf{r}) d \mathbf{r}
$$

em que $F_{H K}[\rho]$ é o funcional universal de $\rho(\mathbf{r})$, que envolve tanto a energia cinética como as interações clássicas e não-clássicas entre os elétrons. Sabendo que a densidade eletrônica calculada sobre todo o volume equivale ao número de elétrons que contido nesse volume, isto é, $\int \rho(\mathbf{r}) d \mathbf{r}=N$, se obtém a energia do estado fundamental através do princípio variacional, ou seja

$$
E\left[\rho_{0}\right] \leq E[\tilde{\rho}],
$$

que mostra que, para uma densidade qualquer $\tilde{\rho}$ diferente da densidade do estado fundamental, a energia calculada sempre será maior ou igual à energia do estado fundamental. A fim de se minimizar a energia total, defini-se uma Lagrangeana através do vínculo do total de elétrons, dada por

$$
L=E[\rho(\mathbf{r})]-\mu\left[\int \rho(\mathbf{r}) d \mathbf{r}-N\right] .
$$


Para minimizar (A.10), faz-se $\delta L=0$, de modo que

$$
\begin{aligned}
\delta\left\{E[\rho(\mathbf{r})]-\mu\left[\int \rho(\mathbf{r}) d \mathbf{r}-N\right]\right\} & =0 \\
\delta E[\rho(\mathbf{r})]-\delta\left[\mu \int \rho(\mathbf{r}) d \mathbf{r}\right]-\delta(\mu N) & =0 \\
\delta E[\rho(\mathbf{r})]-\delta\left[\mu \int \rho(\mathbf{r}) d \mathbf{r}\right]-\delta(\mu \mathrm{A}) & =0 \\
\delta E[\rho(\mathbf{r})]-\left\{\delta \mu \int \rho(\mathbf{r}) d \mathbf{r}+\mu \delta f \rho(\mathbf{r}) d \mathbf{r}\right\} & =0 \\
\delta E[\rho(\mathbf{r})]-\delta \mu \int \rho(\mathbf{r}) d \mathbf{r}-\mu \delta \int \rho(\mathbf{r}) d \mathbf{r} & =0 \\
\int \frac{\delta E[\rho(\mathbf{r})}{\delta \rho(\mathbf{r})} \delta \rho(\mathbf{r}) d \mathbf{r}-\int \mu \delta \rho(\mathbf{r}) d \mathbf{r} & =0 \\
\int\left\{\frac{\delta E[\rho(\mathbf{r})}{\delta \rho(\mathbf{r})}-\mu\right\} \delta \rho(\mathbf{r}) d \mathbf{r} & =0
\end{aligned}
$$

em que a única solução possível é

$$
\begin{aligned}
\frac{\delta E[\rho(\mathbf{r})}{\delta \rho(\mathbf{r})}-\mu & =0 \\
\mu & =\frac{\delta E[\rho(\mathbf{r})}{\delta \rho(\mathbf{r})} .
\end{aligned}
$$

Assim, ao se retornar à equação de energia (A.8) e diferenciá-la em relação à densidade eletrônica, se obtém

$$
\mu=\frac{\delta F_{H K}[\rho(\mathbf{r})]}{\delta \rho(\mathbf{r})}+V_{e x t}(\mathbf{r})
$$

a chamada equação de Hohenberg-Kohn. 


\title{
Apêndice B
}

\section{Testes de convergência em função do número de funções base}

\begin{abstract}
A fim de se obter o conjunto de funções de base mais apropriado para os cálculos de adsorção, foram feitos testes de função de base utilizando o procedimento descrito na seção (2.5). As moléculas foram analisadas de acordo com o comprimento de ligação $\left(d_{a v}\right)$, ângulos $(A \hat{B} C)$, energia de ligação $\left(E_{b}\right)$ e momento de dipolo $(\mu)$, como mostram as tabelas (B.1), (B.2), (B.3), (B.4), respectivamente. Já os clusters foram avaliados de acordo com o comprimento de ligação ponderado $\left(d_{a v}\right)$, número de coordenação efetiva (NCE), e energia de ligação $\left(E_{b}\right)$, como mostram as tabelas (B.5) e (B.6).

Através dos dados obtidos, é possível verificar que para os clusters as variações geométricas são praticamente nulas ao longo das diferentes funções de base, entretanto, as funções de base LT1 e TT1 mostram valores menores para $\left|E_{b}\right|$ do que as funções LT2 e TT2, respectivamente, os quais estão de acordo com cálculos prévios.(67) As moléculas apresentam as mesmas tendências que os clusters, incluindo o fato de que a base LT3 apresenta resultados semelhantes ao conjunto LT2. Assim, a escolha das funções de base para os cálculos de adsorção deveriam incluir bons resultados com um custo computacional razoável. Dessa forma, foi escolhido o conjunto de base LT2 para descrever os clusters e, para manter o mesmo nível de precisão (meV) para as moléculas foi selecionado o conjunto LT3.
\end{abstract}


Tabela B.1 - Comprimentos de ligação $\left(d_{a v}\right.$, em $\AA$ ) para hidroxila, água e etanol-trans utilizando os conjuntos light-tier 1 (LT1), light-tier 2 (LT2), light-tier 2 (LT3), tight-tier 1 (LT1) e tight-tier 2 (TT2).

\begin{tabular}{llllllll}
\hline Molécula & Ligação & LT1 & LT2 & LT3 & TT1 & TT2 & Exp* \\
\hline Hidroxila & O-H & 0.99 & 0.99 & 0.98 & 0.99 & 0.98 & 0.980 \\
Água & & & & & & & \\
Trans-etanol & O-H & 0.97 & 0.97 & 0.97 & 0.97 & 0.97 & 0.972 \\
& & & & & & & \\
& $\mathrm{C}^{1}-\mathrm{O}$ & 1.44 & 1.44 & 1.44 & 1.44 & 1.44 & 1.431 \\
& $\mathrm{C}^{1}-\mathrm{H}$ & 1.11 & 1.11 & 1.11 & 1.11 & 1.11 & 1.098 \\
& $\mathrm{C}^{2}-\mathrm{H}_{\mathrm{A}}$ & 1.10 & 1.10 & 1.10 & 1.10 & 1.10 & 1.10 \\
& $\mathrm{C}^{2}-\mathrm{H}_{\mathrm{B}}$ & 1.10 & 1.10 & 1.10 & 1.10 & 1.10 & 1.10 \\
& $\mathrm{C}-\mathrm{C}$ & 1.52 & 1.52 & 1.52 & 1.52 & 1.52 & 1.512 \\
\hline
\end{tabular}

*Referência (54)

Tabela B.2 - Ângulos $\left(\widehat{A B C}, \mathrm{em}^{\circ}\right)$ para hidroxila, água e etanol-trans utilizando os conjuntos light-tier 1 (LT1), light-tier 2 (LT2), light-tier 2 (LT3), tight-tier 1 (LT1) e tight-tier 2 (TT2).

\begin{tabular}{llcccccc}
\hline Molécula & Ángulo & LT1 & LT2 & LT3 & TT1 & TT2 & Exp* \\
\hline Hidroxila & - & - & - & - & - & - & - \\
Água & & & & & & & \\
\multirow{2}{*}{ Trans-etanol } & $\mathrm{HOH}$ & 104.2 & 104.2 & 104.2 & 104.2 & 104.1 & 104.5 \\
& & & & & & & \\
& $\mathrm{COH}$ & 107.8 & 108.0 & 108.0 & 107.9 & 108.0 & 107.8 \\
& $\mathrm{C}^{2} \mathrm{C}^{1} \mathrm{H}$ & 110.1 & 110.2 & 110.2 & 110.1 & 110.1 & 110.7 \\
& $\mathrm{HC}^{1} \mathrm{H}$ & 107.8 & 107.7 & 107.7 & 107.7 & 107.6 & 108.0 \\
& $\mathrm{C}^{1} \mathrm{C}^{2} \mathrm{H}_{\mathrm{A}}$ & 110.5 & 110.6 & 110.6 & 110.5 & 110.6 & 110.1 \\
& $\mathrm{C}^{1} \mathrm{C}^{2} \mathrm{H}_{\mathrm{B}}$ & 110.3 & 110.3 & 110.3 & 110.4 & 110.4 & 110.5 \\
& $\mathrm{H}_{\mathrm{A}} \mathrm{C}^{2} \mathrm{H}_{\mathrm{A}}$ & 108.3 & 108.3 & 108.3 & 108.3 & 108.3 & 108.4 \\
& $\mathrm{HOC}^{1} \mathrm{C}^{2}$ & 180.0 & 180.0 & 180.0 & 180.0 & 180.0 & 180.0 \\
\hline
\end{tabular}

*Referência (54)

Tabela B.3 - Energia de ligação $\left(E_{b}\right.$, em eV) para hidroxila, água e etanol-trans utilizando os conjuntos light-tier 1 (LT1), light-tier 2 (LT2), light-tier 3 (LT3), tight-tier 1 (TT1) e tight-tier 2 (TT2).

\begin{tabular}{lrrrrrr}
\hline Molécula & LT1 & LT2 & LT3 & TT1 & TT2 & Exp* \\
\hline Hidroxila & -4.70 & -4.77 & -4.77 & -4.69 & -4.76 & -4.64 \\
Água & -10.07 & -10.16 & -10.16 & -10.06 & -10.15 & -10.06 \\
Trans-etanol & -35.50 & -35.64 & -35.65 & -35.48 & -35.61 & $-33.49^{* *}$ \\
\hline
\end{tabular}

*Referência (56).

***Referência (76). 
Tabela B.4 - Momentos de dipolo elétrico ( $\mu$, em D) para hidroxila, água e etanol-trans utilizando os conjuntos light-tier 1 (LT1), light-tier 2 (LT2), light-tier 3 (LT3), tight-tier 1 (TT1) e tight-tier 2 (TT2).

\begin{tabular}{lrrrrrr}
\hline Molécula & LT1 & LT2 & LT3 & TT1 & TT2 & Exp* $^{*}$ \\
\hline Hidroxila & 1.74 & 1.63 & 1.60 & 1.74 & 1.63 & 1.655 \\
Água & 1.97 & 1.85 & 1.80 & 1.97 & 1.85 & 1.8546 \\
Trans-etanol & 1.60 & 1.53 & 1.51 & 1.60 & 1.53 & 1.44 \\
\hline
\end{tabular}

*Referência (56).

Tabela B.5 - Comprimentos de ligação ponderados $\left(d_{a v}\right.$, em $\AA$ ) e número de coordenação efetiva (NCE, em átomos vizinhos próximos) para $\mathrm{MT}_{13}$ ICO e LOW, utilizando conjuntos light-tier 1 (LT1), light-tier 2 (LT2), tight-tier 1 (LT1) e tight-tier 2 (TT2).

\begin{tabular}{|c|c|c|c|c|c|c|c|c|c|}
\hline \multirow[b]{2}{*}{ Cluster } & \multirow[b]{2}{*}{ Estrutura } & \multicolumn{4}{|c|}{$d_{a v}$} & \multicolumn{4}{|c|}{ NCE } \\
\hline & & LT1 & LT2 & TT1 & TT2 & LT1 & LT2 & TT1 & TT2 \\
\hline $\mathrm{Ni}_{13}$ & $\mathrm{ICO}$ & 2.39 & 2.40 & 2.39 & 2.40 & 6.38 & 6.38 & 6.38 & 6.38 \\
\hline $\mathrm{Ni}_{13}$ & LOW & 2.35 & 2.36 & 2.35 & 2.36 & 5.65 & 5.67 & 5.65 & 5.67 \\
\hline $\mathrm{Cu}_{13}$ & $\mathrm{ICO}$ & 2.50 & 2.50 & 2.50 & 2.50 & 6.40 & 6.40 & 6.40 & 6.40 \\
\hline $\mathrm{Cu}_{13}$ & LOW & 2.46 & 2.46 & 2.46 & 2.46 & 5.70 & 5.70 & 5.70 & 5.70 \\
\hline $\mathrm{Pd}_{13}$ & $\mathrm{ICO}$ & 2.74 & 2.74 & 2.74 & 2.74 & 6.36 & 6.36 & 6.36 & 6.36 \\
\hline $\mathrm{Pd}_{13}$ & LOW & 2.68 & 2.68 & 2.68 & 2.68 & 5.66 & 5.66 & 5.66 & 5.65 \\
\hline $\mathrm{Ag}_{13}$ & $\mathrm{ICO}$ & 2.89 & 2.88 & 2.88 & 2.88 & 6.40 & 6.40 & 6.40 & 6.40 \\
\hline $\mathrm{Ag}_{13}$ & LOW & 2.84 & 2.83 & 2.84 & 2.83 & 5.66 & 5.65 & 5.65 & 5.65 \\
\hline $\mathrm{Pt}_{13}$ & $\mathrm{ICO}$ & 2.72 & 2.72 & 2.72 & 2.72 & 6.37 & 6.37 & 6.37 & 6.37 \\
\hline $\mathrm{Pt}_{13}$ & LOW & 2.59 & 2.59 & 2.59 & 2.58 & 4.29 & 4.28 & 4.29 & 4.29 \\
\hline $\mathrm{Au}_{13}$ & $\mathrm{ICO}$ & 2.88 & 2.87 & 2.87 & 2.87 & 6.40 & 6.40 & 6.40 & 6.40 \\
\hline $\mathrm{Au}_{13}$ & LOW3D & 2.78 & 2.78 & 2.78 & 2.78 & 4.94 & 4.94 & 4.94 & 4.94 \\
\hline $\mathrm{Au}_{13}$ & LOW2D & 2.69 & 2.69 & 2.69 & 2.69 & 3.80 & 3.80 & 3.80 & 3.80 \\
\hline
\end{tabular}

Tabela B.6 - Energia de ligação $\left(E_{b}\right.$, em eV/átomo) para $\mathrm{MT}_{13} \mathrm{ICO}$ e LOW, utilizando conjuntos light-tier 1 (LT1), light-tier 2 (LT2), tight-tier 1 (LT1) e tight-tier 2 (TT2).

\begin{tabular}{llrrrr}
\hline Cluster & Estrutura & LT1 & LT2 & TT1 & TT2 \\
\hline $\mathrm{Ni}_{13}$ & ICO & -2.94 & -3.13 & -2.93 & -3.11 \\
$\mathrm{Ni}_{13}$ & LOW & -3.03 & -3.15 & -3.01 & -3.13 \\
$\mathrm{Cu}_{13}$ & ICO & -2.26 & -2.27 & -2.25 & -2.26 \\
$\mathrm{Cu}_{13}$ & LOW & -2.34 & -2.35 & -2.33 & -2.34 \\
$\mathrm{Pd}_{13}$ & ICO & -2.32 & -2.32 & -2.32 & -2.31 \\
$\mathrm{Pd}_{13}$ & LOW & -2.34 & -2.34 & -2.34 & -2.33 \\
$\mathrm{Ag}_{13}$ & ICO & -1.58 & -1.60 & -1.56 & -1.57 \\
$\mathrm{Ag}_{13}$ & LOW & -1.68 & -1.70 & -1.66 & -1.67 \\
$\mathrm{Pt}_{13}$ & ICO & -3.63 & -3.65 & -3.61 & -3.62 \\
$\mathrm{Pt}_{13}$ & LOW & -3.89 & -3.91 & -3.87 & -3.89 \\
$\mathrm{Au}_{13}$ & ICO & -1.92 & -1.93 & -1.91 & -1.91 \\
$\mathrm{Au}_{13}$ & LOW3D & -2.12 & -2.13 & -2.10 & -2.11 \\
$\mathrm{Au}_{13}$ & LOW2D & -2.12 & -2.13 & -2.10 & -2.11 \\
\hline
\end{tabular}

